Review

\title{
Viral reverse transcriptases
}

\author{
Luis Menéndez-Arias*, Alba Sebastián-Martín, Mar Álvarez
}

Centro de Biología Molecular “Severo Ochoa”, Consejo Superior de Investigaciones Científicas and Universidad Autónoma de Madrid, c/Nicolás Cabrera, 1, Campus de Cantoblanco, 28049 Madrid, Spain

\section{A R T I C L E I N F O}

\section{Article history:}

Received 20 October 2016

Received in revised form

19 December 2016

Accepted 24 December 2016

Available online 30 December 2016

\section{Keywords:}

Reverse transcriptase

Retrovirus

HIV

Hepatitis B virus

DNA polymerase

Antiviral drugs

Ribonuclease $\mathrm{H}$

Fidelity

\begin{abstract}
A B S T R A C T
Reverse transcriptases (RTs) play a major role in the replication of Retroviridae, Metaviridae, Pseudoviridae, Hepadnaviridae and Caulimoviridae. RTs are enzymes that are able to synthesize DNA using RNA or DNA as templates (DNA polymerase activity), and degrade RNA when forming RNA/DNA hybrids (ribonuclease $H$ activity). In retroviruses and LTR retrotransposons (Metaviridae and Pseudoviridae), the coordinated action of both enzymatic activities converts single-stranded RNA into a double-stranded DNA that is flanked by identical sequences known as long terminal repeats (LTRs). RTs of retroviruses and LTR retrotransposons are active as monomers (e.g. murine leukemia virus RT), homodimers (e.g. Ty3 RT) or heterodimers (e.g. human immunodeficiency virus type 1 (HIV-1) RT). RTs lack proofreading activity and display high intrinsic error rates. Besides, high recombination rates observed in retroviruses are promoted by poor processivity that causes template switching, a hallmark of reverse transcription. HIV-1 RT inhibitors acting on its polymerase activity constitute the backbone of current antiretroviral therapies, although novel drugs, including ribonuclease $\mathrm{H}$ inhibitors, are still necessary to fight HIV infections. In Hepadnaviridae and Caulimoviridae, reverse transcription leads to the formation of nicked circular DNAs that will be converted into episomal DNA in the host cell nucleus. Structural and biochemical information on their polymerases is limited, although several drugs inhibiting HIV-1 RT are known to be effective against the human hepatitis B virus polymerase. In this review, we summarize current knowledge on reverse transcription in the five virus families and discuss available biochemical and structural information on RTs, including their biosynthesis, enzymatic activities, and potential inhibition.
\end{abstract}

(c) 2016 Elsevier B.V. All rights reserved.

\section{Contents}

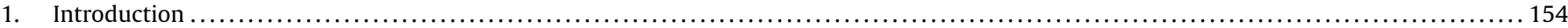

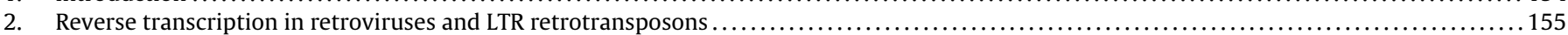

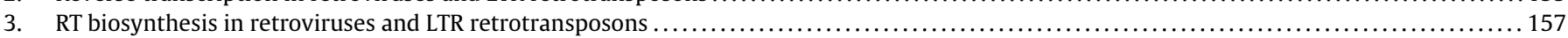

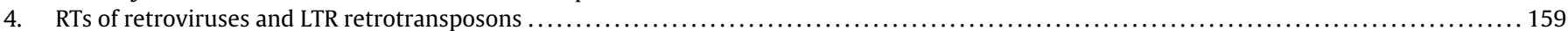

Abbreviations: AIDS, acquired immune deficiency syndrome; ALV, avian leukosis virus; AMV, avian myeloblastosis virus; APOBEC, apolipoprotein B mRNA-editing

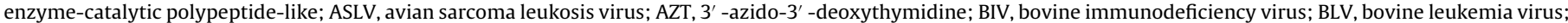

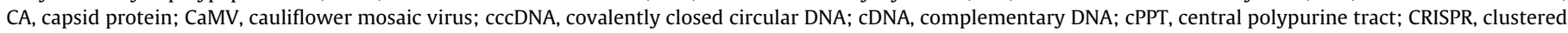

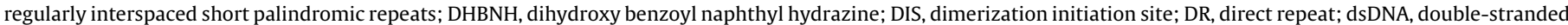

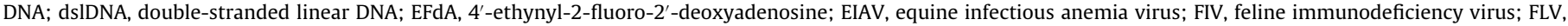

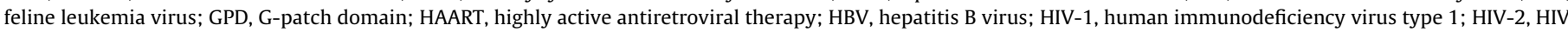

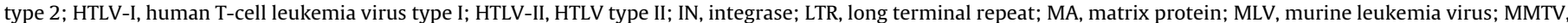

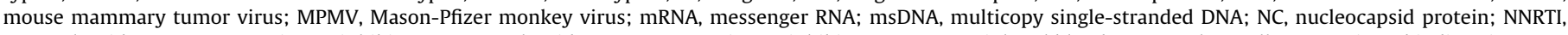

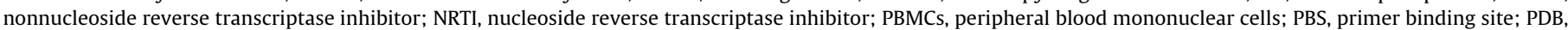

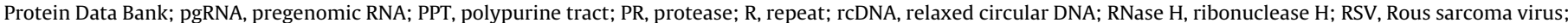

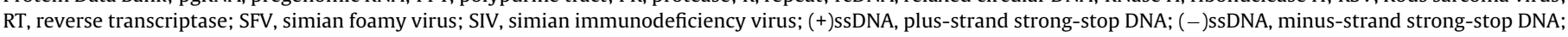

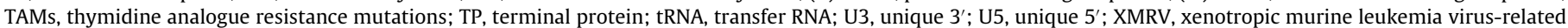
virus.

* Corresponding author.

E-mail address: Imenendez@cbm.csic.es (L. Menéndez-Arias). 


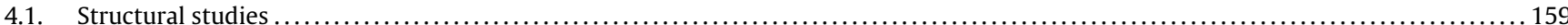

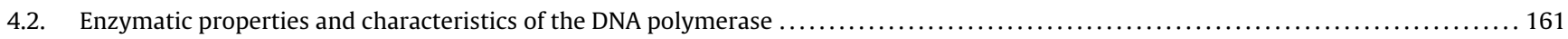

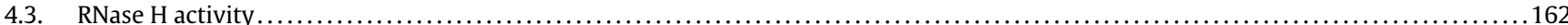

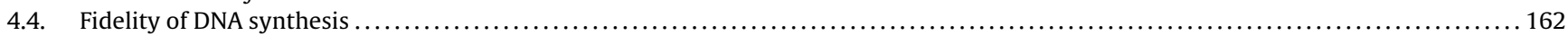

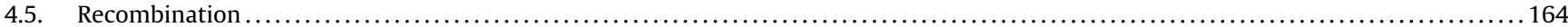

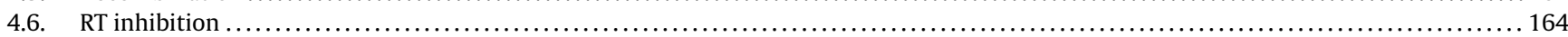

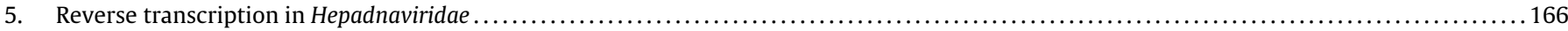

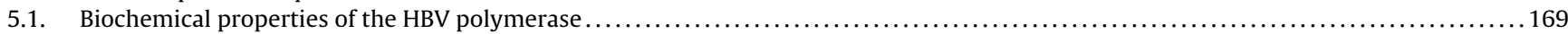

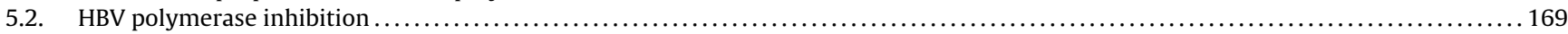

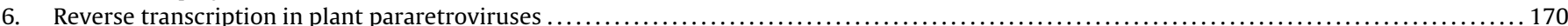

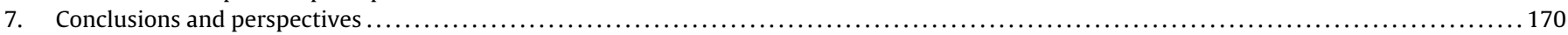

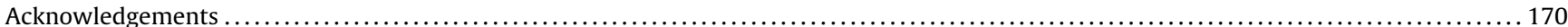

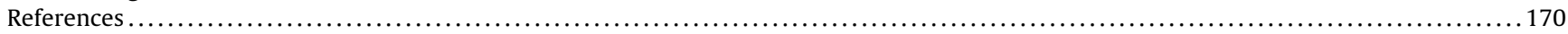

\section{Introduction}

The discovery of retroviral reverse transcriptases (RTs) in 1970 represented a major breakthrough with an enormous impact on life sciences (Baltimore, 1970; Temin and Mizutani, 1970; for a historical account, see Coffin and Fan, 2016). These enzymes were described as nucleic acid polymerases able to synthesize a complementary DNA (cDNA) using RNA as template. Their discovery challenged the prevailing central dogma of molecular biology, which states that DNA is transcribed into RNA, which is then translated into proteins. Further studies showed that RTs were able to use RNA or DNA as templates and had ribonuclease H (RNase $\mathrm{H}$ ) activity. The RNase $\mathrm{H}$ activity of the RTs facilitates cleavage of the RNA strand when forming part of RNA/DNA heteroduplexes. Reverse transcription (i.e. the conversion of RNA to DNA by an RT) plays an important role in the replication of Retroviridae, Metaviridae, Pseudoviridae, Hepadnaviridae and Caulimoviridae. RTs encoded in their genomes are phylogenetically related to those found in mobile genetic elements of prokaryotes and eukaryotes (Fig. 1). Amino acid sequence alignments of RT DNA polymerase domains of different clades show the conservation of a series of motifs (designated as 1, 2, A, B, C, D and E), required for enzymatic function (Fig. 2).

The role of RTs in the replication of retroviruses (then known as 'RNA tumor viruses') gave them notorious relevance for understanding malignant transformation. However, massive genome DNA sequencing has revealed that eukaryotes can have more RT genes than genes encoded for any other protein (Dewannieux and Heidmann, 2013). Most of them are retrotransposable elements or retrotransposons, which were initially discovered in model organisms such as yeast (i.e. Saccharomyces cerevisiae) and the fruitfly (Drosophila melanogaster) (Eickbush and Jamburuthugoda, 2008). In addition to its presence in mobile genetic elements in plants and animals, RT activity is associated with the replication of chromosome ends (telomerase). In prokaryotes, RTs have been found in the coding region of an extrachromosomal satellite DNA, known as multicopy single-stranded DNA (msDNA) (Inouye et al., 1990; Lampson et al., 2005) and in mobile genetic elements known as group II introns that contain an N-terminal RT (RNA-dependent DNA polymerase) domain followed by an RNA-binding maturase domain (Lambowitz and Zimmerly, 2004) (Fig. 1).

Retroviridae, Metaviridae and Pseudoviridae share similar mechanisms of replication and form double-stranded DNA (dsDNA) that integrates into the host cell genomes. The integrated form (proviral DNA) contains direct sequence repeats that flank the internal coding region and are known as long terminal repeats (LTRs). All retroviruses have three major genes, arranged in the order $5^{\prime}$-gagpol-env-3' and can be transmitted horizontally from cell to cell. The gag gene encodes structural proteins including those forming the viral capsid, the pol gene encodes enzymatic activities needed for virus propagation (i.e. protease (PR), RT and integrase (IN)), and env contains the genetic information needed for expression of proteins mediating infection and viral entry.

Metaviridae and Pseudoviridae are LTR retrotransposons found in most eukaryotes. Their genomic structure includes the gag and pol genes that can be organized and expressed in many different ways (Havecker et al., 2004; Curcio et al., 2015). LTR retrotransposons form virus-like particles but unlike retroviruses, most of them can only be transmitted from site to site within the genome of a single cell. However, a number of LTR retrotransposons encode an envelope protein, which allows the virus particle to infect another cell. The best characterized examples of env-containing retroelements are the Drosophila errantiviruses (Metaviridae) gypsy and $Z A M$. The gypsy element has been shown to be infectious and can be transmitted from one individual to another (Leblanc et al., 2000). Genomic studies have shown the widespread distribution of env-like genes in Pseudoviridae (sireviruses) and Metaviridae (errantiviruses, metaviruses and semotiviruses) (Malik et al., 2000; Eickbush and Malik, 2002).

The pararetroviruses, found in both plants (Caulimoviridae family) and animals (Hepadnaviridae family) have rather different replication cycles and replication mechanisms. Hepadnaviruses are small enveloped DNA viruses that infect birds and mammals. Hepatitis B virus (HBV) is the prototypic member of this family and one of the most dangerous human pathogens. Their genome is a partially double-stranded relaxed circular DNA (rcDNA) molecule of about $3 \mathrm{~kb}$ that is transported into the nucleus where it is converted into a covalently closed circular DNA (cccDNA). This episomal DNA is used as template for cellular RNA polymerase II to produce various RNAs, including a pregenomic RNA (pgRNA). After encapsidation with core protein and the viral RT, the pgRNA is converted to rcDNA, while rendering mature viral nucleocapsids (Lucifora and Zoulim, 2011; Hu and Seeger, 2015). The hepadnavirus RT DNA polymerase activity could participate in the synthesis of cccDNA from rcDNA, although its specific role is still unknown. In all hepadnaviruses, double-stranded linear DNA(dslDNA) is also synthesized as a minor viral DNA species during reverse transcription. This DNA is infectious, and its circularization by non-homologous recombination leads to the formation of cccDNA (Yang and Summers, 1998), although this process is not accurate and cannot sustain replication.

Caulimoviridae are viruses transmitted by aphids that infect dicotyledonous plants and replicate by reverse transcription of a pregenomic RNA. The genome of caulimoviruses consists of a double-stranded circular DNA in an open form due to the presence of sequence discontinuities that originate during the reverse transcription process (Haas et al., 2002). The replication of caulimoviruses resembles that of Hepadnaviridae with the viral DNA forming supercoiled mini-chromosome structures upon entering the host nucleus. Unlike retroviruses but similar to hepadnaviruses, integration into the host genome is not required for 


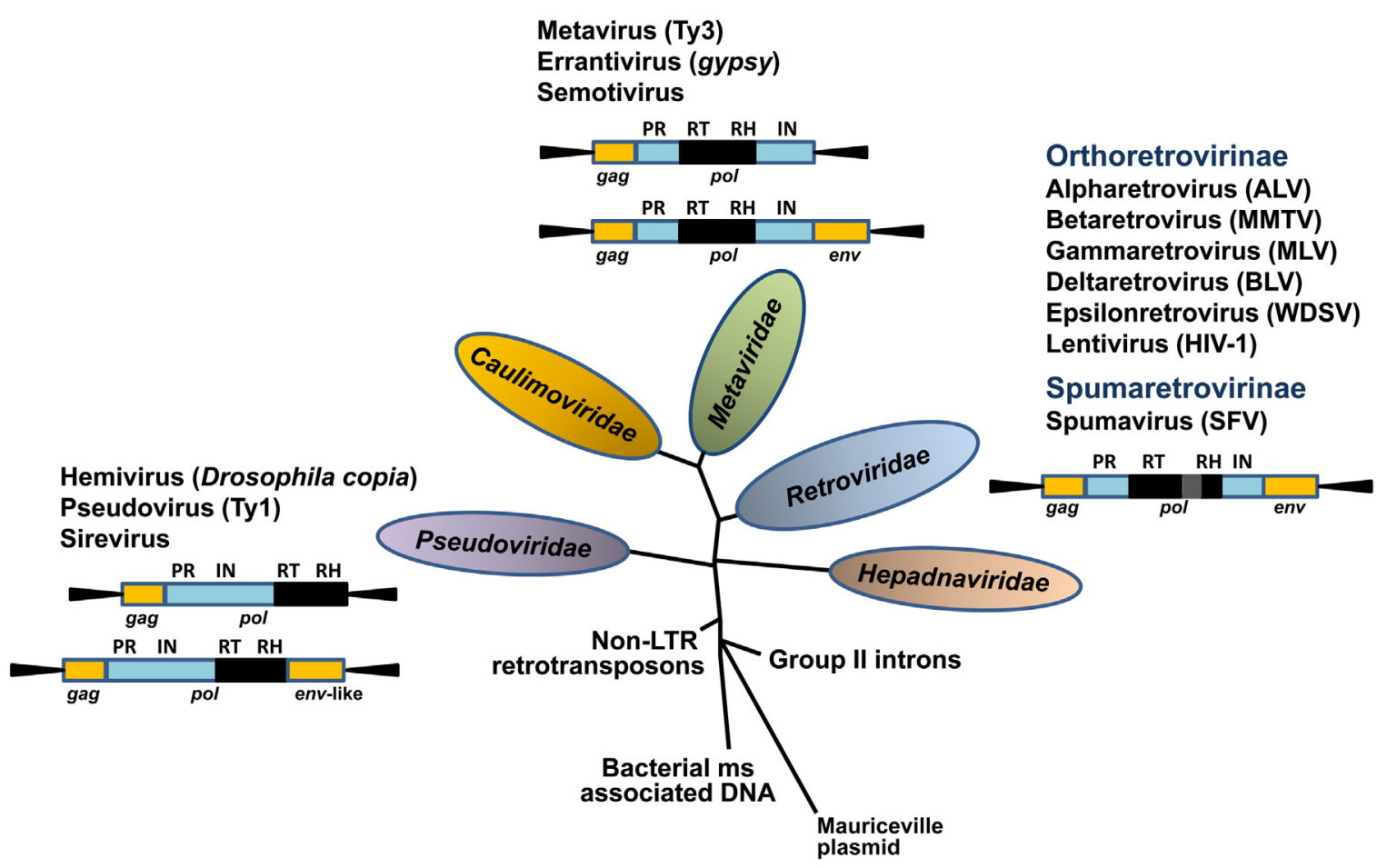

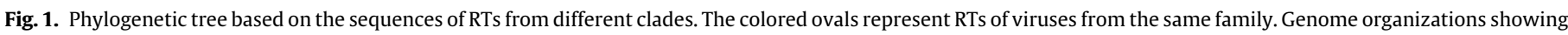

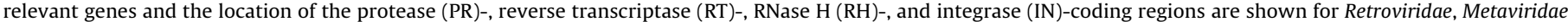

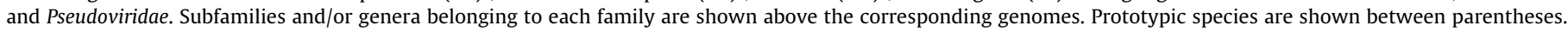

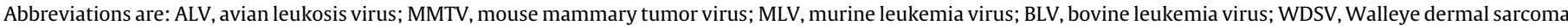

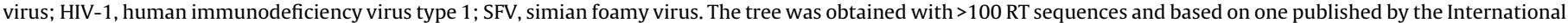
Committee on Taxonomy of Viruses (King et al., 2012).

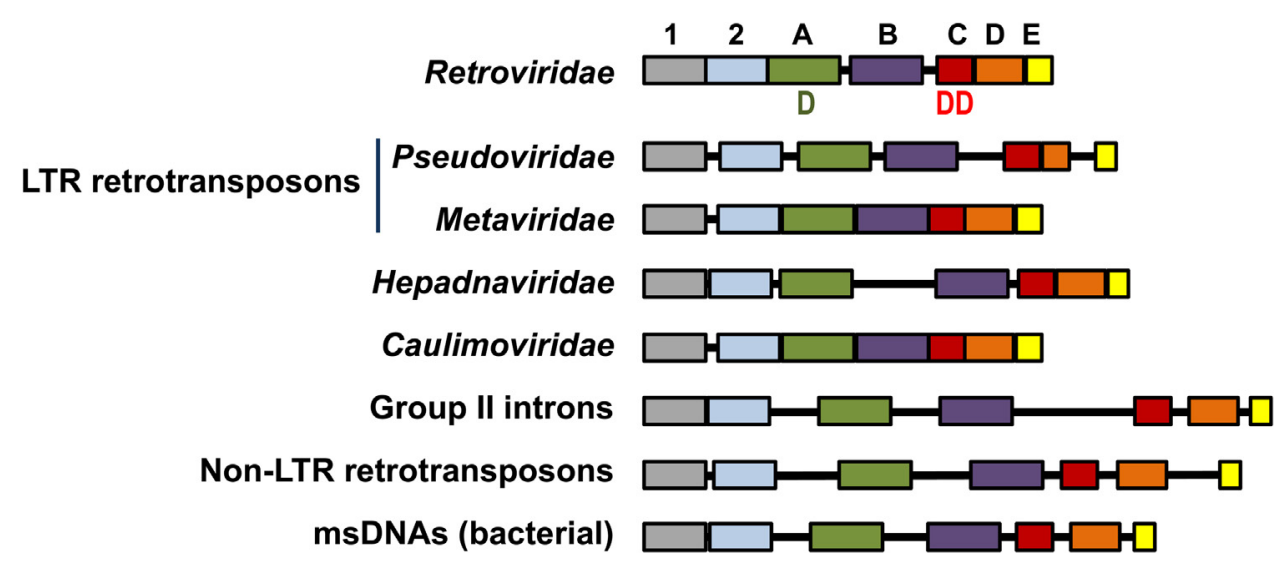

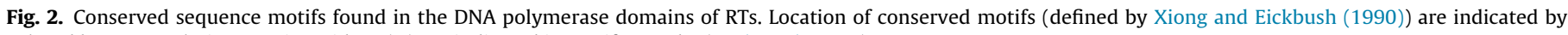
colored boxes. Catalytic aspartic residues (D) are indicated in motifs A and C (Poch et al., 1989).

caulimovirus replication, and their genome lacks an integrasecoding region (Hohn and Rothnie, 2013). True retroviruses are not present in plants. However, endogenous pararetroviral sequences derived from Caulimoviridae have been found in the genomes of many Angiosperms (Chabannes and Iskra-Caruana, 2013). The Caulimoviridae family is composed of six genera (Caulimovirus, Petuvirus, Soymovirus, Cavemovirus, Badnavirus and Tungrovirus) and the most relevant representative is the cauliflower mosaic virus. There is little information on the structure of their RT but it is believed that in the cauliflower mosaic virus the enzyme originates from a polyprotein homologous to the pol gene product of retroviruses, with PR, DNA polymerase and RNase H domains.

Despite the important similarities between RTs of different viruses, major research efforts have been devoted to understand- ing the mechanism of reverse transcription in retroviruses, and the structure of human immunodeficiency virus type 1 (HIV-1) RT as a target of antiretroviral therapy (Menéndez-Arias, 2013a). Although there is a vast literature on those topics, in this review we will provide a broader update covering the most widely studied retroviral RTs and their homologous enzymes in LTR retrotransposons, hepadnaviruses and caulimoviruses.

\section{Reverse transcription in retroviruses and LTR retrotransposons}

In retroviruses and LTR retrotransposons, RT converts ssRNA into dsDNA. The DNA polymerase and RNase $\mathrm{H}$ activities of the RT are sufficient to complete all of the steps in the process, although 
the viral nucleocapsid (NC) protein is a necessary partner (for reviews see Thomas and Gorelick, 2008; Rein, 2010; Darlix et al., 2011). The mature NC protein (p7) has a chaperoning role in reverse transcription facilitating strand transfer events. In addition, NC seems to control early viral DNA synthesis during virus assembly and budding, although the precise mechanism is unknown. In vitro, NC increases RT processivity and fidelity of DNA synthesis (Kim et al., 2012), although these effects have not been reported in vivo.

The genomic viral ssRNA is similar to a messenger RNA (mRNA) and contains a $5^{\prime}$ cap and a polyadenylated tail. The dsDNA is flanked by LTRs. In HIV-1 those sequences have around 634 base pairs, and like in other retroviruses and LTR retrotransposons, they are segmented into three regions, known as U3 (unique $3^{\prime}$ ), R (repeat) and U5 (unique $5^{\prime}$ ). The LTR ends participate in the integration of the dsDNA into the host genome.

The reverse transcription process is outlined in Fig. 3. Reverse transcription initiates after binding of a cellular transfer RNA (tRNA) to the primer binding site (PBS) (reviewed in Abbink and Berkhout, 2007). The PBS is a structured RNA element located close to the $5^{\prime}$ end of the RNA genome in the untranslated leader region. The $3^{\prime}-\mathrm{OH}$ of the tRNA serves as a primer for RNA-dependent DNA synthesis. Retroviruses use different tRNA primers (Marquet et al., 1995; Mak and Kleiman, 1997). All lentiviruses (including HIV-1 and HIV type 2 (HIV-2)) and the mouse mammary tumor virus (MMTV) use tRNA ${ }^{\text {Lys3 }}$. Avian retroviruses (e.g. Rous sarcoma virus (RSV)) use tRNA ${ }^{\text {Trp }}$, many mammalian retroviruses (e.g. human T-cell leukemia viruses types 1 and 2 (HTLV-I and HTLV-II, respectively) and murine leukemia virus (MLV)) use tRNA ${ }^{\text {Pro }}$, and spumaviruses use tRNA ${ }^{\text {Lys } 1,2}$. Studies with HIV-1 mutants carrying altered PBS sequences corresponding to other tRNA species (tRNA ${ }^{\text {Ile }}$, $t R N A^{\text {Lys } 1,2}$, tRNA $^{\text {Phe }}$, tRNA $^{\text {Pro }}$, tRNA $^{\text {Trp }}$ ) demonstrated that they were able to replicate, but at a smaller rate than the wild-type HIV-1 (Das et al., 1995; Abbink and Berkhout, 2007). Priming by tRNAs is also observed in LTR retrotransposons. Thus, the metavirus Ty3 as well as the pseudoviruses Ty1, Ty5 and copia use tRNA $\mathrm{A}_{i}$ Met (Chapman et al., 1992; Keeney et al., 1995; Ke et al., 1999). An exception to this rule was found in the metavirus Tf1 of Schizosaccharomyces pombe. In these elements, the first 11 bases of the primary RNA transcript anneal to a sequence downstream of the $5^{\prime}$ LTR at the typical tRNA PBS. The annealed transcript is excised by the RNase $\mathrm{H}$ activity of the Tf1 RT and then used as primer in reverse transcription (Lin and Levin, 1997).

In HIV-1, the 3 '-terminal 18 nucleotides of the tRNA primer base pair with the complementary PBS (positions +182 to +199 ) in the viral genome. Studies with the HIV-1 RT have shown that the incorporation of the first 5-6 nucleotides at the $3^{\prime}$ end of the tRNA primer is slow and difficult, and then the process speeds up considerably (Isel et al., 1996). The tRNA is extended up to the $5^{\prime}$ end of the genome, generating an intermediate known as minus-strand strong-stop DNA ((-)ssDNA). RNase H cleavage removes the $5^{\prime}$ end of the viral RNA and exposes the newly synthesized (-)ssDNA. The viral RNA contains duplicated sequences at both ends, known as repeats $(R)$. The $R$ sequence in the $(-)$ ssDNA facilitates the strand transfer event by which DNA synthesis can continue from the $3^{\prime}$ of the viral RNA. Retroviral minus-strand DNA synthesis can resume on the same RNA or on a different RNA template (Panganiban and Fiore, 1988; Hu and Temin, 1990a; Wilhelm et al., 1999). In the proviral DNA of HIV-1, a conserved tract of three guanosines is located at the U3/R junction. HIV-1 transcripts containing one, two or three guanosines at their $5^{\prime}$ end are expressed in infected cells, and have been detected in the virion. It has been shown that the number of guanosines at the $5^{\prime}$ end of the viral genomic RNA is a major determinant for successful strand transfer of the (-)ssDNA (Masuda et al., 2015).

The elongation of the (-)ssDNA continues with simultaneous degradation of the template RNA. However, all retroviruses have a purine-rich sequence in the RNA genome that resists cleavage by the RNase $\mathrm{H}$ activity of the RT. This polypurine tract (known as PPT) is located at the U3 region. In HIV-1 and other retroviruses, there is an additional PPT located in the central part of the genome (cPPT). These polypurine tracts serve as primers for synthesis of plus-strand DNA. The cPPT does not seem to be essential for virus replication but increases the efficiency of the process (Charneau et al., 1992; Hungnes et al., 1992). Recently published work suggests that the G-rich sequence of the cPPT could play an important role in keeping the RNA genomes in close proximity, thereby facilitating recombination in numerous hot spots (Piekna-Przybylska et al., 2013).

After addition of a few nucleotides, the PPTs are removed from the plus-strand DNA by the RNase $\mathrm{H}$ activity of the RT. Plus-strand DNA synthesis originating from the 3 '-PPT continues to the 5 '-end of the minus-strand DNA until it reaches the 18th nucleotide in the tRNA where further synthesis is blocked due to the presence of a methylated base (Swanstrom et al., 1981). The obtained DNA is designated as plus-strand strong stop DNA $((+)$ ssDNA). The tRNA is then removed by RT's RNase H activity. In most retroviruses, cleavage occurs at the $3^{\prime}$ end of the tRNA, although in the case of HIV-1, the completed minus-strand DNA contains adenosine monophosphate (riboA) at its 5'end (Whitcomb et al., 1990; Pullen et al., 1992; Smith and Roth, 1992) (Fig. 3).

The second strand transfer reaction involves the annealing of the (+)ssDNA to the $3^{\prime}$ end of the full-length minus-strand DNA, through base pairing of the complementary PBS sequences (Yu et al., 1998). Then, the strand displacement activity of the retroviral RT facilitates the completion of the process and the formation of a full-length, integration-competent, double-stranded DNA with two identical LTRs, one at each end. The strand displacement activity of the RT can also generate flaps constituted by three-stranded structures with overlapping positive-strand sequences (Fig. 3). These flaps are abundant in avian sarcoma leukosis virus (ASLV), where plus-strand DNA synthesis is initiated at many sites. In contrast, MLV has only one initiation site that corresponds to the 3' PPT. The presence of cPPTs in HIV-1 or the retrotransposon Ty1 facilitates the formation of DNA flaps of 88-130 nucleotides. The functional role of these flaps is still uncertain. Cellular endonucleases and ligases can remove the flaps and join the DNA ends to generate a complete provirus that can eventually integrate in the host cell genome.

There is a vast literature on the effects of viral proteins and cell factors on reverse transcription. In most cases, studies have been carried out in the context of HIV-1 infections. However, their mechanism of action and significance is not always clear. It is assumed that reverse transcription initiates in the cytoplasm of infected cells, within a structure known as reverse transcription complex that contains RT and other viral proteins (for a detailed discussion, see Hughes, 2015). The capsid protein (CA) of HIV-1 forms a shell where reverse transcription initiates although a remodeling process may occur while the viral ssRNA is converted to dsDNA. However, other viral proteins such as Nef, Tat, Vif, Vpr, the matrix protein (MA) and the integrase may influence this process (Tekeste et al., 2015). Retroviral dUTPases are also known to influence replication in several retroviruses (e.g. feline immunodeficiency virus (FIV), equine infectious anemia virus (EIAV) or MMTV) (Elder et al., 1992; Köppe et al., 1994; reviewed in Hizi and Herzig, 2015). In addition, cellular proteins such as cyclophilin A, topoisomerase I, cytidine deaminases (apolipoprotein B mRNA-editing enzyme-catalytic polypeptide-like (APOBEC) family), SAMHD1 and the eukaryotic elongation factor 1 (eEF1) have been identified as potential cofactors that affect directly or indirectly HIV-1 reverse transcription (reviewed in Henriet et al., 2009; Warren et al., 2009). A systematic analysis of the available evidence is beyond the scope of a general introduction such as the one intended in this paper, and 


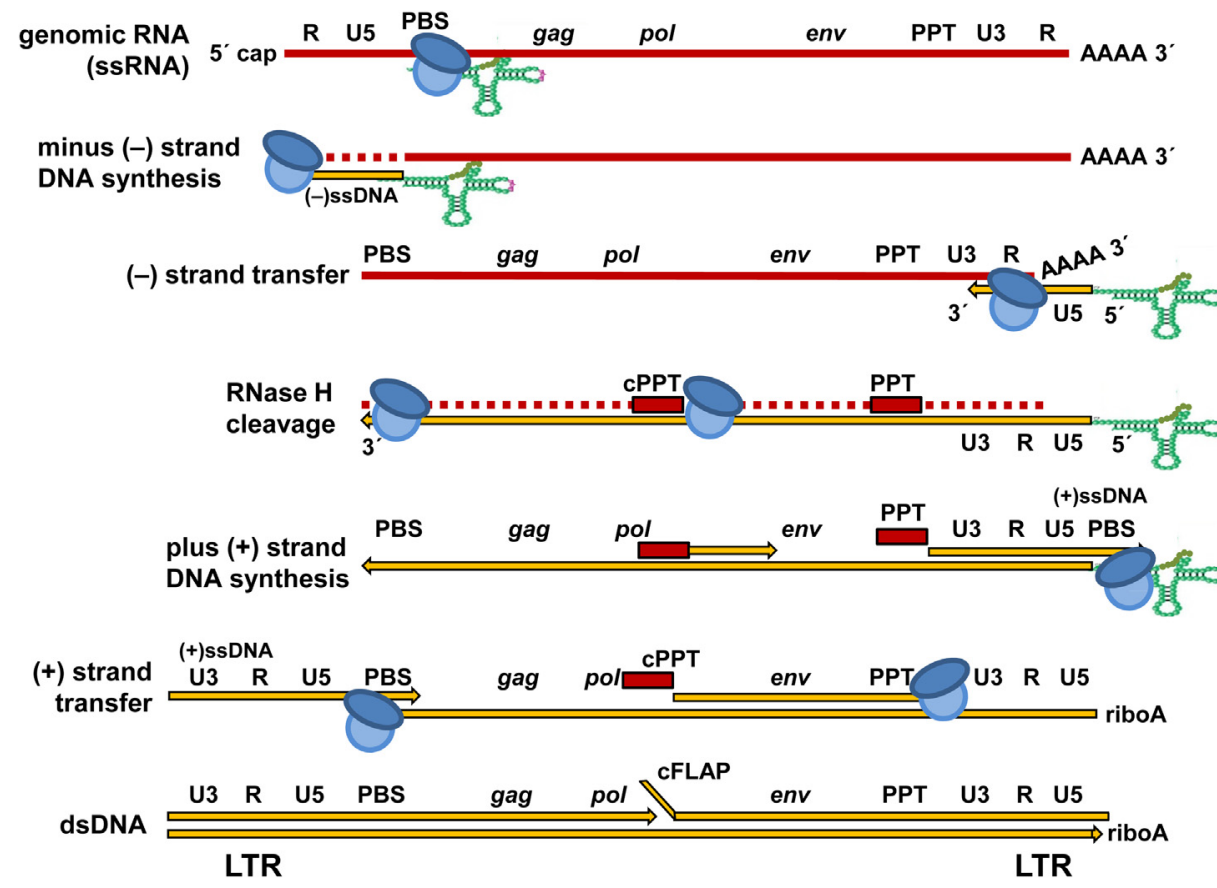

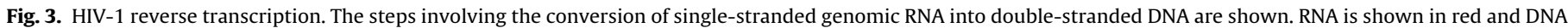
in orange. The heterodimeric RT subunits are shown as dark and light blue ovals.

interested readers may find relevant information in a few recently published reviews (Harris et al., 2012; Hilditch and Towers, 2014; Fujiwara, 2015; Hughes, 2015).

\section{RT biosynthesis in retroviruses and LTR retrotransposons}

In retroviruses and LTR retrotransposons, RTs are encoded within the pol gene. In most retroviruses, this gene contains coding sequences for the viral PR, RT (DNA polymerase plus RNase $\mathrm{H}$ domains) and IN proteins. In some retroviruses (e.g. MMTV and other betaretroviruses), the PR-coding region appears in a separate open reading frame known as pro. RT is normally expressed as part of a large precursor known as Gag-Pol or Gag-Pro-Pol that includes structural proteins such as MA (matrix), CA (capsid) and NC (nucleocapsid). The structural proteins are encoded within the gag gene. However, suppression of the stop codon at the end of gag facilitates the synthesis of large precursors. The stop codon can be bypassed by read-through suppression or -1 frameshifting (Jacks et al., 1987). The first mechanism occurs when gag and pol are in the same open reading frame and separated by a stop codon that is read as Gln with a $5 \%$ frequency. This mechanism is characteristic of gammaretroviruses (e.g. MLV). In contrast, ribosomal frameshifting occurs in retroviruses where gag and pro, gag and pol and/or pro and pol are in a -1 reading frame (Fig. 4). When the pol gene contains the PRcoding region (e.g. in HIV-1), this mechanism allows after only one frameshift event, the synthesis of equimolecular amounts of PR, RT and IN, which are produced in a 20 -fold reduced amount relative to structural proteins encoded within the gag gene. In viruses having gag, pro and pol in different open reading frames (e.g. MMTV or HTLV-I), RT and IN derive from a Gag-Pro-Pol precursor, originated after two frameshift events (Jacks et al., 1987; Hatfield and Oroszlan, 1990) (Fig. 4).

Spumaviruses (foamy viruses) are unique retroviruses because they do not produce Gag-Pol or Gag-Pro-Pol polyproteins and the RT is generated from a separate spliced mRNA (Rethwilm, 2003; Rethwilm, 2010). This RNA lacks the gag sequence and guides the synthesis of the Pol polyprotein that contains the enzymes PR, RT and IN. Another interesting feature of spumaviruses (also shown by hepadnaviruses) is that infectious particles can contain dsDNA (as well as single-stranded RNA), suggesting that reverse transcription occurs during polyprotein packaging and maturation before the virion enters the target cells (Linial and Eastman, 2003; Lee et al., 2013).

The subunit composition of retroviral RTs is rather diverse (Fig. 4). Three enzymatically-active RT isoforms have been purified from virions of alpharetroviruses, such as avian leukosis virus (ALV), ASLV, avian myeloblastosis virus (AMV) or RSV. The most abundant isoform in those viruses is the $\alpha / \beta$ heterodimer. It contains DNA polymerase, RNase $\mathrm{H}$ and IN domains in the $\beta$ subunit (95 kDa) and DNA polymerase and RNase H domains in the $\alpha$ chain $(63 \mathrm{kDa})$. Other isoforms found in purified virions are homodimers $(\beta / \beta)$ and monomers $(\alpha)$ (Hizi and Joklik, 1977). Proteolytic cleavage of the Gag-Pol precursor to obtain $\beta / \beta$ homodimers is needed to obtain an active RT. Then, further processing by the viral PR leads to the formation of $\alpha / \beta$ heterodimers that can dissociate to monomers $\alpha$ and $\beta$, although only the $\beta$ subunit retains activity (for a detailed review, see Herschhorn and Hizi, 2010).

Active heterodimeric RTs have also been found in lentiviruses. However, their size is smaller. HIV-1 virions contain RTs made of 66 and $51 \mathrm{kDa}$ subunits, designated as p66 and p51, respectively. The larger subunit has 560 residues and contains DNA polymerase and RNase $\mathrm{H}$ domains, while p51 (440 residues) lacks the RNase $\mathrm{H}$ domain. The $\mathrm{p} 51$ subunit has a major role in the stabilization of the heterodimer. In addition, p51 contributes to tRNA binding during initiation of reverse transcription (Arts et al., 1996) and accommodates the RNA/DNA substrate for correct positioning in the RNase $\mathrm{H}$ active site (Chung et al., 2013). Although the proteolytic events leading to the formation of p66/p51 in vivo have not been demonstrated, p66 homodimers can be converted to p66/p51 in vitro by the action of the viral PR. Similar heterodimeric compositions have been described for RTs of HIV-2 (p68/p55), simian immunodeficiency virus (SIV) (p66/p51), FIV (p67/p54) and bovine immunodeficiency virus (BIV) (p64/p51) (Hizi and Herschhorn, 2008). Biochemical studies have shown that HIV-1 RT undergoes a complex maturation process that includes three basic steps: (i) domain rearrangements; (ii) dimerization; and (iii) subunit- 

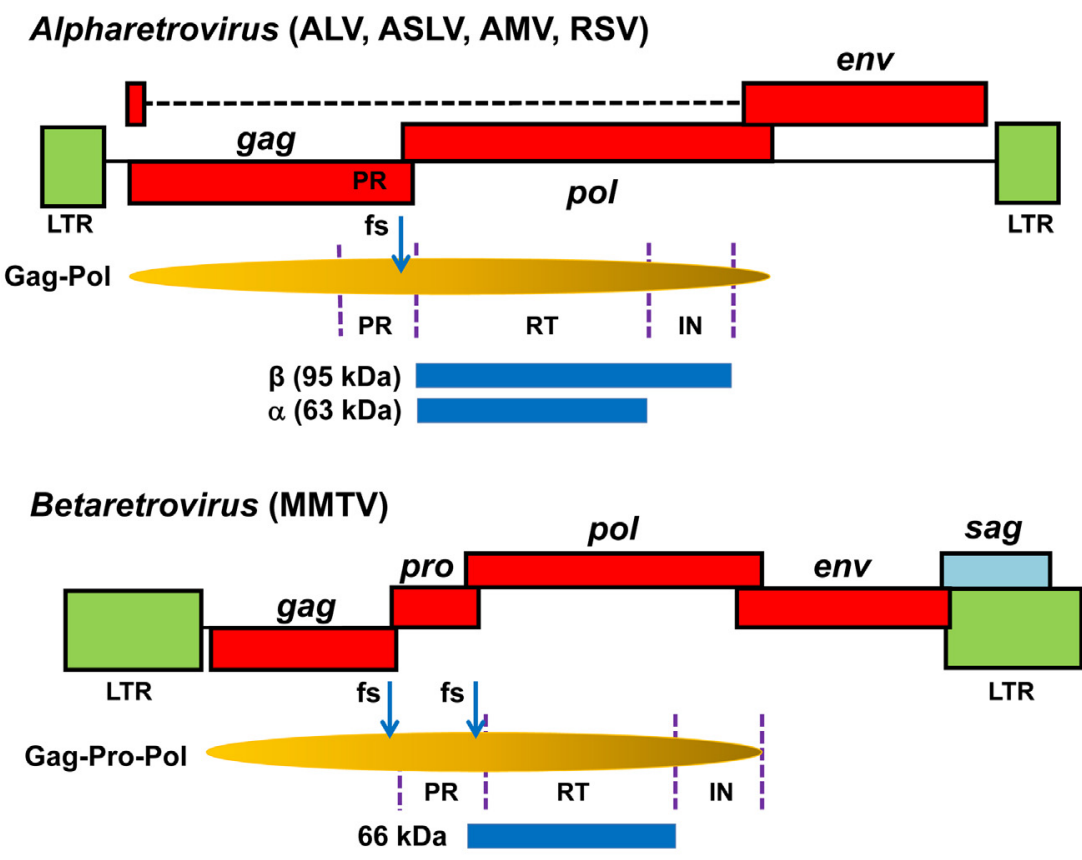

\section{Gammaretrovirus (MLV, XMRV)}
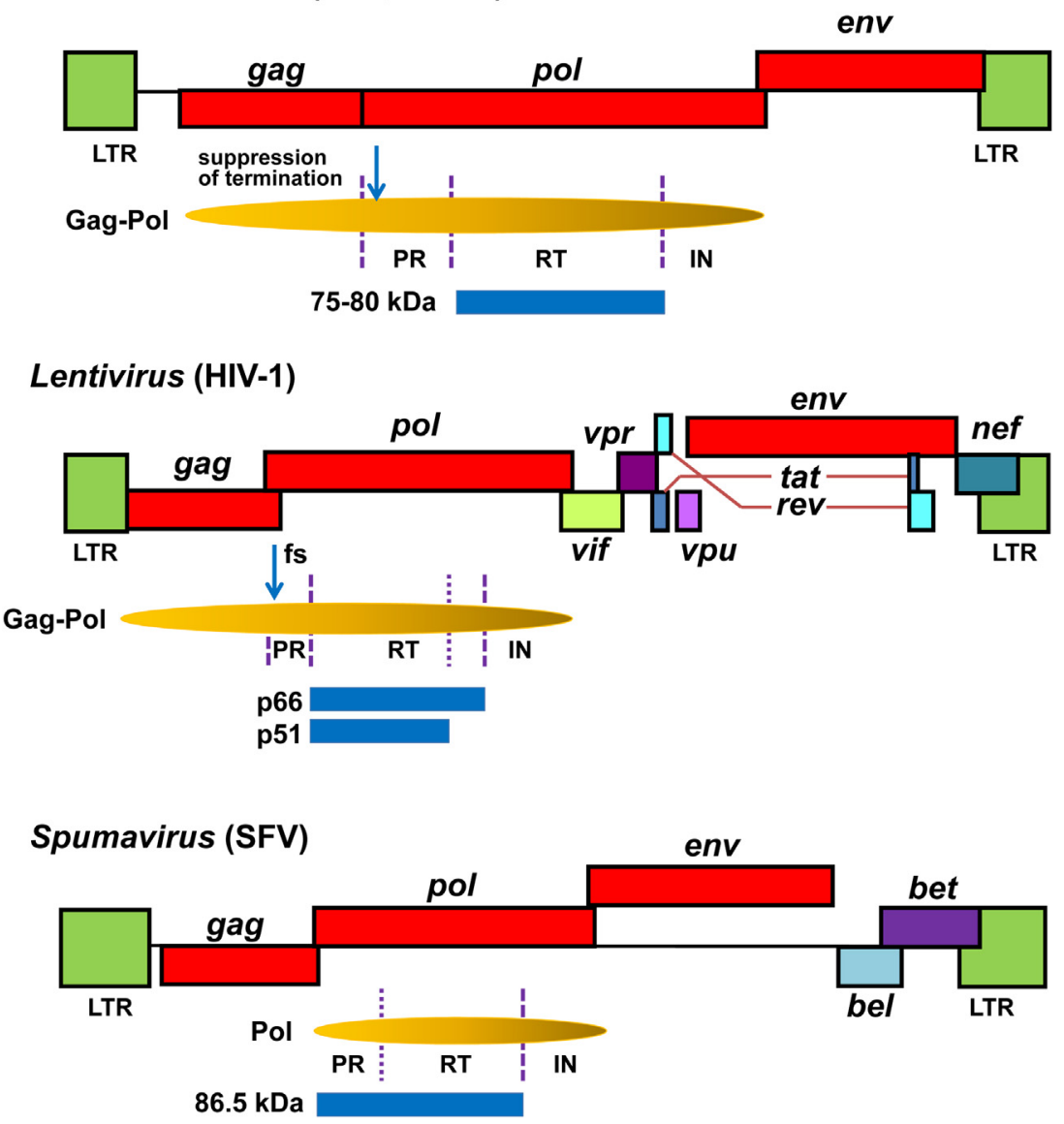

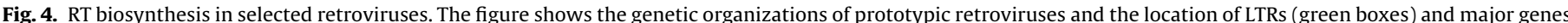

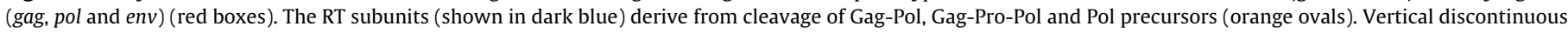

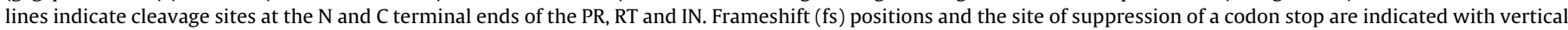
arrows. The size of the retroviral genomes shown range from 7.6 to $11.6 \mathrm{~kb}$, but for the sake of clarity, all were normalized to the same size.

selective RNase $\mathrm{H}$ proteolysis (for a recent review, see London, 2016). Amino acid changes that destabilize the heterodimeric structure of the RT could have a negative effect on polyprotein processing
(Abram and Parniak, 2005; Wapling et al., 2005; Olivares et al., 2007; Dunn et al., 2009). In some cases, the deleterious effect on viral fitness can be compensated by mutations in the viral PR that 
modulate the kinetics of the proteolytic process (Olivares et al., 2007).

In contrast, RTs of gammaretroviruses such as MLV, feline leukemia virus (FLV) or the xenotropic MLV-related virus (XMRV) are active monomers of $75-80 \mathrm{kDa}$ that contain a DNA polymerase domain plus an RNase H domain (Roth et al., 1985; Misra et al., 1998; Operario et al., 2005; Barrioluengo et al., 2012; Ndongwe et al., 2012). Monomers or homodimers of less-studied RTs have been obtained in active forms using recombinant DNA technology. However, their subunit composition in the virion remains unknown. For example, the MMTV RT has been obtained as a 66kDa polypeptide of 630 amino acids, containing 27 residues at its $\mathrm{N}$-terminal end that derived from the C-terminal region of the viral PR (Taube et al., 1998). Using specific antisera, researchers have also shown evidence of the presence in virions of mature MMTV RT fused to PR-derived sequences (Entin-Meer et al., 2003). On the other hand, mutagenesis studies have shown that an $\mathrm{N}-$ terminal extension including a glycine-rich region known as the G-patch domain (GPD) is required for optimal Mason-Pfizer monkey virus (MPMV) RT activity (Křízová et al., 2012). The GPD sequence is found in several betaretroviruses but not in MMTV, and is located between the PR- and the RT-coding regions of their genome. Released MPMV virions contain PR variants with and without the GPD sequence, which have similar proteolytic activities and substrate specificities (Zábranský et al., 1998). Based on immunological evidence, Krrizová et al. proposed that the MPMV RT is a heterodimer with a small subunit that contains the GPD sequence.

As observed with the MMTV RT and suggested for the MPMV polymerase, the bovine leukemia virus (BLV) RT was also expressed and purified with an $\mathrm{N}$-terminal extension. This enzyme was active as a monomer of 584 amino acids that contained 26 residues derived from the viral PR (Perach and Hizi, 1999). Despite being also a deltaretrovirus, the most likely active form of the HTLV-I RT is a p62/p49 heterodimer similar to those found in lentiviruses. Nevertheless, a precursor of $98 \mathrm{kDa}$ containing the RT fused to the IN has been detected in HTLV-I virions (Mitchell et al., 2006). Expression and biochemical characterization of recombinant HTLV-I RT has not been yet reported.

In spumaviruses, the polyprotein Pol is cleaved between the RNase $\mathrm{H}$ and the IN domains to produce a mature PR-RT and the IN (Fig. 4). The PR-RT polypeptide found in mature virions is monomeric (Hartl et al., 2008), although dimerization of the PR is required for proteolytic activity (Hartl et al., 2011). Viral PR-mediated cleavage of Gag is required for initiation of reverse transcription, although the unprocessed Pol precursor has RT and IN activities within the viral capsid (Hütter et al., 2013; Spannaus et al., 2013). The PR domain corresponds to the first 101 amino acids of Pol, while residues 102-751 include the DNA polymerase and RNase $\mathrm{H}$ domains of the RT. Using pol deletion mutants of a simian foamy virus (SFV) infecting macaques, researchers have shown that the sequence comprising residues $107-143$ is critical for polymerase activity but not for protease activity. In addition, the connection subdomain (residues 454-590) modulates RT function, while affecting substrate affinity and protein stability (Schneider et al., 2014). In contrast to orthoretroviruses, reverse transcription is a late event in foamy virus replication that takes place in producer cells. Evidence indicates that this can be attributed to the Pol polyprotein itself, because the expression of the spumavirus RT as an engineered Gag-Pol polyprotein did not affect the timing of reverse transcription (Jackson et al., 2013).

A number of RTs derived from LTR retrotransposons have been purified and characterized. Examples are the Saccharomyces cerevisiae Ty1 and Ty3 RTs and the Saccharomyces pombe Tf1 RT. These enzymes were expressed and purified in $E$. coli as single polypeptides of around $55-65 \mathrm{kDa}$, with histidine tails at their C-terminal ends (Rausch et al., 2000; Wilhelm et al., 2000; Kirshenboim et al.,
2007). Successful expression of Ty1 RT required the addition of a small acidic tail at the $\mathrm{N}$-terminus of the polymerase domain that mimics the C-terminal region of the Ty1 IN (Wilhelm et al., 2000; Wilhelm and Wilhelm, 2005). Structural studies have recently shown that the Ty3 RT adopts an asymmetric homodimeric architecture whose assembly is substrate dependent (Nowak et al., 2014).

\section{RTs of retroviruses and LTR retrotransposons}

\subsection{Structural studies}

Current knowledge on the mechanism of action of retroviral RTs is based on many available crystal structures of HIV-1 RTs (for reviews, see Ren and Stammers, 2008; Sarafianos et al., 2009). Among them, the ternary complex of HIV- $1_{\mathrm{HXB} 2}$ RT with dsDNA and dTTP (PDB file 1RTD; Huang et al., 1998) is probably one of the most relevant to understand the influence of specific amino acids on DNA polymerase and RNase $\mathrm{H}$ activities (Fig. 5). Other structures that provide additional insights into RT function are: (i) binary complexes of RT bound to dsDNA (PDB files 3KJV, 3KK1, 3KK2, 3KK3, 1 T05 and 2HMI) (Ding et al., 1998), (ii) HIV-1 RTs in complex with dsDNA in pre- and post-translocation states (1N5Y, 1N6Q) (Sarafianos et al., 2002), (iii) HIV-1 RT bound to a cleavage-resistant polypurine tract (1HYS) (Sarafianos et al., 2001), and (iv) other structures including the apoenzyme alone, bound to RT inhibitors or complexed with nucleic acids with or without antiretroviral drugs (e.g. 4B3O, 4B3P, 4B3Q, 4PUO, 4PWD, 4Q0B, 3JYT, 3JSM, etc.) (Tuske et al., 2004; Ren and Stammers, 2008; Das et al., 2009; Tu et al., 2010; Das et al., 2012; Lapkouski et al., 2013).

Unlike in the case of HIV-1 RT, there is only one crystal structure available for HIV-2 RT (Ren et al., 2002). It is an unliganded form of the enzyme with subunits of 559 and 427 residues, respectively. Although the size of the small HIV-2 RT subunit in vivo is uncertain, biochemical evidence suggests that cleavage leading to the formation of p55 occurs after Met ${ }^{484}$, and not at the equivalent site of HIV-1 RT (i.e. between Phe ${ }^{440}$ and $\mathrm{Tyr}^{441}$ ) (Fan et al., 1995). The smaller size of this subunit in the crystal structure has been attributed to degradation of p68 by bacterial proteases (Bird et al., 2003).

Crystal structures of HIV-1 and HIV-2 RTs show similar folds. In HIV RTs both subunits contain four subdomains, designated fingers, palm, thumb and connection, whereas the large subunit has a C-terminal RNase H domain. Despite their sequence identity, the spatial organization of the subdomains differs substantially in both subunits. The p51 subunit is tightly packed and cannot participate in the catalysis. On the other hand, p66 adopts an open conformation and provides the catalytic residues for the DNA polymerase $\left(\right.$ Asp $^{110}$, Asp $^{185}$ and Asp $\left.{ }^{186}\right)$ and RNase H $\left(\right.$ Asp $^{443}, \mathrm{Glu}^{478}$, Asp $^{498}$ and $\mathrm{Asp}^{549}$ ) activities, as well as most of the nucleic acid binding cleft interactions (Fig. 5). The fingers, palm and thumb subdomains of p66 provide lateral and apical interactions with the nucleic acid substrate, while the 'floor' of the cleft is provided by the connection subdomains of both subunits and the thumb subdomain of p51 (Jacobo-Molina et al., 1993). The nucleic acid binding cleft can accommodate 17-18 base pairs between the active sites of the DNA polymerase and the RNase H. HIV-1 RT regions that interact with the template-primer in the binary complex are the 'primer grip' (residues 227-235 of p66), the 'helix clamp' (residues 255-268 and 278-286 of p66), the 'RNase H primer grip' (residues 358-361, 473-476, 501 and 505 of p66, and 395-396 of p51) and the 'template grip' (residues $73-77,78-83,86-90$ and $141-174$ of p66) (Ding et al., 1998). The primer grip is important to maintain the $3^{\prime}-$ $\mathrm{OH}$ of the primer in an appropriate orientation for the nucleophilic attack on the incoming dNTP. 

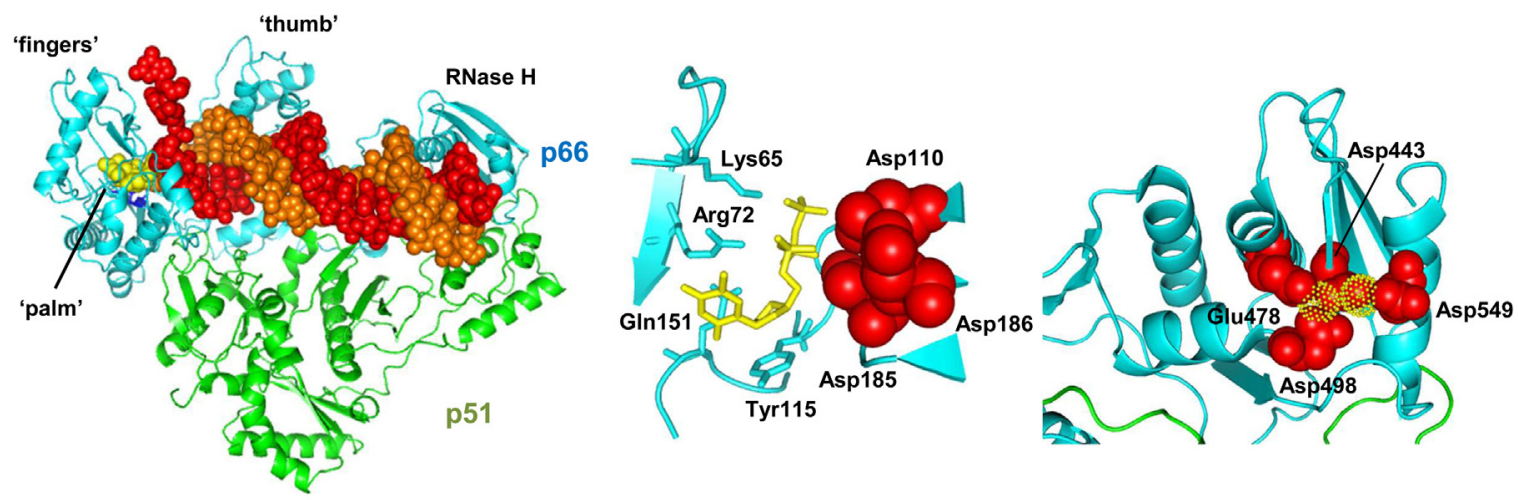

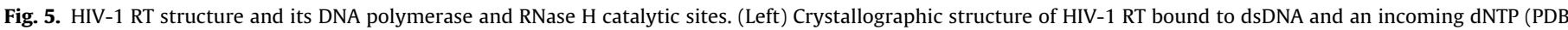

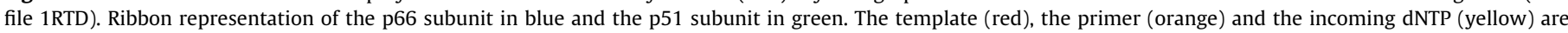

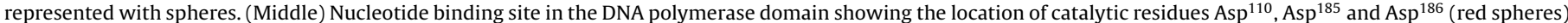

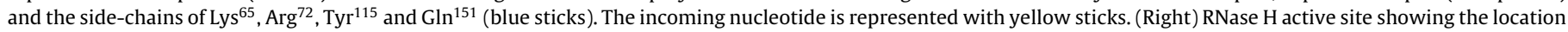
of $\mathrm{Asp}^{443}, \mathrm{Glu}^{478}, \mathrm{Asp}^{498}$ and Asp ${ }^{549}$ (red spheres), and the coordinating metal ions (dot yellow surfaces). Coordinates were taken from PDB file 3LP1.

The catalytic residues of the DNA polymerase active site are close to the $3^{\prime}$ end of the primer. Asp ${ }^{185}$ and Asp ${ }^{186}$ are part of the conserved YMDD motif and allow proper coordination with metal cofactors and trigger the nucleophilic attack of the $3^{\prime}-\mathrm{OH}$ of the primer terminus on the $\alpha$ phosphorous of the incoming dNTP (Huang et al., 1998; Mendieta et al., 2008). The incoming dNTP is tightly coordinated by the side-chains of Lys ${ }^{65}$ and $\mathrm{Arg}^{72}$ in the fingers subdomain of $\mathrm{p} 66$, the main chain amido groups of $\mathrm{Asp}^{113}$ and Ala $^{114}$, and two magnesium cations. Other important residues that delineate the dNTP binding pocket are $\mathrm{Tyr}^{115}$, $\mathrm{Phe}^{116}$ and $\mathrm{Gln}^{151}$ (Fig. 5). Site-directed mutagenesis studies have shown that Lys ${ }^{65}$ has a major influence on the fidelity of HIV-1 RTs, and its substitution by Arg renders enzymes with more than 8-fold increased fidelity of DNA synthesis (Shah et al., 2000; Mansky et al., 2003; Garforth et al., 2010; Barrioluengo et al., 2011). On the other hand, the aromatic ring of $\mathrm{Tyr}^{115}$ acts as a steric gate that allows the incorporation of dNTPs, but prevents the incorporation of rNTPs due to the presence of the $2^{\prime}-\mathrm{OH}$ in their ribose ring (Gao et al., 1997; Cases-González et al., 2000).

The RNase $\mathrm{H}$ activity of HIV RTs degrades the template RNA and the primer tRNA during minus-strand and plus-strand DNA synthesis, respectively, and facilitates the generation of PPTs needed for plus-strand DNA synthesis. The structure of the RNase $\mathrm{H}$ domain of HIV-1 RT shows a high similarity to E. coli RNase H. It is made of $5 \beta$-sheet structures, flanked by $4 \alpha$-helices. Catalytic residues in the active site are coordinated with two manganese cations in the crystal structure, although most likely these are $\mathrm{Mg}^{2+}$ in vivo (for a detailed description of the catalytic mechanism, see Le Grice, 2012). Crystal structures showed extensive contacts between the HIV-1 RT and nucleic acid next to the RNase $\mathrm{H}$ active site (Sarafianos et al., 2001). RT residues in this region are collectively designated 'RNase $\mathrm{H}$ primer grip' and interact with the DNA primer 4-9 nucleotides upstream of the scissile bond. The RNase H primer grip determines the trajectory of the RNA strand necessary for its endonucleolytic cleavage.

Apart from HIV RTs, there are crystal structures available for RTs of Moloney MLV (MoMLV) (Das and Georgiadis, 2004; reviewed in Coté and Roth, 2008), XMRV (PDB file 4HKQ; Nowak et al., 2013) and the Ty3 element of $S$. cerevisiae (PDB file 40L8; Nowak et al., 2014) (Fig. 6). MoMLV and XMRV RTs share 97.5\% sequence identity and are monomeric enzymes. Crystal structures of the two full-length proteins bound to dsDNA are available, but in the case of the MoMLV RT the RNase H domain was disordered (Das and Georgiadis, 2004). The structure of XMRV RT bound to dsDNA showed that the nucleic acid interacts with all domains of the protein and sits in a positively-charged substrate-binding chan-

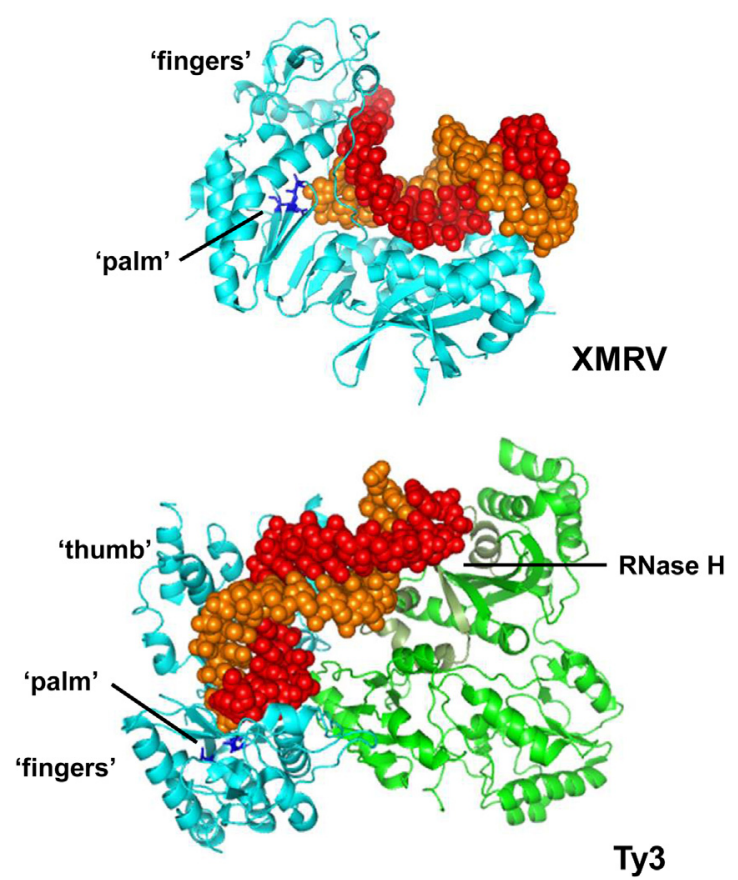

Fig. 6. Crystal structures of the XMRV RT (DNA polymerase domain) and Ty3 RTs complexed with nucleic acid. Ribbons are used to represent the protein backbones (blue for the monomeric XMRV RT and blue and green for the dimeric Ty3 RT). Templates and primers are represented with red and orange spheres, respectively. Coordinates for XMRV and Ty3 RTs were taken from PDB files 4HKQ and 4OL8, respectively.

nel (Nowak et al., 2013). The protein covers 14 nucleotides of the primer and 16 nucleotides of the template. The architecture of the DNA polymerase active sites of XMRV and HIV-1 RTs are very similar, and the trajectory of the substrate near the catalytic site is superimposable. Differences between both enzymes affect the positioning of the fingers subdomains which are in a more open conformation in binary complexes of HIV-1 RT and nucleic acid. Another remarkable difference relates to the positioning of the RNase H domain, which shows increased mobility in the XMRV $\mathrm{RT}$, in the absence of substrate. However, these differences do not seem to affect strand transfer or PPT generation and removal, since HIV-1 RT can use MoMLV PPT with only slightly affected cleavage specificity (Pullen et al., 1993; reviewed in Champoux and Schultz, 2009). 
The Ty3 RT is an asymmetric homodimer of 55-kDa subunits that associates in the presence of the template-primer (Nowak et al., 2014). In the absence of nucleic acid, the Ty3 RT behaves as a monomer (Rausch et al., 2000). The overall conformations of Ty3 and HIV-1 RTs are similar. One of the subunits of the Ty3 RT mimics p51 by adopting a more compact conformation, which also seems to be preferred in the absence of nucleic acid. These findings are also consistent with recently published NMR data showing that HIV-1 RT p66/p66 homodimers are heterodimeric from a structural point of view, and possess conformations very similar to those in mature RT (Sharaf et al., 2014; Zheng et al., 2014; Zheng et al., 2015).

Another notable difference between retroviral RTs and the Ty3 enzyme is that DNA polymerase and RNase $\mathrm{H}$ active sites are separated by only 13 base pairs (Lener et al., 2002), although the crystal structure of the Ty3 RT shows that the trajectories of the nucleic acid substrates are very similar to those found in the XMRV RT. Biochemical studies showed that in the Ty3 RT the second carboxylate of the YLDD motif (i.e. Asp ${ }^{214}$ ) is not essential for DNA polymerization, although substitutions at this position were found to be lethal for Ty3 transposition (Bibillo et al., 2005). Another unique feature of the Ty3 enzyme is that DNA polymerase and RNase $\mathrm{H}$ activities are located in different subunits (Nowak et al., 2014). Still, it is not known whether this is a general property of RTs of LTR retrotransposons.

\subsection{Enzymatic properties and characteristics of the DNA polymerase}

Retroviral RTs have two different catalytic sites: one for DNA polymerization and a second one for RNA cleavage on RNA/DNA hybrids. Both catalytic sites work simultaneously without being tightly coupled (Li et al., 2016). The DNA polymerization reaction starts with the binding of the RT to the template-primer (usually DNA/DNA or RNA/DNA), followed by the interaction of the incoming dNTP with its binding site in the polymerase active site of the enzyme (Huang et al., 1998). The rate-limiting step in nucleotide incorporation is a conformational change that affects the fingers subdomain of the catalytic subunit. The largest motion within the subdomain occurs at the $\beta 3-\beta 4$ hairpin loop and facilitates the proper alignment of the $\alpha$-phosphate of the incoming dNTP with the $3^{\prime}$-end of the primer. The geometry for the nucleophilic attack is facilitated by binding of metal ions with the right size and coordination geometry (Yang et al., 2006). All RTs require two divalent cations for DNA synthesis. $\mathrm{Mg}^{2+}$ is the preferred one, although gammaretroviral RTs showed higher specific activity in the presence of $\mathrm{Mn}^{2+}$. Studies carried out with HIV-1 RT showed the different properties of the two $\mathrm{Mg}^{2+}$ binding sites (Mendieta et al., 2008). The lower affinity binding site involves interactions with the sidechains of $\mathrm{Asp}^{110}$, Asp $^{185}$ and $\mathrm{Asp}^{186}$ and the $3^{\prime}-\mathrm{OH}$ of the primer. Binding of $\mathrm{Mg}^{2+}$ to this site is required to obtain an RT catalytically competent for DNA polymerization.

Kinetic measurements carried out in vitro have shown that retroviral RTs are relatively slow in comparison to other DNA polymerases. Although nucleotide incorporation rates depend on the substrate and assay conditions, reported values have been usually in the range of 10-105 nucleotides per second (Kati et al., 1992; Zinnen et al., 1994; Kerr and Anderson 1997; Mendieta et al., 2008; Kisic et al., 2011; Li et al., 2016). Completing minus-strand DNA synthesis in cells may take several hours. In HIV-1-infected 293T cells and in human primary CD4+ T lymphocytes, it has been estimated that this process proceeds at approximately 68-70 nucleotides/min (Thomas et al., 2007). Moreover, compared to other polymerases, RTs show low processivity. In general, RTs may be able to incorporate a few hundred nucleotides in one round of DNA synthesis. However, the presence of RNA secondary structures (e.g. pseu- doknots) or specific sequences can cause the dissociation of the enzyme.

Similar to other DNA polymerases that lack $3^{\prime} \rightarrow 5^{\prime}$ exonuclease activity, RTs can add non-templated nucleotides at the $3^{\prime}$ end of nascent DNA in vitro (Golinelli and Hughes, 2002a; Golinelli and Hughes, 2002b). The best nucleotide substrate of the reaction was dATP, although the efficiency and base specificity were strongly affected by the sequence at the $3^{\prime}$ end of the blunt-ended duplex. This reaction can take place with RNA/DNA or DNA/DNA complexes. However, the RT has to be in a large excess over the template-primer and requires relatively high dNTP concentrations. Since non-templated nucleotide addition proceeds at a much slower rate than template-dependent polymerization, this reaction may have little impact on retroviral replication in vivo. Addition of non-templated nucleotides at the $3^{\prime}$ end of the DNA can facilitate non-specific strand transfer if the $3^{\prime}$ overhangs are complementary to 3'-end sequences of the acceptor strand. It has been shown in vitro that RTs of retroviruses and LTR retrotransposons can extend 3 ' overhangs of 1,2 or 3 nucleotides if the reaction takes place in the presence of oligonucleotides showing complementarity at their $3^{\prime}$ end with the overhanging nucleotides (Oz-Gleenberg et al., 2011). This activity (known as 'clamp activity') can allow strand transfers onto compatible acceptor strands while synthesizing DNA and can help RTs in bridging over nicks in the copied RNA or DNA templates (Fig. 7).

The RT of the LTR retrotransposon Tf1 has a non-templated nucleotide addition activity that is substantially higher than that of HIV-1 or MLV RTs. The Tf1 RT can add up to seven nucleotides while the other enzymes may incorporate only one dNTP (Kirshenboim et al., 2007; Oz-Gleenberg et al., 2012). This high activity could explain why Tf1 cDNA molecules produced in vivo have relatively long extra sequences beyond the highly conserved CA at their 3'ends (Atwood-Moore et al., 2005).

Another interesting property of retroviral RTs is their capacity to switch templates. Reverse transcription involves at least two strand transfer events facilitated by the presence of repeated sequences in the viral genome. The first strand transfer can be either interor intramolecular, while the plus-strand DNA transfer is predominantly intramolecular (reviewed in Basu et al., 2008; see Section 2). A basic feature of the strand transfer mechanism is that RNA degradation by the RT RNase $\mathrm{H}$ activity plays an important role by generating the single-stranded DNA region that anneals to the acceptor molecule. The strand transfer process is facilitated by the viral NC protein that enhances minus-strand transfer, by accelerating the annealing of $5^{\prime}$ repeat cDNA to the $3^{\prime}$ repeat sequence of the viral RNA genome.

RTs of retroviruses and retrotransposons (LTR and non-LTR) possess strand displacement activity (Huber et al., 1989; Whiting and Champoux, 1994; Kurzynska-Kokorniak et al., 2007). This activity is needed during plus-strand DNA synthesis and is mediated by the RT-associated helicase activity that facilitates unwinding of the dsDNA during polymerization. Retroviral RTs appear to closely couple dsDNA melting with synthesis-driven translocation of the enzyme, although they do not behave as classical helicases and do not require ATP or any other nucleotide to catalyze processive unwinding at a nick. During reverse transcription, the strand displacement activity helps to eliminate discontinuous plus-strand DNA segments and generates the dsDNA needed for successful integration into the host cell genome. Displacement DNA synthesis is less processive and proceeds at a slower rate than non-displacement synthesis (Whiting and Champoux, 1998). Molecular determinants of the strand displacement activity seem to be associated with specific residues of the fingers subdomain. Thus, mutagenesis studies showed that the deleterious effect on viral replication of amino acid substitutions affecting $P^{61}$ in HIV-1 RT and Tyr ${ }^{64}$ in MLV RT can be attributed to a defect in 

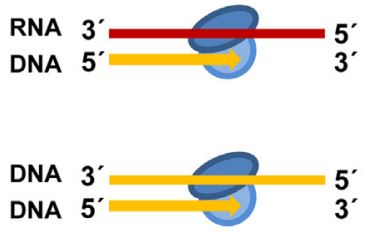

Template-dependent polymerization
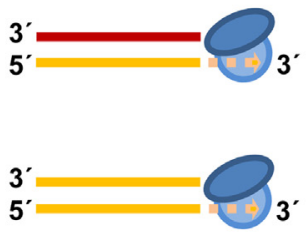

Non-templated nucleotide addition
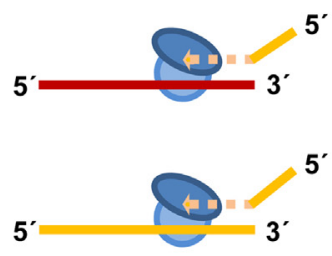

Non-specific strand transfer

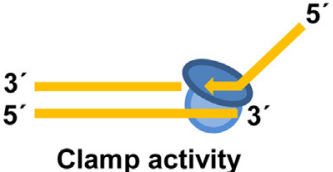

Clamp activity

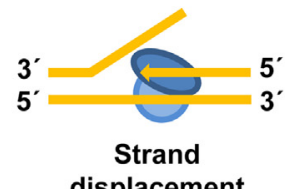

displacement

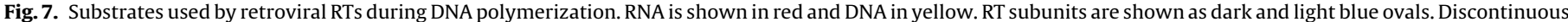

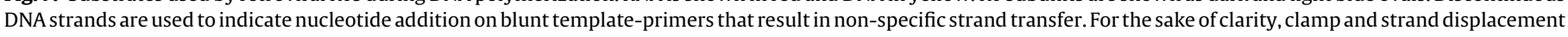
activities are shown only for DNA:DNA complexes.

strand displacement activity (Fisher et al., 2003; Paulson et al., 2007).

\subsection{RNase H activity}

The RNase $\mathrm{H}$ activity present in RTs hydrolyzes phosphodiester bonds to produce a 3'-OH and a 5'-phosphate end. This characteristic is important during reverse transcription because it facilitates the generation of RNA fragments that can be used as primers for DNA synthesis (e.g. PPTs). The specificity of this cleavage is different from that shown by pancreatic RNase A and other related endonucleases that leave a phosphorylated $3^{\prime}$ end. As described for the DNA polymerase active site, RNase $\mathrm{H}$ activity involves a two- $\mathrm{Mg}^{2+}$-ion catalytic mechanism. RNA/DNA substrates can adopt polymerasedependent or -independent modes of interaction with the RT (reviewed in Beilhartz and Götte, 2010). Polymerase-dependent (also known as DNA 3'-directed cleavage) occurs when the $3^{\prime}$ end of the DNA strand locates at the polymerase active site, resulting in the cleavage of the RNA 15-20 nucleotides away from the 3' end of the growing strand (Fig. 8). In this conformation and in the presence of dNTPs, the RT will advance, while its RNase $\mathrm{H}$ activity will eventually cut the RNA template. However, it has been estimated that the rate of RNase $\mathrm{H}$ cleavage is approximately 5-10 times smaller than nucleotide incorporation (DeStefano et al., 1991; Kati et al., 1992; Li et al., 2016). Other modes of action that involve binding of the RT in an internal region of the DNA are considered polymeraseindependent, although many authors make the distinction between RNA 5'-directed cleavage (when the 5' end of the RNA locates at the polymerase active site) or an internal cleavage, when the nucleic acid ends do not influence RT positioning.

The main function of the RNase $\mathrm{H}$ activity in reverse transcription is the elimination of the viral genomic RNA to facilitate the synthesis of viral dsDNA. In principle, specificity is not very important and cleavage preferences are not clearly defined. Therefore, differences between retroviral RTs are relatively small (Nair et al., 2012). However, RNase H specificity is important for the formation of PPT primers and for the elimination of RNA primers used in reverse transcription (i.e. PPT and tRNA). Removal of PPT requires the previous addition of two or three nucleotides at its $3^{\prime}$ end. Then, cleavage occurs at the junction between the RNA primer and the incorporated deoxynucleotides. With some RTs and RNA primers, cleavage specificity is slightly different and can be modulated by the flanking DNA sequences. For example, the tRNA removal reaction catalyzed by the HIV-1 RT leaves a single ribonucleotide (riboA) at the $5^{\prime}$ end of the minus-strand DNA, while in HIV-2, the tRNA is removed completely (Champoux and Schultz, 2009). In addition, it has been shown that some RT inhibitors, such as efavirenz or rilpivirine promote RNase $\mathrm{H}$-mediated trimming of the PPT primer and prematurely block initiation of plus-strand DNA synthesis (Betancor et al., 2015).
Interestingly, the RNase $\mathrm{H}$ domain alone is not able to cleave RNA/DNA complexes and requires other elements in the RT structure that are responsible for the proper binding of the template-primer. In agreement with these observations, mutations in the connection subdomain, away from the RNase $\mathrm{H}$ active site can have a measurable impact on RNase $\mathrm{H}$ activity (Nikolenko et al., 2005; Delviks-Frankenberry et al., 2008; Menéndez-Arias et al., 2011; Betancor et al., 2015).

\subsection{Fidelity of DNA synthesis}

Retroviral RTs are devoid of $3^{\prime} \rightarrow 5^{\prime}$ exonucleolytic proofreading activity and show intrinsic error rates in the range $10^{-4}-10^{-5}$, much higher than those reported for eukaryotic replicative DNA polymerases (Matsuda et al., 2000; Kunkel, 2004; McCulloch and Kunkel, 2008; and references therein). Although it has been argued that retroviral genetic variability is a consequence of the high error rate of the RT, there is also an important contribution of the eukaryotic RNA polymerase II as the enzyme responsible for the synthesis of the viral genome using the integrated provirus as template. Transcription errors are very difficult to quantify and current estimates of transcription fidelity are derived from artificial constructs applied to just a few organisms. Despite large differences in error rates reported by several groups, a rough overall average value of $10^{-5}$ per nucleotide has been suggested (Ninio, 1991), and recent estimates are in agreement with this proposal (Gout et al., 2013; Magnuson et al., 2016; Traverse and Ochman, 2016).

The relative contribution of the viral RT and the host cell RNA polymerase to the high HIV-1 mutation rate has been evaluated in a single cycle of virus replication. These studies support the notion of a larger contribution of the RT, although differences were relatively small, with transcription errors contributing about one third of the error rate found in the progeny virus (O'Neil et al., 2002). On the other hand, viral and host factors can influence mutation rates by different mechanisms. For example, an error rate of $3.4 \times 10^{-5}$ per nucleotide and replication cycle has been estimated for HIV-1, but the deletion of the vpr gene resulted in a 4-fold increase in mutant frequency (Mansky, 1996). Vpr facilitates the incorporation of the nuclear form of uracil DNA glycosylase (UNG2) into HIV-1 virions. UNG2 is a component of cellular DNA repair mechanisms. Interestingly, DNA repair by the nonhomologous end-joining pathway has been associated with mutational escape of HIV-1 from clustered regularly interspaced short palindromic repeats-Cas9 (CRISPR-Cas9) inhibition in transfected T cells (Wang et al., 2016). Cytidine deaminases such as those of the APOBEC family can be incorporated into HIV and induce deamination of cytidines in the negative strand of the viral DNA, and as a consequence promote $G \rightarrow A$ hypermutation on the plus-strand DNA. APOBEC3-driven mutagenesis occurs mostly at $5^{\prime}-\mathrm{GG}-3^{\prime}$ and 


\title{
Polymerase- dependent mode
}

\author{
DNA 3'-directed \\ cleavage

\section{Polymerase-} \\ independent mode
}

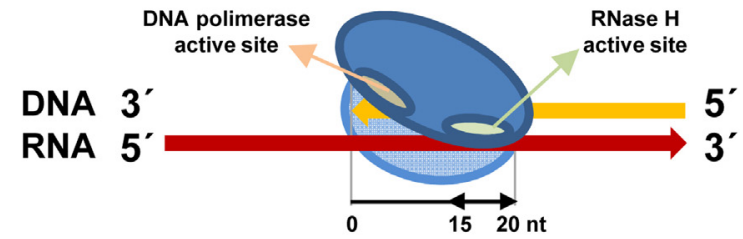

Internal cleavage

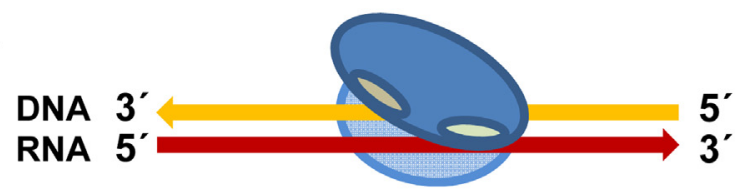

RNA 5'-directed cleavage

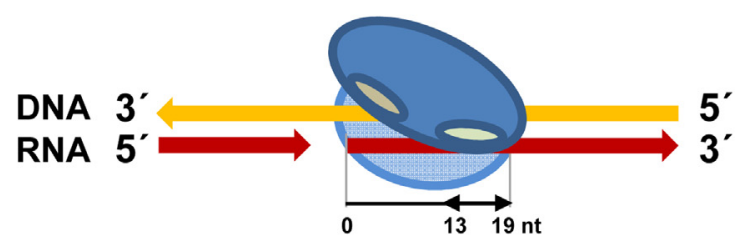

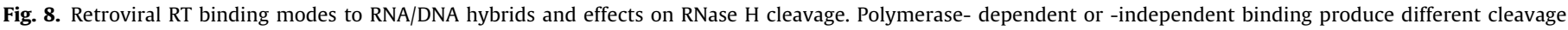
patterns and result from different orientations of the RT relative to the template-primer.

5'-GA-3' dinucleotide contexts (Wood et al., 2009) and contributes to adaptation and evolution in HIV-1 infection (Kim et al., 2014). Other cellular proteins (e.g. adenosine deaminases), viral proteins (e.g. dUTPases) and the available nucleotide levels during reverse transcription may also contribute to the genetic variability found in retroviruses (for further discussion, see Menéndez-Arias, 2013b; Hughes, 2015).

The intrinsic fidelity of purified retroviral RTs has been estimated by measuring mutant frequencies in a reporter gene (e.g. lac $Z \alpha$ ) or in enzymological assays (also known as gel-based assays) (for recent reviews, see Menéndez-Arias, 2009; Menéndez-Arias, 2013b). Reported error rates for HIV-1 RT using the M13mp2 lacZ $\alpha$ gene as a mutational target range from $6.0 \times 10^{-5}$ to $6.7 \times 10^{-4}$ (Roberts et al., 1988; Eckert and Kunkel, 1993; Rezende et al., 1998; Weiss et al., 2004; Matamoros et al., 2008; Álvarez et al., 2013). The large differences observed could be attributed to the diverse conditions used in those assays and the specific RT variant used in the assays. Reported values are underestimates of the mutation rates because assays fail to detect silent mutations or errors that have no effect on the lacZ $\alpha$ phenotype. Comparative studies have shown that oncoretroviral RTs are about 10-30 times more faithful than lentiviral RTs (Table 1 ).

Nucleotide incorporation assays carried out with heteropolymeric template-primers have demonstrated that RTs have a good discrimination capacity between correct and incorrect nucleotides. In general, catalytic efficiencies of nucleotide incorporation are $10^{3}-10^{6}$ times higher for the correct dNTP than for the incorrect one. However, similar assays carried out with a correct nucleotide but using template-primer substrates with either matched or mismatched termini showed that extension efficiencies were 100-10,000 times lower when the template-primer had a $3^{\prime}$ mispaired end. Extension of mismatched $3^{\prime}$ termini has been recognized as a major determinant of the low accuracy of HIV-1 and other retroviral RTs (Perrino et al., 1989; Yu and Goodman, 1992). However, most of those enzymological studies have been carried out with DNA/DNA hybrids. Similar assays carried out with RNA/DNA complexes revealed only some relevant differences in pre-steadystate kinetic assays carried out with specific template-primers. Thus, authors have reported the higher accuracy of HIV-1 RT in the incorporation of $\mathrm{C}, \mathrm{A}$, or $\mathrm{G}$ opposite $\mathrm{A}$ in assays carried out with
RNA/DNA duplexes in comparison to DNA/DNA duplexes (Kerr and Anderson, 1997). However, this behavior was not observed with all template-primers, and for some mispairs, differences in accuracy between RNA- and DNA-dependent polymerization were not significant.

As an important target of antiretroviral intervention, the fidelity of HIV-1 RT and the effects of amino acid substitutions in its accuracy have been extensively analyzed. These studies have shown that the major determinants of fidelity locate in the DNA polymerase domain, including: (i) dNTP binding residues (e.g. Lys ${ }^{65}$, $\mathrm{Tyr}^{115}$ or $\mathrm{Met}^{184}$ ), (ii) residues that interact with the template strand (e.g. Leu ${ }^{74}$ or $\mathrm{Val}^{75}$ ) or the primer strand (e.g. $\mathrm{Met}^{230}$ ), and (iii) minor groove binding track residues (e.g. Gly ${ }^{262}$ or $\operatorname{Trp}^{266}$ ) (for extensive reviews, see Menéndez-Arias, 2002; Menéndez-Arias, 2009). Interestingly, amino acid substitutions conferring resistance to RT inhibitors such as K65R or M184V are known to increase the intrinsic fidelity of the HIV-1 RT (Wainberg et al., 1996; Shah et al., 2000; Barrioluengo et al., 2011). However, increased accuracy is not necessarily related to drug resistance, as observed for other amino acid changes emerging during treatment with RT inhibitors (e.g. L74V, Q151M) (for a review, see Menéndez-Arias, 2009).

Apart from those described above, there are additional determinants of fidelity in the RNase H primer grip of the HIV-1 RT. In this enzyme, $\mathrm{Tyr}^{501}$ is part of a conserved motif found in all retroviral RNase $\mathrm{H}$ domains except in the RSV RT. The equivalent residue in MLV RT is $\mathrm{Tyr}^{586}$ and its substitution by Phe produces a fivefold increase of the mutation rate in vivo that is a consequence of the large increase in the frequency of base substitution mutations within homopolymeric adenine and thymidine tracts (Zhang et al., 2002). On the other hand and unexpectedly, HIV-1 RT RNase H inactivation by mutations such as D443N or E478Q has a significant impact on fidelity of DNA-dependent DNA synthesis. Those substitutions produced 2.0- to 6.6-fold increases in fidelity, mainly due to a significant reduction in the base substitution error rates (Álvarez et al., 2013). Although the physiological significance of these findings remains unclear, it was also noted that HIV-1 group O RTs bearing RNase $\mathrm{H}$-inactivating mutations showed higher frameshift error rates, probably as a result of their higher tendency to dissociate from the template-primers. 
Table 1

Error rates of recombinant retroviral RTs determined with the forward mutation assay, using M13mp2 lacZ $\alpha$ as reporter gene.

\begin{tabular}{|c|c|c|c|c|c|}
\hline Retrovirus type & RT & Error rate & Accuracy ${ }^{\mathrm{a}}$ (fold-change) & HIV-1 RT & References \\
\hline Alpharetroviruses & AMV & $5.9 \times 10^{-5}$ & 9.5 & $(\mathrm{p} 66 / \mathrm{p} 51)^{\mathrm{b}}$ & Roberts et al. $(1988,1989)$ \\
\hline \multirow[t]{4}{*}{ Gammaretroviruses } & MLV & $3.3 \times 10^{-5}$ & 14.3 & $(\mathrm{p} 66 / \mathrm{p} 51)^{\mathrm{b}}$ & Roberts et al. $(1988,1989)$ \\
\hline & & $1.2 \times 10^{-5}$ & 11.7 & BH10 (p66/p51) & Barrioluengo et al. (2012) \\
\hline & XMRV & $1.2 \times 10^{-5}$ & 11.7 & BH10 (p66/p51) & Barrioluengo et al. (2012) \\
\hline & FeLV & $5.8 \times 10^{-6}$ & 29 & $\mathrm{BH} 10(\mathrm{p} 66 / \mathrm{p} 51)^{\mathrm{c}}$ & Operario et al. (2005) \\
\hline \multirow[t]{5}{*}{ Lentiviruses } & HIV-1 group $\mathrm{O}$ & $5.5 \times 10^{-5}$ & 2.5 & BH10 (p66/p51) & Álvarez et al. (2009) \\
\hline & $\mathrm{SIV}_{\mathrm{agm}}$ & $2.9 \times 10^{-5}$ & 1.8 & HXB2 (p66/p51) & Stuke et al. (1997) \\
\hline & SIV $_{\text {mne }}$ & $1.2 \times 10^{-4}(\mathrm{CL} 8)^{\mathrm{d}}$ & 1.3 & $\mathrm{BH} 10(\mathrm{p} 66 / \mathrm{p} 51)^{\mathrm{c}}$ & Diamond et al. (2003) \\
\hline & & $1.6 \times 10^{-5}(170)$ & 9.7 & & \\
\hline & FIV & $6.2 \times 10^{-5}$ & 2.8 & BH10 (p66/p51) ${ }^{\mathrm{c}}$ & Operario et al. (2005) \\
\hline Spumaviruses & PFV & $1.7 \times 10^{-4}$ & 0.4 & BH10 (p66/p51) & Boyer et al. (2007) \\
\hline
\end{tabular}

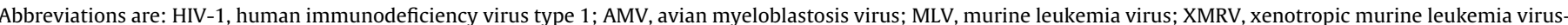

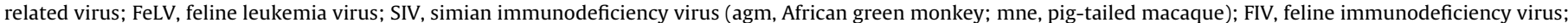
PFV, prototype primate foamy virus.

a Increase relative to the wild-type HIV-1 RT (prototypic HIV-1 group M subtype B strains).

b Purified from HIV-1 subtype B virions (unreported strain) (Roberts et al., 1988).

c Data for HIV-1 RT were not provided in the referenced papers. For comparative purposes, mutation rates for HIV-1 RT obtained in the same lab were taken from Weiss et al. (2004).

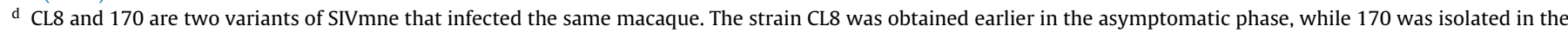
late symptomatic phase of the infection.

\subsection{Recombination}

Retroviruses show high recombination rates. Their virions contain two copies of full-length viral RNA, and the RT can use parts of each one as templates during reverse transcription, thereby facilitating the generation of recombinant variants ( $\mathrm{Hu}$ and Temin, 1990b). Among retroviruses, recombination rates are higher for primate lentiviruses (e.g. HIV-1, HIV-2 and SIV $_{\text {agm }}$ ) than for MLV or spleen necrosis virus (Onafuwa et al., 2003; Rhodes et al., 2003; Rhodes et al., 2005; Chen et al., 2006). In HIV-1, recombination is a powerful force that influences the evolution of its genome (for recent reviews, see Smyth et al., 2012; Lau and Wong, 2013). It has been estimated that the global prevalence of recombinant forms is close to $50 \%$ of the total infections worldwide (Hemelaar et al., 2011). The generation of recombinants requires the coinfection of the cell by more than one parental virus. Only cells containing different proviruses can generate heterozygous virions. A sequence in the $5^{\prime}$ untranslated region of the RNA acts as a dimerization initiation site (DIS) and facilitates the packaging of two RNAs in the same particle (Moore et al., 2007). This is a palindromic sequence that in HIV-1 is GCGCGC or GUGCAC.

Sequence similarity facilitates template switching and is required for efficient recombination (An and Telesnitsky, 2002; Baird et al., 2006). Recombinant breakpoints are not randomly distributed across the retroviral genome. Hot spots in the genomes of HIV-1 intersubtype recombinants appear to be consistently found at specific regions of the gag gene, but also flanking env (Fan et al., 2007; Archer et al., 2008; Simon-Loriere et al., 2009; Smyth et al., 2014). However, specific features of those sequences have not been correlated with hot spot propensities. It is assumed that template switching could be facilitated by the presence of nicks in the genomic RNA, or by strong pausing sites during reverse transcription due to the presence of RNA secondary structures (reviewed in Simon-Loriere et al., 2011). These stops enhance the efficiency of template switching because they facilitate the degradation of the RNA by the RNase H activity of the RT and increase the time of residency of the RT in the specific sequence. These ideas constitute the basis of the so-called dynamic copy-choice model which proposes that template switching is influenced by a balance between the polymerase and RNase H activities of the RT (for recent reviews, see Onafuwa-Nuga and Telesnitsky, 2009; Delviks-Frankenberry et al., 2011).

A recombination rate of $1.35 \times 10^{-3}$ per nucleotide and replication cycle has been estimated using the HIV-1 gag gene as a reference (Schlub et al., 2010). This value is two orders of magnitude higher than the mutation rates obtained ex vivo (Mansky, 1996). A detailed high-throughput sequencing analysis of HIV collected after a single round of infection in primary $\mathrm{T}$ lymphocytes revealed an even higher mutation rate at recombined regions (Schlub et al., 2014). Moreover, recombination-associated mutations were found to represent $15-20 \%$ of all mutations occurring during reverse transcription. If mutation induces recombination or vice versa is still an unsolved question that warrants further studies in this area.

\subsection{RT inhibition}

Thirty years ago, the discovery of AZT (zidovudine or 3'-azido3 '-deoxythymidine) as an effective therapeutic agent against HIV infection represented a major breakthrough in the fight against AIDS. AZT-triphosphate blocks DNA polymerization and its molecular target is the viral RT. Still today HIV-1 RT inhibitors constitute the backbone of widely used anti-AIDS therapies and their development has been a successful and very active field of research for many years (Arts and Hazuda, 2012; De Clercq, 2013). There are two major classes of drugs that block reverse transcription: nucleoside analogues (NRTIs) and nonnucleoside RT inhibitors (NNRTIs). Chemical structures of NRTIs currently approved or in advanced preclinical development are given in Fig. 9. These are compounds with a structure similar to natural nucleosides. They are administered as prodrugs that need to be phosphorylated to their triphosphate forms to act as competitive inhibitors (or alternative substrates) of the RT. Once incorporated into the growing DNA chain, DNA synthesis stops due to the lack of a $3^{\prime}-\mathrm{OH}$ in their ribose ring. In this class, zidovudine, lamivudine, abacavir, emtricitabine and tenofovir are the most commonly used drugs in the treatment against HIV infection. Tenofovir is an adenosine-monophosphate analogue that is usually combined with emtricitabine and an NNRTI as first-line highly active antiretroviral therapy (HAART).

NRTIs interact with the dNTP binding site of the RT. HIV-1 resistance to these drugs is usually associated with the emergence of amino acid substitutions that increase the catalytic efficiency of incorporation of natural dNTP substrates relative to triphosphate derivatives of the nucleoside analogues. Examples of mutations acting through this discrimination mechanism are M184V or M184I that confer resistance to lamivudine and emtricitabine (Sarafianos et al., 1999), or K65R that confers resistance to tenofovir (Das et al., 2009). This mechanism is also relevant for multidrug resistance as demonstrated for the combination A62V/V75I/F77L/F116Y/Q151M 


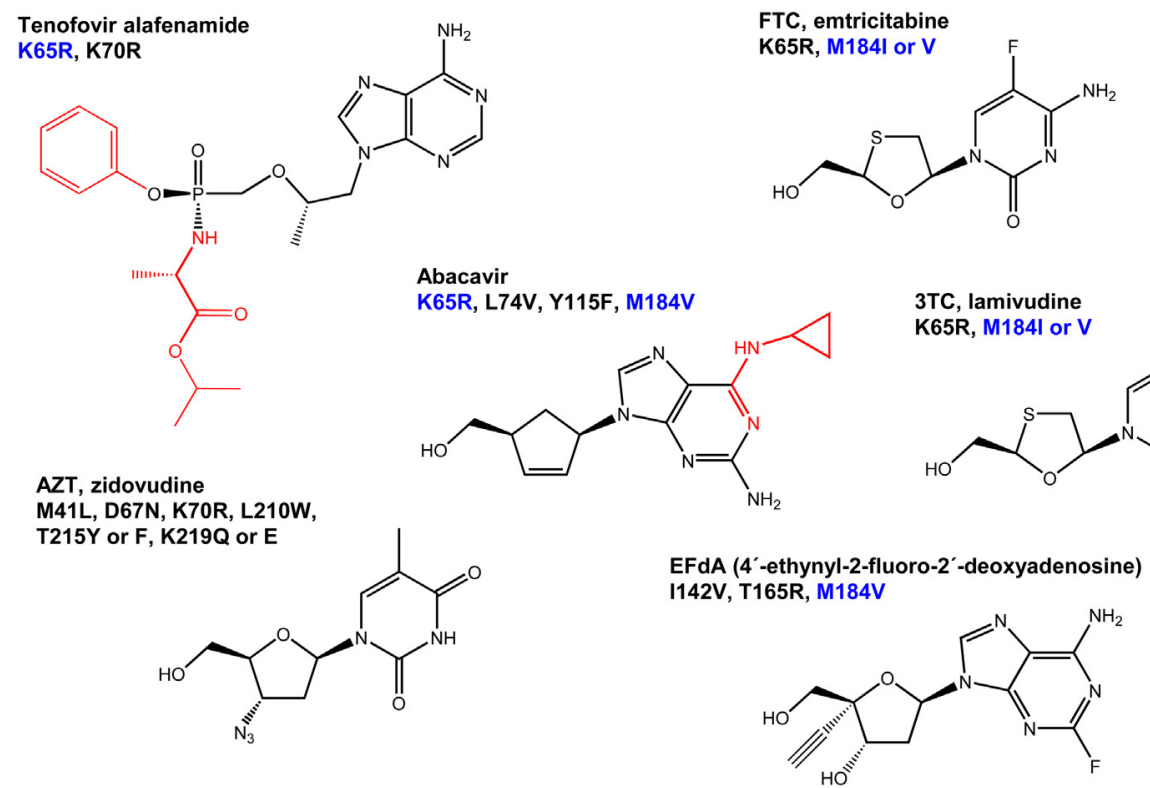

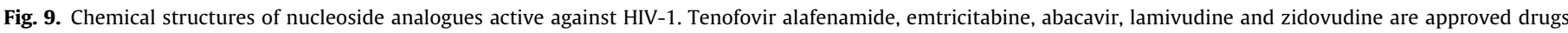

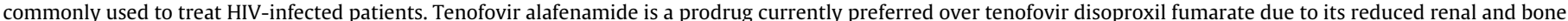

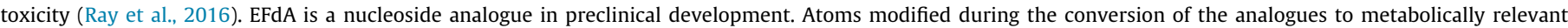

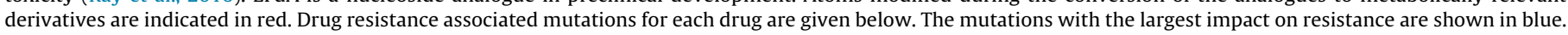
Combinations of TAMs associated with zidovudine resistance are also responsible for cross-resistance with abacavir and tenofovir.

(Deval et al., 2002; Deval et al., 2005). This combination confers resistance to all approved nucleoside analogues except tenofovir (reviewed in Menéndez-Arias, 2008). An alternative mechanism of resistance to NRTIs involves the acquisition of mutations such as M41L, D67N, K70R, L210W, T215F or Y, and K219E or Q, widely known as 'thymidine analogue resistance mutations' (TAMs). HIV1 RTs carrying different combinations of those mutations are able to excise $3^{\prime}$-terminal chain-terminators from blocked DNA primers in the presence of a pyrophosphate donor (most likely ATP, under physiological conditions) (Meyer et al., 1999). Zidovudine, stavudine and tenofovir are good substrates of the excision reaction, while cytidine analogues (i.e. lamivudine or emtricitabine) are removed very inefficiently (Mas et al., 2002). Substitutions involved in this mutational pathway affect residues in the vicinity of the $\gamma$-phosphate of the incoming $\operatorname{dNTP}\left(\mathrm{Asp}^{67}, \mathrm{Lys}^{70}\right.$ and Lys $^{219}$ ), and amino acids located away from the dNTP binding site $\left(\right.$ Met $^{41}$, Leu ${ }^{210}$, Thr ${ }^{215}$ ) (Huang et al., 1998). Structural analyses of RT/dsDNA/AZTppppA complexes (containing mutant or wild-type RTs) indicated that the side-chain of $\mathrm{Tyr}^{215}$ stabilizes the interaction of the RT with the adenine moiety of ATP, while the side-chains at positions 67,70 and 219 impose constraints to the $\beta 3-\beta 4$ hairpin loop and facilitate the proper alignment of the pyrophosphate moiety in the excision reaction (Tu et al., 2010). More information and a detailed analysis of the molecular mechanisms of resistance to NRTIs can be found in previously published reviews (MenéndezArias, 2008; Das and Arnold, 2013a,b; Menéndez-Arias, 2013a).

An interesting NRTI in advanced preclinical development is the 4'-ethynyl-2-fluoro-2'-deoxyadenosine (EFdA) (Fig. 9). This drug blocks HIV replication in peripheral blood mononuclear cells (PBMCs) at picomolar concentrations, and therefore it is orders of magnitude more potent than any other approved NRTI (Ohrui, 2006). EFdA is also effective against wild-type and clinical drugresistant HIV strains (Kawamoto et al., 2008). The drug can act as a bona fide chain terminator, but it can also allow the subsequent incorporation of one nucleotide that in this case would produce a mismatch that would be difficult to extend. This mechanism of inhibition is known as delayed chain termination and prevents excision of the inhibitor by the ATP-dependent phosphorolytic pathway
(Michailidis et al., 2014). Crystallographic analysis of HIV-1 RT complexes containing the inhibitor reveal that the high potency of the NRTI can be attributed to additional interactions established between the $4^{\prime}$-ethynyl group and a hydrophobic pocket in the RT polymerase active site, not observed with other nucleotide analogues or natural dNTPs (Salie et al., 2016).

NNRTIs are small hydrophobic molecules that act as allosteric inhibitors of HIV-1 RT (Fig. 10). They bind to a pocket located about $10 \AA$ away from the dNTP binding site. Only HIV-1 isolates of the major phylogenetic group (including the most abundant subtypes $B$ and $C$ ) are inhibited by approved NNRTIs such as nevirapine, efavirenz, etravirine or rilpivirine. Almost all retroviral RTs (including those of HIV-1 group O, HIV-2 and SIV) lack the NNRTI binding pocket and are resistant to these inhibitors. High-level resistance to these inhibitors can be developed easily, particularly to nevirapine and efavirenz which are considered as first-generation inhibitors. Ten or more single amino acid substitutions are known to confer by themselves $>40$-fold increased resistance to nevirapine (e.g. K103N, Y181C, G190A) or efavirenz (e.g. K101P, K103N, Y188L) in phenotypic assays (reviewed in Menéndez-Arias et al., 2011; Menéndez-Arias, 2013a).

Next-generation inhibitors such as etravirine and rilpivirine show a higher genetic barrier and studies in vitro revealed that at least two amino acid substitutions were needed to achieve high-level resistance to those drugs. Examples are V179F/Y181C, V179F/Y181I and Y181I/M230L in the case of etravirine (Azijn et al., 2010; Javanbakht et al., 2010). However, clinical studies have shown the emergence of E138K and M184I in patients failing treatment with rilpivirine (combined with the NRTIs tenofovir and emtricitabine) (Cohen et al., 2011; Molina et al., 2011). E138K and other amino acid changes at this position appear to be major determinants of resistance for both etravirine and rilpivirine (Asahchop et al., 2013). A similar diarylpyrimidine known as dapivirine is in an advanced stage of development as a microbicide for women (Baeten et al., 2016). K103N, Y181C and G190A are frequently found in transmitted HIV-1, particularly in resource-limited countries (Rhee et al., 2015; Avila-Rios et al., 2016). Doravirine, a novel NNRTI in clinical trials, has a relatively high genetic barrier in vitro 
<smiles>Cc1ccnc2c1NC(=O)c1cccnc1N2C1CC1</smiles>

Nevirapine<smiles>Cc1cc(/C=C/C#N)cc(C)c1Nc1ccnc(Nc2ccc(C#N)cc2)n1</smiles>

Rilpivirine<smiles>O=C1Nc2ccc(Cl)cc2[C@@](C#CC2CC2)(C(F)(F)F)O1</smiles>

Efavirenz<smiles>Cc1cc(C#N)cc(C)c1Oc1nc(Nc2ccc(C#N)cc2)nc(N)c1Br</smiles>

Etravirine<smiles>Cc1cc(C)c(Nc2ccnc(Nc3ccc(C#N)cc3)n2)c(C)c1</smiles>

Dapivirine<smiles>Cn1c(Cn2ccc(C(F)(F)F)c(Oc3cc(Cl)cc(C#N)c3)c2=O)n[nH]c1=O</smiles>

Doravirine

Fig. 10. Chemical structures of nonnucleoside RT inhibitors.

and shows remarkable inhibitory activity against HIV-1 strains bearing the most prevalent NNRTI resistance-associated mutations (Feng et al., 2015). In addition, recent work reveals that mutations that reduce the potency of doravirine and rilpivirine are nonoverlapping (Smith et al., 2016), thereby increasing the interest in this drug.

Inhibitors of the RNase $\mathrm{H}$ activity have not yet been developed into effective antiretroviral drugs, despite their expected potency against drug-resistant strains. The structural similarity between the active sites of HIV-1 IN and RNase $\mathrm{H}$ and the development of raltegravir as an IN inhibitor stimulated new efforts in this area of research that led to the discovery of many RNase $\mathrm{H}$ inhibitors active in in vitro assays. Newly identified compounds can be classified as active site or allosteric RNase $\mathrm{H}$ inhibitors (for a review, see Ilina et al., 2012). Active site inhibitors are based on pharmacophores that interact with the two cations of the RNase $\mathrm{H}$ active site. Compounds having micromolar or submicromolar potency against the HIV-1 RNase $\mathrm{H}$ activity are based on pharmacophore scaffolds such as diketo acids, N-hydroxy naphthypyridinones, N-hydroxyimides, pyrimidinol carboxylic acids, and tropolones (Kirschberg et al., 2009). GSK5724 (a pyrimidinol carboxylic acid) was identified as a very potent RNase $\mathrm{H}$ inhibitor in vitro $\left(\mathrm{IC}_{50}=3 \mathrm{nM}\right)$ and had strong antiviral activity in cell culture $\left(\mathrm{IC}_{50}=10 \mathrm{nM}\right)$ (Johns and Velthuisen, 2011). The drug also showed sub-micromolar inhibitory activity against the viral IN. Many RNase $\mathrm{H}$ active site inhibitors, including the well-known $\beta$-thujaplicinol (a tropolone derivative) show slow binding kinetics while dissociating rapidly. GSK5750 is a novel 1-hydroxy-pyridopyrimidinone analogue that forms long lasting complexes with HIV-1 RT, and binds the enzyme with an equilibrium dissociation constant $\left(K_{\mathrm{d}}\right)$ of $\sim 400 \mathrm{nM}$ (Beilhartz et al., 2014).

A few compounds have been identified as allosteric inhibitors of the RT RNase $\mathrm{H}$. These drugs do not bind directly to the active site and cannot be displaced by nucleic acid substrates. Thiocarbamates, 1,2,4-triazoles, acylhydrazones and vinylogous ureas are pharmacophores found in the most effective inhibitors of this class. The vinylogous urea NSC727447 appears to interact with the thumb subdomain of p51 at the interface with the RNase H domain of HIV1 RT (Chung et al., 2012). Interestingly, acylhydrazone derivatives such as the dihydroxy benzoyl naphthyl hydrazone (DHBNH) and other related compounds were shown to inhibit both HIV-1 RNase $\mathrm{H}$ and DNA polymerase activities (Borkow et al., 1997; Gong et al., 2011; Corona et al., 2016). The specific mechanisms involved in this dual inhibition are not clear and could be diverse. For example, the isatin-based compound RMNC6 seems to bind at different sites in the polymerase and RNase H domains of the RT (Corona et al., 2016). In contrast, DHBNH binds to the DNA polymerase domain in a way that alters the trajectory of the RNA/DNA hybrid causing defects in the RNase $\mathrm{H}$ activity (Himmel et al., 2006).

\section{Reverse transcription in Hepadnaviridae}

Hepadnaviruses are small hepatotropic viruses that infect mammals and birds. Hepatitis B virus (HBV) is one of the most important pathogens in humans. The HBV polymerase (or $\mathrm{P}$ protein) is a multifunctional enzyme of approximately $90 \mathrm{kDa}$ that contains four domains: (i) a terminal protein (TP) domain, (ii) a spacer domain, (iii) an RNA-dependent and DNA-dependent DNA polymerase domain, and (iv) an RNase $\mathrm{H}$ domain. The DNA polymerase and RNase $\mathrm{H}$ domains are structurally similar to the equivalent ones found in retroviruses, such as HIV-1 or MLV (Fig. 11), with conserved motifs such as YMDD in the catalytic active site of the polymerase or the conserved D-E-D-D motif in the RNase H domain (reviewed in Menéndez-Arias et al., 2014; Hu and Seeger, 2015). The catalytic role of $\mathrm{Asp}^{702}, \mathrm{Glu}^{731}$ and $\mathrm{Asp}^{750}$ in the RNase $\mathrm{H}$ domain has been inferred from sequence alignments and molecular modelling with HIV-1 RT, and demonstrated in vitro by mutational studies (Tavis et al., 2013). The fourth residue is more difficult to assign based on comparative sequence analysis. Nevertheless, it has 

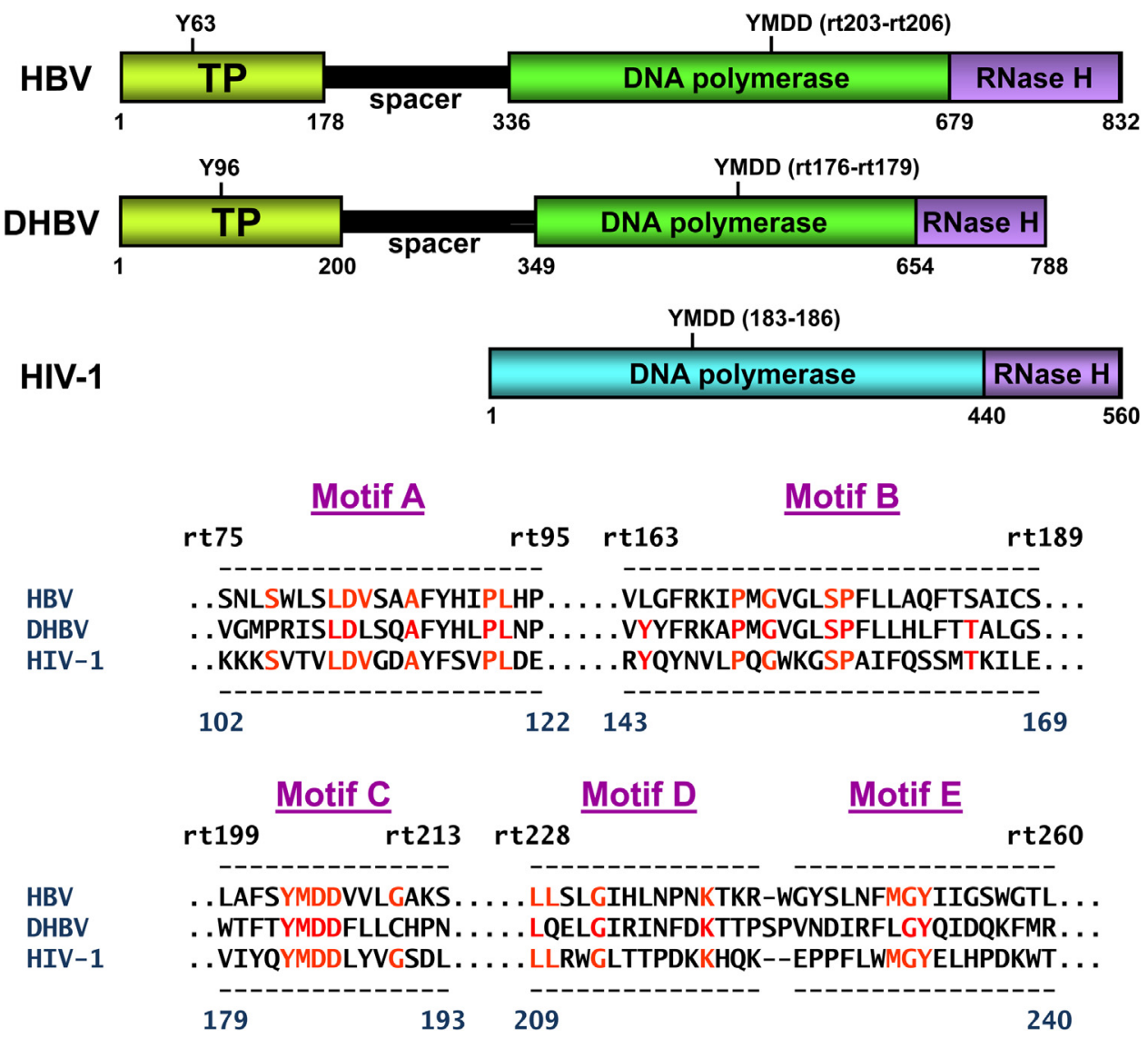

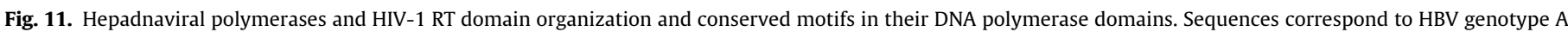

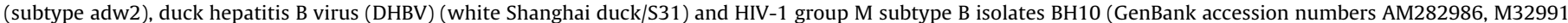

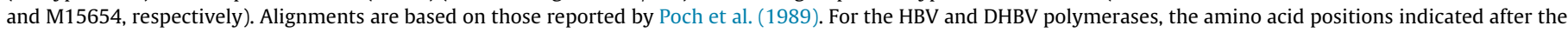

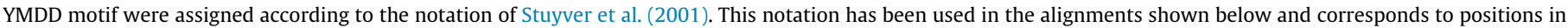
the DNA polymerase domains of both enzymes.

been shown that mutating $A s p^{790}$ leads to an RNase H-deficient phenotype (Ko et al., 2014).

The TP domain of the viral polymerase is needed for initiation of reverse transcription and is unique to hepadnaviruses. The $\mathrm{OH}$ group in a specific Tyr residue in this domain $\mathrm{Tyr}^{63}$ in HBV polymerase) is used as a $3^{\prime}$-hydroxyl end of a nucleic acid primer (reviewed in Nassal, 2008; Clark and Hu, 2015). The template molecule is a pgRNA that contains at its $5^{\prime}$ end an RNA stem-loop structure termed epsilon $(\varepsilon)$. The pgRNA has a structure similar to that of cellular mRNAs with a cap at its $5^{\prime}$ end and a polyadenylated tail at its $3^{\prime}$ end. In addition it has repeated sequences, known as direct repeats 1 and 2 (DR1 and DR2) that facilitate strand transfer during reverse transcription. These sequences are located at the $5^{\prime}$ end (DR1) and at the $3^{\prime}$ end of the pgRNA (DR2 and a second DR1) (Fig. 12).

The interaction of the polymerase with $\varepsilon$ triggers its coencapsidation with the pgRNA in newly forming nucleocapsids, and the initiation of viral DNA synthesis. The DNA polymerase and RNase $\mathrm{H}$ activities are not required for RNA packaging (Hirsch et al., 1990; Jones et al., 2014). Cellular proteins belonging to the family of molecular chaperones (i.e. Hop, p23, Hsc70, Hsp40 and Hsp90) are required for the initial binding of the polymerase to the $\varepsilon$ RNA (Hu and Seeger, 1996; Hu et al., 1997; Hu et al., 2004; reviewed in $\mathrm{Hu}$ and Seeger, 2015). HBV RNA packaging and protein priming is also dependent on the presence of a $5^{\prime}$ cap structure, which has to be separated by less than 70 nucleotides from the $\varepsilon$ structure (Jeong et al., 2000; Jones et al., 2012). Synthesis of the DNA genome of mature hepadnaviruses with the pgRNA template takes place inside viral cores, in the host cell cytoplasm. Structural studies revealed that these cores have an asymmetric structure when filled with RNA, although the polymerase sits on an ordered RNA lattice where the $5^{\prime}$ and $3^{\prime}$ ends of the pgRNA locate close to each other stabilizing a circular conformation of the pgRNA (Abraham and Loeb, 2007; Wang et al., 2014).

The protein priming reaction involves the formation of a covalent phosphotyrosyl bond between the Tyr of the TP domain and dGMP. Two to three additional nucleotides are then added to generate a sequence GTAA, complementary to the UUAC sequence found in the bulge of the $\varepsilon$ RNA stem-loop in duck HBV, or GAA complementary to UUC in the case of human HBV. This reaction takes place in the presence of $\mathrm{Mg}^{2+}$ and is completely dependent on the viral $\varepsilon$ structure in these conditions (Jones et al., 2012). However, an $\varepsilon$-independent protein-primed transferase activity has also been detected in vitro in the presence of low concentrations of $\mathrm{Mn}^{2+}$. For this activity, the viral polymerase could use all four dNTPs, although dTTP was the preferred substrate (Jones and Hu, 2013).

The GTAA sequence obtained in the $\varepsilon$-dependent reaction, which is covalently attached to the RT protein, is translocated (minus-strand primer transfer) to anneal with a complementary sequence motif located at the $3^{\prime}$ end of the pgRNA, in the 10-12nucleotides long DR1 region. This process is facilitated by the presence of additional elements in the RNA (i.e. $\varphi$ and $\omega$ ) that stabilize the circular conformation of the pgRNA and promote transfer of the short minus-strand DNA (Abraham and Loeb, 2007). The same mechanism operates for human HBV although in this case protein priming initiates with the sequence GAA (reviewed in Nassal, 2008; 

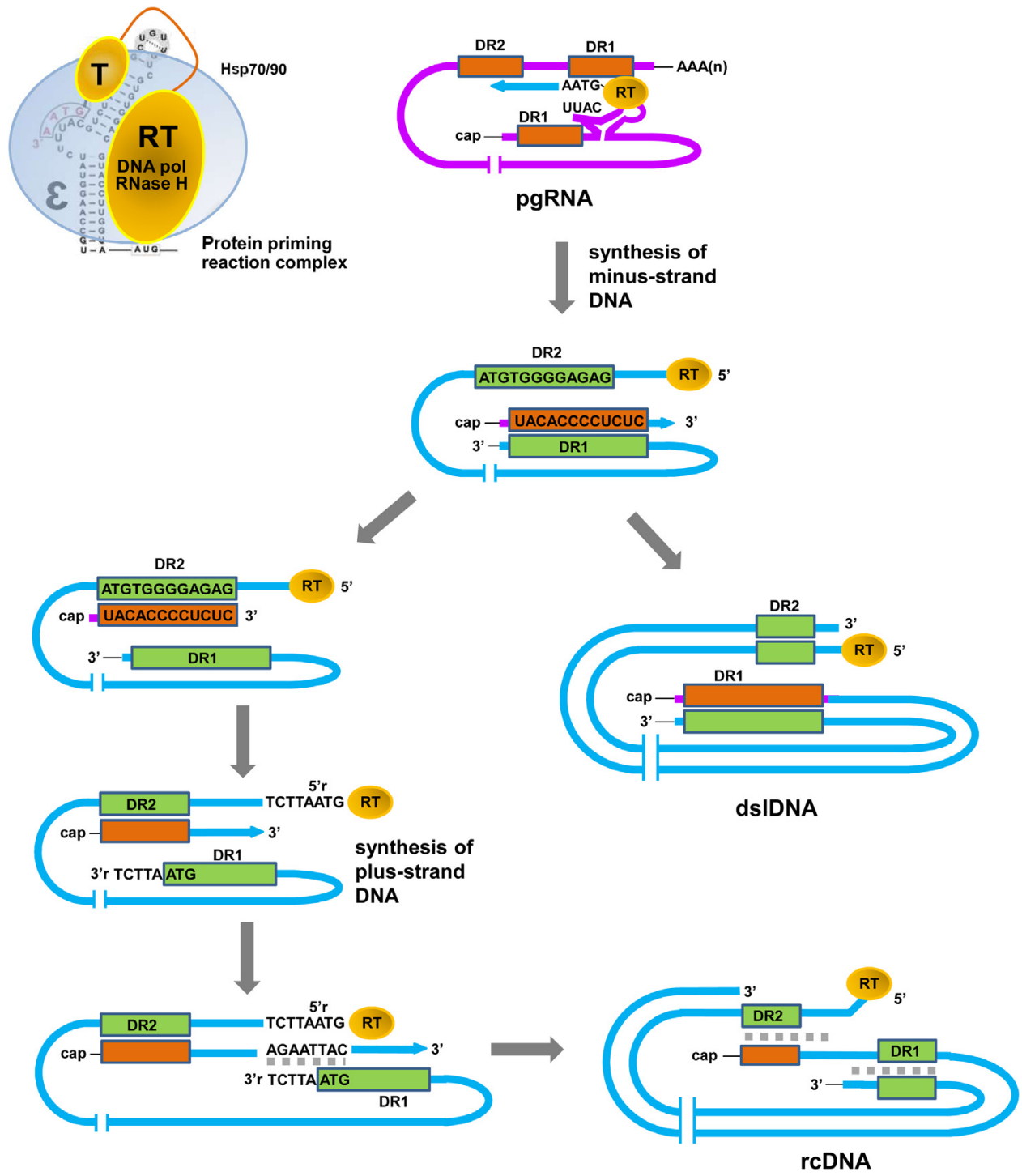

Fig. 12. Reverse transcription in Hepadnaviridae. The model shows the formation of rcDNA and dsIDNA from pgRNA. A schematic representation of the ribonucleoprotein complex necessary for the protein priming reaction is shown in the upper left panel. Synthesis of minus-strand DNA (depicted in blue) using pgRNA (purple) as template leads to an intermediate that contains a DR1 primer that could be elongated to generate dsIDNA. Alternatively, the DR1 primer can anneal to a DR2 sequence at the 5' of the minus-strand DNA and after elongation and additional strand transfer events generate the rcDNA molecule.

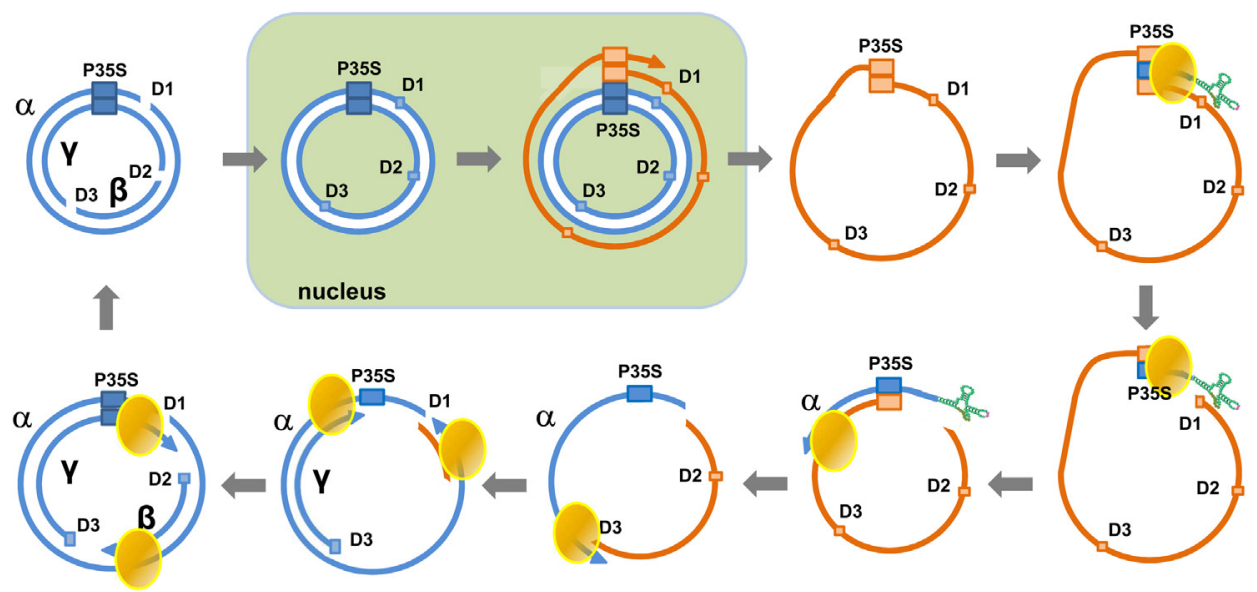

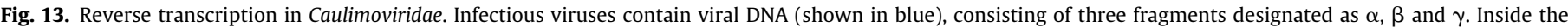

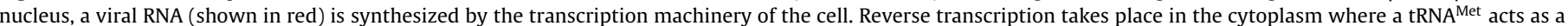

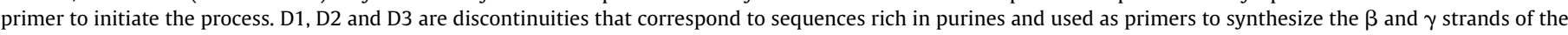
DNA. The viral RT is represented by an orange spheroid. 
Hu and Seeger, 2015). After template switching, the minus-strand DNA synthesis reaction proceeds until the $5^{\prime}$ end of the pgRNA, with the concomitant degradation of the template by the RNase $\mathrm{H}$ activity of the P protein.

Plus-strand DNA synthesis is primed by a capped RNA oligonucleotide derived from the $5^{\prime}$ end of the pgRNA. This 18-nt long oligomer contains part of the DR1 sequence and could either be used as a primer, in situ, to initiate the synthesis of the plus-strand DNA, or as occurs in about $80 \%$ of the cases, translocate to the DR2 region at the $5^{\prime}$ end of the minus-strand DNA. By using this alternative priming site, the viral polymerase completes plus-strand DNA synthesis all the way up to the $5^{\prime}$ end of the minus-strand DNA, while an additional template switch facilitates the circularization of the genome. Redundant sequences ( $r$ ) at the $5^{\prime}$ and $3^{\prime}$ ends of the minus-strand DNA facilitate this process. As a result, most infectious virions contain rcDNA, although a minority may have dsIDNA (Hu and Seeger, 2015).

One of the hallmarks of hepadnavirus infection is the formation of cccDNA. This episomal DNA serves as template for all viral RNA transcription and is stable in nuclei of infected cells (Nassal, 2015). The mechanism for cccDNA formation has not been clearly established. The cccDNA originates from rcDNA after: (i) full extension of plus-stranded DNA, (ii) removal of the P protein from the $5^{\prime}$ end of the minus-stranded DNA, of the 18-nt long RNA primer used in plus-stranded DNA synthesis, and of one of the 9-nucleotidelong redundant sequences on minus-strand DNA, and (iii) ligation of both DNA strands forming the cccDNA. It is not clear whether the viral polymerase has a role in this conversion of rcDNA to cccDNA. The participation of cellular enzymes involved in DNA repair pathways (e.g. endonucleases, DNA polymerase $\kappa$ and different ligases) is possible, and a tyrosyl-DNA phosphodiesterase (known as Tdp2) has been recently implicated in the release of the RT from the 5 end of minus-strand DNA (Jones et al., 2012; Jones and Hu, 2013; Königer et al., 2014; Cui et al., 2015).

\subsection{Biochemical properties of the HBV polymerase}

Despite being an important target for antiviral therapy and its essential role in virus replication, structural and biochemical studies with the HBV polymerase have been limited by difficulties in obtaining sufficient quantities of the recombinant enzyme. Duck HBV polymerase has been used as a model system although it shares only about $20 \%$ sequence identity. Duck HBV polymerase expressed by in vitro translation in the rabbit reticulocyte lysate is active in authentic protein priming (Wang and Seeger, 1992). Studies using this in vitro system led to the identification of host cell chaperones required for polymerase functions (Hu and Seeger, 1996; Hu et al., 1997). Truncated duck HBV polymerase has been obtained in E. coli. In the presence of metal ions and after reconstitution with recombinant host chaperones and an ATP-regenerating system, this enzyme showed in vitro priming and elongation activity (Hu and Anselmo, 2000; Beck and Nassal, 2001; Hu et al., 2002; Beck and Nassal, 2003). Unfortunately, human HBV polymerase obtained from rabbit reticulocyte lysates did not show enzymatic activity and the enzyme obtained in insect cells with baculovirus systems had very low protein-priming activity, detectable in the absence of the $\varepsilon$ RNA element (Lanford et al., 1995; Lanford et al., 1997). HBV polymerase has recently been expressed in mammalian cells, together with the viral $\varepsilon$ RNA. When purified as a protein-RNA complex, it showed authentic protein priming activity in vitro (Jones et al., 2012). Interestingly, a protein-primed transferase activity independent of the $\varepsilon$ RNA element was also discovered in the human HBV polymerase (Jones and $\mathrm{Hu}, 2013$ ).

Recently, the TP domain (residues 1-192) and the RT-RNase H domains (residues 303-778) of the human HBV polymerase have been successfully expressed in $E$. coli, purified in high yields and solubilized and refolded in buffers containing an amphipathic carbohydrate polymer (Vörös et al., 2014). These domains were found to have a high $\alpha$-helical content. This approach may provide new possibilities for structural and biochemical characterization of the viral polymerase. As in the case of retroviral RTs, the HBV polymerases are devoid of proofreading activity and are expected to display relatively low fidelity. Mutation rates for duck HBV replication were estimated to be around $2 \times 10^{-5}$ per nucleotide and generation (Pult et al., 2001), and as in the case of HIV-1 and other retroviruses, APOBEC proteins could be packed into the viral cores and affect reverse transcription efficiency and its error rate (Baumert et al., 2007; reviewed in Janahi and McGarvey, 2013).

The RNase $\mathrm{H}$ domain of human HBV shares 23\% identity with the equivalent in HIV-1 RT (Tavis et al., 2013). An extensive biochemical characterization of the HBV RNase $\mathrm{H}$ activity has been possible after its successful expression and characterization as a fusion protein with a maltose-binding domain at the N-terminus and a hexahistidine tag at the C-terminal end (Villa et al., 2016). In the presence of $\mathrm{Mg}^{2+}$ and ATP, authors obtained monomeric recombinant enzyme with endonucleolytic activity. A minimal size of 14 nucleotides was necessary for cleavage of RNA/DNA hybrids. The HBV RNase $\mathrm{H}$ also showed processive $3^{\prime} \rightarrow 5^{\prime}$ exoribonuclease activity but its catalytic rate was reduced in comparison with that observed for the endonucleolytic activity. HBV is genetically diverse and eight or nine genotypes have been identified. Active RNase $\mathrm{H}$ has been obtained from genotypes B, C, D and $\mathrm{H}$.

\subsection{HBV polymerase inhibition}

Approved nucleoside/nucleotide inhibitors of the HBV polymerase include lamivudine, adefovir, telbivudine, entecavir and tenofovir. In addition, clevudine has been licensed in South Korea and the Philippines for treating chronic hepatitis B. Development of those drugs has been facilitated in part by large efforts in antiretroviral therapy, and the functional and structural similarities between the HBV polymerase and the HIV-1 RT (Michailidis et al., 2012). Lamivudine and tenofovir are drugs approved for clinical use against both HIV and HBV infection. In addition, the anti-HIV drug emtricitabine has not been approved for treatment of HBV infection, but shows inhibitory activity against HBV replication (reviewed in Menéndez-Arias, 2013a; Menéndez-Arias et al., 2014).

All these drugs need to be converted into triphosphate derivatives in order to become substrates of the HBV polymerase. In general, those compounds act as competitive inhibitors (reviewed in Clark and Hu, 2015). Thus, entecavir triphosphate is a dGTP analogue that inhibits reverse transcription initiation by interfering with the protein priming reaction. Entecavir triphosphate has a $3^{\prime}-\mathrm{OH}$ in its ribose ring and is a delayed chain terminator (Jones et al., 2013). After priming, the incorporation of A can be impaired by the incorporation of tenofovir diphosphate or adefovir diphosphate. These drugs act as competitive inhibitors that block DNA synthesis. Cytidine analogues (i.e. lamivudine and emtricitabine) lack a 3'-OH in their ribose ring and block DNA polymerization after translocation of the polymerase complex to the DR1 sequence near the $3^{\prime}$ end of the pgRNA. Interestingly, clevudine triphosphate is not incorporated into the DNA and does not affect polymerase binding to $\varepsilon$ RNA. It inhibits protein priming and subsequent polymerization steps in a non-competitive manner, probably by distorting the polymerase active site (Jones et al., 2013). As described for HIV-1 RT, resistance to nucleoside/nucleotide inhibitors of HBV polymerase is usually associated with amino acid substitutions at the vicinity of the DNA polymerase active site. Mutations such as L180M, M204I or V, A181T or V and N236T are commonly associated with resistance to approved nucleos(t)ide inhibitors (for a review, see Menéndez-Arias et al., 2014). NRTIs in development include novel 
prodrugs of tenofovir and adefovir, as well as new drugs such as besifovir or 4'-modified nucleosides (e.g. 4'-C-cyano-2-amino-2'deoxyadenosine and $4^{\prime}$ - $C$-cyano-2-amino- $2^{\prime}$-deoxyguanosine) that were shown to be active against HBV strains resistant to currently approved therapies (Block et al., 2015; Takamatsu et al., 2015).

The RNase $\mathrm{H}$ is also a promising target that remains unexploited. A number of inhibitors with $\mathrm{IC}_{50}$ values in the low micromolar range have demonstrated efficacy against HBV RNase $\mathrm{H}$ (reviewed in Tavis and Lomonosova, 2015). The most effective were napthyridinones ( $\left.\mathrm{IC}_{50} \sim 4.1-5.7 \mu \mathrm{M}\right)$ and $\alpha$-hydroxylated tropolones such as the $\beta$ thujaplicinol $\left(\mathrm{IC}_{50} \mathrm{~s}\right.$ range from 2.3 to $5.9 \mu \mathrm{M}$ depending on the HBV genotype), although they also showed some inhibitory activity against the human RNase $\mathrm{H}$ (Hu et al., 2013; Tavis et al., 2013; Cai et al., 2014; Lu et al., 2015).

\section{Reverse transcription in plant pararetroviruses}

Caulimoviridae are plant pararetroviruses that replicate through transcription and reverse transcription. Unlike retroviruses, the viral DNA obtained after reverse transcription does not integrate into the host cell (reviewed in Rothnie et al., 1994; Hohn and Rothnie, 2013). Their replicative cycle has similarities with that of hepadnaviruses, accumulating episomal copies (minichromosomes) in the host cell nucleus. The best known viruses of this family are the cauliflower mosaic virus (CaMV) (Haas et al., 2002) and the rice tungro viruses (Hull, 1996). CaMV capsids contain double-stranded circular DNA of about $8 \mathrm{~kb}$. This DNA has an open circular form because it contains interruptions in both plus and minus DNA strands, again reminiscent of hepadnavirus rcDNA. Inside the nucleus, these discontinuities are repaired by the host cell machinery and the supercoiled episomal molecule, like hepadnavirus cccDNA, is used to synthesize two polyadenylated transcripts, known as 35S and 19S RNAs. The 35S RNA shows redundancy at its $5^{\prime}$ and $3^{\prime}$ ends, with identical copies of its promoter at both ends. This RNA is used for the expression of five viral proteins including the RT (known as P5 in the CaMV). P5 is a 78-kDa protein with aspartyl protease, DNA polymerase and RNase $\mathrm{H}$ domains. Unlike in the case of retroviral pol-derived polyproteins, it lacks the integrase domain. An autocatalytic reaction releases the protease from P5 (Torruella et al., 1989). Viral DNA and protein synthesis occurs in the cytoplasm in electron dense inclusion bodies.

Reverse transcription starts after annealing of a tRNA ${ }^{\text {Met }}$ initiator at a site close to a discontinuity (D1) near the $5^{\prime}$ end of the 35S RNA (Fig. 13). DNA synthesis proceeds while the RNase $\mathrm{H}$ activity of $\mathrm{P} 5$ removes RNA from the RNA/DNA hybrid, leaving behind the DNA. The newly synthesized DNA binds the 35S RNA promoter at the $3^{\prime}$ end of the template, and after this switch DNA polymerization continues. At the same time, purine-rich regions at discontinuities D2 and D3 are resistant to RNase $\mathrm{H}$ activity and are used to synthesize DNAs with plus-strand polarity that because of their discontinuities have an open circular conformation. Reverse transcription in rice tungro viruses is similar, but only two discontinuities were observed in these viruses. The rice tungro virus polymerase has been expressed in insect cells using a baculovirus system. Polypeptides of 62 and $55 \mathrm{kDa}$ were obtained, both with DNA polymerase activity, although only the $55 \mathrm{kDa}$ form had RNase H activity (reviewed in Hull, 1996). Caulimoviridae RTs lack significant strand displacement activity and produce only small overhangs at the sites where discontinuities are observed. So far, there is hardly any information on the biochemical characteristics and structure of CaMV P5 or closely related proteins.

\section{Conclusions and perspectives}

Evidence summarized in this article reveals the complexity of the reverse transcription process in many viruses. Viral RTs are quite remarkable in their ability to exploit their DNA polymerase and RNase $\mathrm{H}$ activities. By using different types of substrates and their capacity to switch templates, viral RTs are able to produce unique and sophisticated dsDNAs which facilitate virus persistence in infected cells (e.g. LTR-containing proviruses in retrovirus, or cccDNA in hepadnaviruses). After their discovery in 1970, retroviral RTs received attention due to their expected role in RNA tumor virus pathogenicity. However, the discovery of HIV-1 as the etiological agent causing the acquired immunodeficiency syndrome (AIDS) and the need of drugs to block HIV replication fueled research on reverse transcription. During the last four decades, HIV replication has remained as an important research area and RT inhibitors constitute the backbone of current antiretroviral treatments. Part of this knowledge has been transferred to HBV, and several nucleoside analogues acting on the HBV polymerase have been identified and approved for treatment of HBV infections.

Despite the significant progress there are still important gaps in our understanding of the reverse transcription process. In retroviruses, and particularly in HIV, the contribution of viral and host factors to triggering the events that initiate reverse transcription (e.g. uncoating) is still poorly understood. Little is known of the formation of the reverse transcription complex and how this is transformed into a preintegration complex while the viral dsDNA synthesis is being completed. In the case of hepadnaviruses, progress has been slower and very important issues remain unsolved. For example, three-dimensional structures of HBV polymerases are not available and efforts to improve antiviral drugs are hampered by the lack of high-resolution structural information. In addition, we know only the basics of the reverse transcription process, and fates and relevance of its products need to be further studied. This is even more evident in plant pararetroviruses and LTR retrotransposons where biochemical studies are not fueled by the necessity to combat deadly diseases for humans.

Future studies on reverse transcription will be necessary for a better control of viral infections and may provide additional targets of antiviral intervention. Besides, RTs can be also useful tools for biotechnological applications, nowadays especially relevant with the advent of; 1 ; massive sequencing technologies.

\section{Acknowledgements}

We express our gratitude to Profs. Ben Berkhout, Jianming Hu and Raul Andino for critical reading of the manuscript. This work was supported in part by a grant of the Spanish Ministry of Economy and Competitiveness (BIO2013-48788-C2-1-R) and an institutional grant of Fundación Ramón Areces. A. S.-M. is a recipient of a predoctoral fellowship of the Spanish Ministry of Education, Culture and Sport (grant no. FPU2013-00693).

\section{References}

Abbink, T.E., Berkhout, B., 2007. HIV-1 reverse transcription: close encounters between the viral genome and a cellular tRNA. Adv. Pharmacol. 55, 99-135.

Abraham, T.M., Loeb, D.D., 2007. The topology of hepatitis B virus pregenomic RNA promotes its replication. J. Virol. 81, 11577-11584

Abram, M.E., Parniak, M.A., 2005. Virion instability of human immunodeficiency virus type 1 reverse transcriptase (RT) mutated in the protease cleavage site between RT p51 and the RT RNase H domain. J. Virol. 79, 11952-11961.

Álvarez, M., Matamoros, T., Menéndez-Arias, L., 2009. Increased thermostability and fidelity of DNA synthesis of wild-type and mutant HIV-1 group 0 reverse transcriptases. J. Mol. Biol. 392, 872-884.

Álvarez, M., Barrioluengo, V., Afonso-Lehmann, R.N., Menéndez-Arias, L., 2013. Altered error specificity of RNase H-deficient HIV-1 reverse transcriptases during DNA-dependent DNA synthesis. Nucleic Acids Res. 41, 4601-4612.

An, W., Telesnitsky, A., 2002. Effects of varying sequence similarity on the frequency of repeat deletion during reverse transcription of a human immunodeficiency virus type 1 vector. J. Virol. 76, 7897-7902.

Archer, J., Pinney, J.W., Fan, J., Simon-Loriere, E., Arts, E.J., Negroni, M., Robertson, D.L., 2008. Identifying the important HIV-1 recombination breakpoints. PLoS Comput. Biol. 4, e1000178. 
Arts, E.J., Hazuda, D.J., 2012. HIV-1 antiretroviral drug therapy. Cold Spring Harb. Perspect. Med. 2, a007161.

Arts, E.J., Ghosh, M., Jacques, P.S., Ehresmann, B., Le Grice, S.F., 1996. Restoration of tRNA3Lys-primed(-)-strand DNA synthesis to an HIV-1 reverse transcriptase mutant with extended tRNAs: implications for retroviral replication. J. Biol. Chem. 271, 9054-9061

Asahchop, E.L., Wainberg, M.A., Oliveira, M., Xu, H., Brenner, B.G., Moisi, D. Ibanescu, I.R., Tremblay, C., 2013. Distinct resistance patterns to etravirine and rilpivirine in viruses containing nonnucleoside reverse transcriptase inhibitor mutations at baseline. AIDS 27, 879-887.

Atwood-Moore, A., Ejebe, K., Levin, H.L., 2005. Specific recognition and cleavage of the plus-strand primer by reverse transcriptase. J. Virol. 79, 14863-14875.

Avila-Rios, S., Sued, O., Rhee, S.Y., Shafer, R.W., Reyes-Teran, G., Ravasi, G., 2016. Surveillance of HIV transmitted drug resistance in Latin America and the Caribbean: a systematic review and meta-analysis. PLoS One 11, e0158560.

Azijn, H., Tirry, I., Vingerhoets, J., de Béthune, M.P., Kraus, G., Boven, K., Jochmans, D., Van Craenenbroeck, E., Picchio, G., Rimsky, L.T., 2010. TMC278, a next-generation nonnucleoside reverse transcriptase inhibitor (NNRTI), active against wild-type and NNRTI-resistant HIV-1. Antimicrob. Agents Chemother. 54, 718-727

Baeten, J.M., Palanee-Phillips, T., Brown, E.R., Schwartz, K., Soto-Torres, L.E., Govender, V., Mgodi, N.M., Matovu Kiweewa, F., Nair, G., Mhlanga, F., Siva, S. Bekker, L.G., Jeenarain, N., Gaffoor, Z., Martinson, F., Makanani, B., Pather, A., Naidoo, L., Husnik, M., Richardson, B.A., Parikh, U.M., Mellors, J.W., Marzinke, M.A., Hendrix, C.W., van der Straten, A., Ramjee, G., Chirenje, Z.M., Nakabiito, C., Taha, T.E., Jones, J., Mayo, A., Scheckter, R., Berthiaume, J., Livant, E., Jacobson, C., Ndase, P., White, R., Patterson, K., Germuga, D., Galaska, B., Bunge, K., Singh, D., Szydlo, D.W., Montgomery, E.T., Mensch, B.S., Torjesen, K., Grossman, C.I., Chakhtoura, N., Nel, A., Rosenberg, Z., McGowan, I., Hillier, S. MTN-020-ASPIRE Study Team, 2016. Use of a vaginal ring containing dapivirine for HIV-1 prevention in women. N. Engl. J. Med. 375, 2121-2132.

Baird, H.A., Galetto, R., Gao, Y., Simon-Loriere, E., Abreha, M., Archer, J., Fan, J. Robertson, D.L., Arts, E.J., Negroni, M., 2006. Sequence determinants of breakpoint location during HIV-1 intersubtype recombination. Nucleic Acids Res. 34, 5203-5216.

Baltimore, D., 1970. RNA-dependent DNA polymerase in virions of RNA tumour viruses. Nature 226, 1209-1211.

Barrioluengo, V., Álvarez, M., Barbieri, D., Menéndez-Arias, L., 2011. Thermostable HIV-1 group O reverse transcriptase variants with the same fidelity as murine leukaemia virus reverse transcriptase. Biochem. J. 436, 599-607.

Barrioluengo, V., Wang, Y., Le Grice, S.F., Menéndez-Arias, L., 2012. Intrinsic DNA synthesis fidelity of xenotropic murine leukemia virus-related virus reverse transcriptase. FEBS J. 279, 1433-1444

Basu, V.P., Song, M., Gao, L., Rigby, S.T., Hanson, M.N., Bambara, R.A., 2008. Strand transfer events during HIV-1 reverse transcription. Virus Res. 134, 19-38.

Baumert, T.F., Rösler, C., Malim, M.H., von Weizsäcker, F., 2007. Hepatitis B virus DNA is subject to extensive editing by the human deaminase APOBEC3C. Hepatology 46, 682-689.

Beck, J., Nassal, M., 2001. Reconstitution of a functional duck hepatitis B virus replication initiation complex from separate reverse transcriptase domains expressed in Escherichia coli. J. Virol. 75, 7410-7419.

Beck, J., Nassal, M., 2003. Efficient Hsp90-independent in vitro activation by Hsc70 and Hsp40 of duck hepatitis B virus reverse transcriptase, an assumed Hsp90 client protein. J. Biol. Chem. 278, 36128-36138.

Beilhartz, G.L., Götte, M., 2010. HIV-1 ribonuclease H: structure, catalytic mechanism and inhibitors. Viruses 2, 900-926.

Beilhartz, G.L., Ngure, M., Johns, B.A., DeAnda, F., Gerondelis, P., Götte, M., 2014. Inhibition of the ribonuclease $\mathrm{H}$ activity of HIV-1 reverse transcriptase by GSK5750 correlates with slow enzyme-inhibitor dissociation. J. Biol. Chem. 289, 16270-16277.

Betancor, G., Álvarez, M., Marcelli, B., Andrés, C., Martínez, M.A., Menéndez-Arias, L., 2015. Effects of HIV-1 reverse transcriptase connection subdomain mutations on polypurine tract removal and initiation of (+)-strand DNA synthesis. Nucleic Acids Res. 43, 2259-2270.

Bibillo, A., Lener, D., Klarmann, G.J., Le Grice, S.F.J., 2005. Functional roles of carboxylate residues comprising the DNA polymerase active site triad of Ty3 reverse transcriptase. Nucleic Acids Res. 33, 171-181.

Bird, L.E., Chamberlain, P.P., Stewart-Jones, G.B., Ren, J., Stuart, D.I., Stammers, D.K. 2003. Cloning, expression, purification, and crystallisation of HIV-2 reverse transcriptase. Protein Expr. Purif. 27, 12-18.

Block, T.M., Rawat, S., Brosgart, C.L., 2015. Chronic hepatitis B: a wave of new therapies on the horizon. Antiviral Res. 121, 69-81.

Borkow, G., Fletcher, R.S., Barnard, J., Arion, D., Motakis, D., Dmitrienko, G.I., Parniak, M.A., 1997. Inhibition of the ribonuclease $\mathrm{H}$ and DNA polymerase activities of HIV-1 reverse transcriptase by $\mathrm{N}$-(4-tert-butylbenzoyl)-2-hydroxy-1-naphthaldehyde hydrazone. Biochemistry 36, 3179-3185.

Boyer, P.L., Stenbak, C.R., Hoberman, D., Linial, M.L., Hughes, S.H., 2007. In vitro fidelity of the prototype primate foamy virus (PFV) RT compared to HIV-1 RT. Virology 367, 253-264

Cai, C.W., Lomonosova, E., Moran, E.A., Cheng, X., Patel, K.B., Bailly, F., Cotelle, P. Meyers, M.J., Tavis, J.E., 2014. Hepatitis B virus replication is blocked by a 2-hydroxyisoquinoline-1,3(2H,4H)-dione (HID) inhibitor of the viral ribonuclease $\mathrm{H}$ activity. Antiviral Res. 108, 48-55.

Cases-González, C.E., Gutiérrez-Rivas, M., Menéndez-Arias, L., 2000. Coupling ribose selection to fidelity of DNA synthesis: the role of Tyr-115 of human immunodeficiency virus type 1 reverse transcriptase. J. Biol. Chem. 275 19759-19767.

Chabannes, M., Iskra-Caruana, M.L., 2013. Endogenous pararetroviruses-a reservoir of virus infection in plants. Curr. Opin. Virol. 3, 615-620.

Champoux, J.J., Schultz, S.J., 2009. Ribonuclease H: properties, substrate specificity and roles in retroviral reverse transcription. FEBS J. 276, 1506-1516.

Chapman, K.B., Byström, A.S., Boeke, J.D., 1992. Initiator methionine tRNA is essential for Ty1 transposition in yeast. Proc. Natl. Acad. Sci. U. S. A. 89, 3236-3240.

Charneau, P., Alizon, M., Clavel, F., 1992. A second origin of DNA plus-strand synthesis is required for optimal human immunodeficiency virus replication. J. Virol. 66, 2814-2820.

Chen, J., Powell, D., Hu, W.S., 2006. High frequency of genetic recombination is a common feature of primate lentivirus replication. J. Virol. 80, 9651-9658.

Chung, S., Miller, J.T., Johnson, B.C., Hughes, S.H., Le Grice, S.F., 2012. Mutagenesis of human immunodeficiency virus reverse transcriptase p51 subunit defines residues contributing to vinylogous urea inhibition of ribonuclease $\mathrm{H}$ activity. J. Biol. Chem. 287, 4066-4075.

Chung, S., Miller, J.T., Lapkouski, M., Tian, L., Yang, W., Le Grice, S.F., 2013. Examining the role of the HIV-1 reverse transcriptase p51 subunit in positioning and hydrolysis of RNA/DNA hybrids. J. Biol. Chem. 288 $16177-16184$

Clark, D.N., Hu, J., 2015. Hepatitis B virus reverse transcriptase - Target of curren antiviral therapy and future drug development. Antiviral Res. 123, 132-137.

Coffin, J.M., Fan, H., 2016. The discovery of reverse transcriptase. Annu. Rev. Virol 3, 29-51.

Cohen, C.J., Andrade-Villanueva, J., Clotet, B., Fourie, J., Johnson, M.A., Ruxrungtham, K., Wu, H., Zorrilla, C., Crauwels, H., Rimsky, L.T., Vanveggel, S. Boven, K., THRIVE Study group, 2011. Rilpivirine versus efavirenz with two background nucleoside or nucleotide reverse transcriptase inhibitors in treatment-naive adults infected with HIV-1 (THRIVE): a phase 3, randomised, non-inferiority trial. Lancet 378, 229-237.

Corona, A., Meleddu, R., Esposito, F., Distinto, S., Bianco, G., Masaoka, T., Maccioni, E., Menéndez-Arias, L., Alcaro, S., Le Grice, S.F.J., Tramontano, E., 2016. Ribonuclease H/DNA polymerase HIV-1 reverse transcriptase dual inhibitor: mechanistic studies on the allosteric mode of action of isatin-based compound RMNC6. PLoS One 11, e0147225.

Coté, M.L., Roth, M.J., 2008. Murine leukemia virus reverse transcriptase: structural comparison with HIV-1 reverse transcriptase. Virus Res. 134, 186-202.

Cui, X., McAllister, R., Boregowda, R., Sohn, J.A., Cortes Ledesma, F., Caldecott, K.W., Seeger, C., Hu, J., 2015. Does tyrosyl DNA phosphodiesterase-2 play a role in hepatitis B virus genome repair? PLoS One 10, e0128401.

Curcio, M.J., Lutz, S., Lesage, P., 2015. The Ty1 LTR-retrotransposon of budding yeast, Saccharomyces cerevisiae. Microbiol. Spectr. 3, 1-35 (MDNA3-0053-2014)

Darlix, J.L., Godet, J., Ivanyi-Nagy, R., Fossé, P., Mauffret, O., Mély, Y., 2011. Flexible nature and specific functions of the HIV-1 nucleocapsid protein. J. Mol. Biol. $410,565-581$

Das, K., Arnold, E., 2013a. HIV-1 reverse transcriptase and antiviral drug resistance. Part 1. Curr. Opin. Virol. 3, 111-118.

Das, K., Arnold, E., 2013b. HIV-1 reverse transcriptase and antiviral drug resistance. Part 2. Curr. Opin. Virol. 3, 119-128.

Das, D., Georgiadis, M.M., 2004. The crystal structure of the monomeric reverse transcriptase from Moloney murine leukemia virus. Structure 12, 819-829.

Das, A.T., Klaver, B., Berkhout, B., 1995. Reduced replication of human immunodeficiency virus type 1 mutants that use reverse transcription primers other than the natural tRNA ${ }^{\text {Lys,3 }}$. J. Virol. 69, 3090-3097.

Das, K., Bandwar, R.P., White, K.L., Feng, J.Y., Sarafianos, S.G., Tuske, S., Tu, X., Clark Jr., A.D., Boyer, P.L., Hou, X., Gaffney, B.L., Jones, R.A., Miller, M.D., Hughes, S.H., Arnold, E., 2009. Structural basis for the role of the K65R mutation in HIV-1 reverse transcriptase polymerization, excision antagonism, and tenofovir resistance. J. Biol. Chem. 284, 35092-35100.

Das, K., Martinez, S.E., Bauman, J.D., Arnold, E., 2012. HIV-1 reverse transcriptase complex with DNA and nevirapine reveals non-nucleoside inhibition mechanism. Nat. Struct. Mol. Biol. 19, 253-259.

De Clercq, E., 2013. The nucleoside reverse transcriptase inhibitors, nonnucleoside reverse transcriptase inhibitors, and protease inhibitors in the treatment of HIV infections (AIDS). Adv. Pharmacol. 67, 317-358.

Delviks-Frankenberry, K.A., Nikolenko, G.N., Boyer, P.L., Hughes, S.H., Coffin, J.M., Jere, A., Pathak, V.K., 2008. HIV-1 reverse transcriptase connection subdomain mutations reduce template RNA degradation and enhance AZT excision. Proc. Natl. Acad. Sci. U. S. A. 105, 10943-10948.

Delviks-Frankenberry, K., Galli, A., Nikolaitchik, O., Mens, H., Pathak, V.K., Hu, W.-S., 2011. Mechanisms and factors that influence high frequency retroviral recombination. Viruses 3, 1650-1680.

DeStefano, J.J., Buiser, R.G., Mallaber, L.M., Myers, T.W., Bambara, R.A., Fay, P.J., 1991. Polymerization and RNase $H$ activities of the reverse transcriptases from avian myeloblastosis, human immunodeficiency, and Moloney murine leukemia viruses are functionally uncoupled. J. Biol. Chem. 266, 7423-7431.

Deval, J., Selmi, B., Boretto, J., Egloff, M.P., Guerreiro, C., Sarfati, S., Canard, B., 2002. The molecular mechanism of multidrug resistance by the Q151M human immunodeficiency virus type 1 reverse transcriptase and its suppression using $\alpha$-boranophosphate nucleotide analogues. J. Biol. Chem. 277, 42097-42104.

Deval, J., Alvarez, K., Selmi, B., Bermond, M., Boretto, J., Guerreiro, C., Mulard, L., Canard, B., 2005. Mechanistic insights into the suppression of drug resistance 
by human immunodeficiency virus type 1 reverse transcriptase using $\alpha$-boranophosphate nucleoside analogs. J. Biol. Chem. 280, 3838-3846.

Dewannieux, M., Heidmann, T., 2013. Endogenous retroviruses: acquisition, amplification and taming of genome invaders. Curr. Opin. Virol. 3, 646-656.

Diamond, T.L., Souroullas, G., Weiss, K.K., Lee, K.Y., Bambara, R.A., Dewhurst, S., Kim, B., 2003. Mechanistic understanding of an altered fidelity simian immunodeficiency virus reverse transcriptase mutation, V148I, identified in a pig-tailed macaque. J. Biol. Chem. 278, 29913-29924.

Ding, J., Das, K., Hsiou, Y., Sarafianos, S.G., Clark Jr., A.D., Jacobo-Molina, A., Tantillo, C., Hughes, S.H., Arnold, E., 1998. Structure and functional implications of the polymerase active site region in a complex of HIV-1 RT with a double-stranded DNA template-primer and an antibody Fab fragment at $2.8 \mathrm{~A}$ resolution. J. Mol. Biol. 284, 1095-1111.

Dunn, L.L., McWilliams, M.J., Das, K., Arnold, E., Hughes, S.H., 2009. Mutations in the thumb allow human immunodeficiency virus type 1 reverse transcriptase to be cleaved by protease in virions. J. Virol. 83, 12336-12344.

Eckert, K.A., Kunkel, T.A., 1993. Fidelity of DNA synthesis catalyzed by human DNA polymerase $\alpha$ and HIV-1 reverse transcriptase: effect of reaction $\mathrm{pH}$. Nucleic Acids Res. 21, 5212-5220

Eickbush, T.H., Jamburuthugoda, V.K., 2008. The diversity of retrotransposons and the properties of their reverse transcriptases. Virus Res. 134, 221-234.

Eickbush, T.H., Malik, H.S., 2002. Origins and evolution of retrotransposons. In: Craig, N.L., Craigie, R., Gellert, M., Lambowitz, A.L. (Eds.), Mobile DNA II. ASM Press, Washington DC, pp. 1111-1144.

Elder, J.H., Lerner, D.L., Hasselkus-Light, C.S., Fontenot, D.J., Hunter, E., Luciw, P.A Montelaro, R.C., Phillips, T.R., 1992. Distinct subsets of retroviruses encode dUTPase. J. Virol. 66, 1791-1794.

Entin-Meer, M., Avidan, O., Hizi, A., 2003. The mature reverse transcriptase molecules in virions of mouse mammary tumor virus possess protease-derived sequences. Virology 310, 157-162.

Fan, N., Rank, K.B., Leone, J.W., Heinrikson, R.L., Bannow, C.A., Smith, C.W., Evans, D.B., Poppe, S.M., Tarpley, W.G., Rothrock, D.J., Tomasselli, A.G., Sharma, S.K. 1995. The differential processing of homodimers of reverse transcriptases from human immunodeficiency viruses type 1 and 2 is a consequence of the distinct specificities of the viral proteases. J. Biol. Chem. 270, 13573-13579.

Fan, J., Negroni, M., Robertson, D.L., 2007. The distribution of HIV-1 recombination breakpoints. Infect. Genet. Evol. 7, 717-723.

Feng, M., Wang, D., Grobler, J.A., Hazuda, D.J., Miller, M.D., Lai, M.T., 2015. In vitro resistance selection with doravirine (MK-1439), a novel nonnucleoside reverse transcriptase inhibitor with distinct mutation development pathways. Antimicrob. Agents Chemother. 59, 590-598.

Fisher, T.S., Darden, T., Prasad, V.R., 2003. Substitutions at Phe61 in the $\beta 3-\beta 4$ hairpin of HIV-1 reverse transcriptase reveal a role for the Fingers subdomain in strand displacement DNA synthesis. J. Mol. Biol. 325, 443-459.

Fujiwara, H., 2015. Site-specific non-LTR retrotransposons. Microbiol. Spectr. 3 , MDNA3-0001-2014.

Gao, G., Orlova, M., Georgiadis, M.M., Hendrickson, W.A., Goff, S.P., 1997. Conferring RNA polymerase activity to a DNA polymerase: a single residue in reverse transcriptase controls substrate selection. Proc. Natl. Acad. Sci. U. S. A. 94, 407-411.

Garforth, S.J., Domaoal, R.A., Lwatula, C., Landau, M.J., Meyer, A.J., Anderson, K.S., Prasad, V.R., 2010. K65R and K65A substitutions in HIV-1 reverse transcriptase enhance polymerase fidelity by decreasing both dNTP misinsertion and mispaired primer extension efficiencies. J. Mol. Biol. 401, 33-44

Golinelli, M.P., Hughes, S.H., 2002a. Nontemplated base addition by HIV-1 RT can induce nonspecific strand transfer in vitro. Virology 294, 122-134.

Golinelli, M.P., Hughes, S.H., 2002b. Nontemplated nucleotide addition by HIV-1 reverse transcriptase. Biochemistry 41, 5894-5906.

Gong, Q., Menon, L., Ilina, T., Miller, L.G., Ahn, J., Parniak, M.A., Ishima, R., 2011. Interaction of HIV-1 reverse transcriptase ribonuclease $\mathrm{H}$ with an acylhydrazone inhibitor. Chem. Biol. Drug Des. 77, 39-47.

Gout, J.F., Thomas, W.K., Smith, Z., Okamoto, K., Lynch, M., 2013. Large-scale detection of in vivo transcription errors. Proc. Natl. Acad. Sci. U. S. A. 110 18584-18589.

Haas, M., Bureau, M., Geldreich, A., Yot, P., Keller, M., 2002. Cauliflower mosaic virus: still in the news. Mol. Plant Pathol. 3, 419-429.

Harris, R.S., Hultquist, J.F., Evans, D.T., 2012. The restriction factors of human immunodeficiency virus. J. Biol. Chem. 287, 40875-40883.

Hartl, M.J., Wöhrl, B.M., Rösch, P., Schweimer, K., 2008. The solution structure of the simian foamy virus protease reveals a monomeric protein. J. Mol. Biol. 381, $141-149$.

Hartl, M.J., Bodem, J., Jochheim, F., Rethwilm, A., Rösch, P., Wöhrl, B.M., 2011. Regulation of foamy virus protease activity by viral RNA: a novel and unique mechanism among retroviruses. J. Virol. 85, 4462-4469.

Hatfield, D., Oroszlan, S., 1990. The where, what and how of ribosomal frameshifting in retroviral protein synthesis. Trends Biochem. Sci. 15, 186-190.

Havecker, E.R., Gao, X., Voytas, D.F., 2004. The diversity of LTR retrotransposons. Genome Biol. 5, 225

Hemelaar, J., Gouws, E., Ghys, P.D., Osmanov, S., WHO-UNAIDS Network for HIV Isolation and Characterisation, 2011. Global trends in molecular epidemiology of HIV-1 during 2000-2007. AIDS 25, 679-689.

Henriet, S., Mercenne, G., Bernacchi, S., Paillart, J.C., Marquet, R., 2009. Tumultuous relationship between the human immunodeficiency virus type 1 viral infectivity factor (Vif) and the human APOBEC-3G and APOBEC-3F restriction factors. Microbiol. Mol. Biol. Rev. 73, 211-232.
Herschhorn, A., Hizi, A., 2010. Retroviral reverse transcriptases. Cell. Mol. Life Sci. $67,2717-2747$

Hilditch, L., Towers, G.J., 2014. A model for cofactor use during HIV-1 reverse transcription and nuclear entry. Curr. Opin. Virol. 4, 32-36.

Himmel, D.M., Sarafianos, S.G., Dharmasena, S., Hossain, M.M., McCoy-Simandle, K., Ilina, T., Clark Jr., A.D., Knight, J.L., Julias, J.G., Clark, P.K., Krogh-Jespersen, K. Levy, R.M., Hughes, S.H., Parniak, M.A., Arnold, E., 2006. HIV-1 reverse transcriptase structure with RNase $\mathrm{H}$ inhibitor dihydroxy benzoyl naphthyl hydrazone bound at a novel site. ACS Chem. Biol. 1, 702-712.

Hirsch, R.C., Lavine, J.E., Chang, L.J., Varmus, H.E., Ganem, D., 1990. Polymerase gene products of hepatitis $\mathrm{B}$ viruses are required for genomic RNA packaging as well as for reverse transcription. Nature 344, 552-555.

Hizi, A., Herschhorn, A., 2008. Retroviral reverse transcriptases (other than those of HIV-1 and murine leukemia virus): a comparison of their molecular and biochemical properties. Virus Res. 134, 203-220.

Hizi, A., Herzig, E., 2015. dUTPase: the frequently overlooked enzyme encoded by many retroviruses. Retrovirology 12, 70, Erratum in: Retrovirology 12, 2015 , 77

Hizi, A., Joklik, W.K., 1977. RNA-dependent DNA polymerase of avian sarcoma virus B77 I. Isolation and partial characterization of the $\alpha, \beta 2$, and $\alpha \beta$ forms of the enzyme. J. Biol. Chem. 252, 2281-2289.

Hohn, T., Rothnie, H., 2013. Plant pararetroviruses: replication and expression. Curr. Opin. Virol. 3, 621-628.

Hu, J., Anselmo, D., 2000. In vitro reconstitution of a functional duck hepatitis B virus reverse transcriptase: posttranslational activation by Hsp90. J. Virol. 74, 11447-11455.

Hu, J., Seeger, C., 1996. Hsp90 is required for the activity of a hepatitis B virus reverse transcriptase. Proc. Natl. Acad. Sci. U. S. A. 93, 1060-1064.

Hu, J., Seeger, C., 2015. Hepadnavirus genome replication and persistence. Cold Spring Harb. Perspect. Med. 5, a021386

Hu, W.S., Temin, H.M., 1990a. Retroviral recombination and reverse transcription. Science 250, 1227-1233.

Hu, W.S., Temin, H.M., 1990b. Genetic consequences of packaging two RNA genomes in one retroviral particle: pseudodiploidy and high rate of genetic recombination. Proc. Natl. Acad. Sci. U. S. A. 87, 1556-1560.

Hu, J., Toft, D.O., Seeger, C., 1997. Hepadnavirus assembly and reverse transcription require a multi-component chaperone complex which is incorporated into nucleocapsids. EMBO J. 16, 59-68.

Hu, J., Toft, D., Anselmo, D., Wang, X., 2002. In vitro reconstitution of functional hepadnavirus reverse transcriptase with cellular chaperone proteins. J. Virol. $76,269-279$.

Hu, J., Flores, D., Toft, D., Wang, X., Nguyen, D., 2004. Requirement of heat shock protein 90 for human hepatitis B virus reverse transcriptase function. J. Virol. 78, 13122-13131.

Hu, Y., Cheng, X., Cao, F., Huang, A., Tavis, J.E., 2013. $\beta$-Thujaplicinol inhibits hepatitis B virus replication by blocking the viral ribonuclease $\mathrm{H}$ activity. Antiviral Res. 99, 221-229.

Huang, H., Chopra, R., Verdine, G.L., Harrison, S.C., 1998. Structure of a covalently trapped catalytic complex of HIV-1 reverse transcriptase: implications for drug resistance. Science 282, 1669-1675.

Huber, H.E., McCoy, J.M., Seehra, J.S., Richardson, C.C., 1989. Human immunodeficiency virus 1 reverse transcriptase. Template binding, processivity, strand displacement synthesis, and template switching. J. Biol. Chem. 264, 4669-4678.

Hughes, S.H., 2015. Reverse transcription of retroviruses and LTR retrotransposons Microbiol. Spectr. 3, MDNA3-0027-2014.

Hull, R., 1996. Molecular biology of rice tungro viruses. Annu. Rev. Phytopathol. 34 275-297.

Hungnes, O., Tjotta, E., Grinde, B., 1992. Mutations in the central polypurine tract of HIV-1 result in delayed replication. Virology 190, 440-442.

Hütter, S., Müllers, E., Stanke, N., Reh, J., Lindemann, D., 2013. Prototype foamy virus protease activity is essential for intraparticle reverse transcription initiation but not absolutely required for uncoating upon host cell entry. J. Virol. 87, 3163-3176.

Ilina, T., Labarge, K., Sarafianos, S.G., Ishima, R., Parniak, M.A., 2012. Inhibitors of HIV-1 reverse transcriptase-associated ribonuclease $\mathrm{H}$ activity. Biology (Basel) $1,521-541$

Inouye, S., Herzer, P.J., Inouye, M., 1990. Two independent retrons with highly diverse reverse transcriptases in Myxococcus xanthus. Proc. Natl. Acad. Sci. U. S. A. $87,942-945$.

Isel, C., Lanchy, J.M., Le Grice, S.F., Ehresmann, C., Ehresmann, B., Marquet, R., 1996 Specific initiation and switch to elongation of human immunodeficiency virus type 1 reverse transcription require the post-transcriptional modifications of primer tRNA3Lys. EMBO J. 15, 917-924.

Jacks, T., Townsley, K., Varmus, H.E., Majors, J., 1987. Two efficient ribosomal frameshifting events are required for synthesis of mouse mammary tumor virus gag-related polyproteins. Proc. Natl. Acad. Sci. U. S. A. 84, 4298-4302.

Jackson, D.L., Lee, E.G., Linial, M.L., 2013. Expression of prototype foamy virus pol as a Gag-Pol fusion protein does not change the timing of reverse transcription J. Virol. 87, 1252-1254.

Jacobo-Molina, A., Ding, J., Nanni, R.G., Clark Jr., A.D., Lu, X., Tantillo, C., Williams, R.L., Kamer, G., Ferris, A.L., Clark, P., Hizi, A., Hughes, S.H., Arnold, E., 1993. Crystal structure of human immunodeficiency virus type 1 reverse transcriptase complexed with double-stranded DNA at 3.0 ̊̊ resolution shows bent DNA. Proc. Natl. Acad. Sci. U. S. A. 90, 6320-6324. 
Janahi, E.M., McGarvey, M.J., 2013. The inhibition of hepatitis B virus by APOBEC cytidine deaminases. J. Viral Hepat. 20, 821-828.

Javanbakht, H., Ptak, R.G., Chow, E., Yan, J.M., Russell, J.D., Mankowski, M.K., Hogan, P.A., Hogg, J.H., Vora, H., Hang, J.Q., Li, Y., Su, G., Paul, A., Cammack, N., Klumpp, K., Heilek, G., 2010. In vitro resistance development for RO-0335, a novel diphenylether nonnucleoside reverse transcriptase inhibitor. Antiviral Res. 86 212-219.

Jeong, J.K., Yoon, G.S., Ryu, W.S., 2000. Evidence that the 5'-end cap structure is essential for encapsidation of hepatitis B virus pregenomic RNA. J. Virol. 74, 5502-5508.

Johns, B.A., Velthuisen, E.J., 2011. Therapeutic compounds. WO2011075747 (A1) Patent.

Jones, S.A., Hu, J., 2013. Protein-primed terminal transferase activity of hepatitis B virus polymerase. J. Virol. 87, 2563-2576, Erratum in: J. Virol. 87, 2013, 12505

Jones, S.A., Boregowda, R., Spratt, T.E., Hu, J., 2012. In vitro $\varepsilon$ RNA-dependent protein priming activity of human hepatitis B virus polymerase. J. Virol. 86, 5134-5150, Erratum in: J. Virol. 87, 2013, 12504.

Jones, S.A., Murakami, E., Delaney, W., Furman, P., Hu, J., 2013. Noncompetitive inhibition of hepatitis B virus reverse transcriptase protein priming and DNA synthesis by the nucleoside analog clevudine. Antimicrob. Agents Chemother. 57, 4181-4189, Erratum in: Antimicrob. Agents Chemother. 57, 2013, 5788.

Jones, S.A., Clark, D.N., Cao, F., Tavis, J.E., Hu, J., 2014. Comparative analysis of hepatitis B virus polymerase sequences required for viral RNA binding, RNA packaging, and protein priming. J. Virol. 88, 1564-1572.

Kati, W.M., Johnson, K.A., Jerva, L.F., Anderson, K.S., 1992. Mechanism and fidelity of HIV reverse transcriptase. J. Biol. Chem. 267, 25988-25997.

Kawamoto, A., Kodama, E., Sarafianos, S.G., Sakagami, Y., Kohgo, S., Kitano, K., Ashida, N., Iwai, Y., Hayakawa, H., Nakata, H., Mitsuya, H., Arnold, E., Matsuoka, M., 2008. 2'-Deoxy-4'-C-ethynyl-2-halo-adenosines active against drug-resistant human immunodeficiency virus type 1 variants. Int. J. Biochem. Cell Biol. 40, 2410-2420.

Ke, N., Gao, X., Keeney, J.B., Boeke, J.D., Voytas, D.F., 1999. The yeast retrotransposon Ty5 uses the anticodon stem-loop of the initiator methionine tRNA as a primer for reverse transcription. RNA 5, 929-938.

Keeney, J.B., Chapman, K.B., Lauermann, V., Voytas, D.F., Aström, S.U., von Pawel-Rammingen, U., Byström, A., Boeke, J.D., 1995. Multiple molecular determinants for retrotransposition in a primer tRNA. Mol. Cell. Biol. 15 217-226.

Kerr, S.G., Anderson, K.S., 1997. RNA dependent DNA replication fidelity of HIV-1 reverse transcriptase: evidence of discrimination between DNA and RNA substrates. Biochemistry 36, 14056-14063.

Kim, J., Roberts, A., Yuan, H., Xiong, Y., Anderson, K.S., 2012. Nucleocapsid protein annealing of a primer-template enhances (+)-strand DNA synthesis and fidelity by HIV-1 reverse transcriptase. J. Mol. Biol. 415, 866-880.

Kim, E.Y., Lorenzo-Redondo, R., Little, S.J., Chung, Y.S., Phalora, P.K., Maljkovic Berry, I., Archer, J., Penugonda, S., Fischer, W., Richman, D.D., Bhattacharya, T. Malim, M.H., Wolinsky, S.M., 2014. Human APOBEC3 induced mutation of human immunodeficiency virus type-1 contributes to adaptation and evolution in natural infection. PLoS Pathog. 10, e1004281.

King, A.M.Q., Adams, M.J., Carstens, E.B., Lefkowitz, E.J. (Eds.), 2012. Virus Taxonomy: Classification and Nomenclature of Viruses: Ninth Report of the International Committee on Taxonomy of Viruses. Elsevier, San Diego (1338 $\mathrm{pp})$.

Kirschberg, T.A., Balakrishnan, M., Squires, N.H., Barnes, T., Brendza, K.M., Chen, X., Eisenberg, E.J., Jin, W., Kutty, N., Leavitt, S., Liclican, A., Liu, Q., Liu, X., Mak, J., Perry, J.K., Wang, M., Watkins, W.J., Lansdon, E.B., 2009. RNase H active site inhibitors of human immunodeficiency virus type 1 reverse transcriptase: design, biochemical activity, and structural information. J. Med. Chem. 52, 5781-5784.

Kirshenboim, N., Hayouka, Z., Friedler, A., Hizi, A., 2007. Expression and characterization of a novel reverse transcriptase of the LTR retrotransposon Tf1. Virology 366, 263-276

Kisic, M., Matamoros, T., Nevot, M., Mendieta, J., Martinez-Picado, J., Martínez, M.A., Menéndez-Arias, L., 2011. Thymidine analogue excision and discrimination modulated by mutational complexes including single amino acid deletions of Asp-67 or Thr-69 in HIV-1 reverse transcriptase. J. Biol. Chem. 286, 20615-20624.

Ko, C., Shin, Y.C., Park, W.J., Kim, S., Kim, J., Ryu, W.S., 2014. Residues Arg703, Asp777, and Arg781 of the RNase H domain of hepatitis B virus polymerase are critical for viral DNA synthesis. J. Virol. 88, 154-163.

Königer, C., Wingert, I., Marsmann, M., Rösler, C., Beck, J., Nassal, M., 2014 Involvement of the host DNA-repair enzyme TDP2 in formation of the covalently closed circular DNA persistence reservoir of hepatitis B viruses. Proc. Natl. Acad. Sci. U. S. A. 111, E4244-E4253.

Köppe, B., Menéndez-Arias, L., Oroszlan, S., 1994. Expression and purification of the mouse mammary tumor virus gag-pro transframe protein p30 and characterization of its dUTPase activity. J. Virol. 68, 2313-2319.

Křízová, I., Hadravová, R., Štokrová, J., Günterová, J., Doležal, M., Ruml, T., Rumlová, M., Pichová, I., 2012. The G-patch domain of Mason-Pfizer monkey virus is a part of reverse transcriptase. J. Virol. 86, 1988-1998.

Kunkel, T.A., 2004. DNA replication fidelity. J. Biol. Chem. 279, 16895-16898.

Kurzynska-Kokorniak, A., Jamburuthugoda, V.K., Bibillo, A., Eickbush, T.H., 2007. DNA-directed DNA polymerase and strand displacement activity of the reverse transcriptase encoded by the R2 retrotransposon. J. Mol. Biol. 374, 322-333.

Lambowitz, A.M., Zimmerly, S., 2004. Mobile group II introns. Annu. Rev. Genet. 38, $1-35$.
Lampson, B.C., Inouye, M., Inouye, S., 2005. Retrons, msDNA, and the bacterial genome. Cytogenet. Genome Res. 110, 491-499.

Lanford, R.E., Notvall, L., Beames, B., 1995. Nucleotide priming and reverse transcriptase activity of hepatitis B virus polymerase expressed in insect cells. J. Virol. 69, 4431-4439.

Lanford, R.E., Notvall, L., Lee, H., Beames, B., 1997. Transcomplementation of nucleotide priming and reverse transcription between independently expressed TP and RT domains of the hepatitis B virus reverse transcriptase. J. Virol. 71, 2996-3004.

Lapkouski, M., Tian, L., Miller, J.T., Le Grice, S.F., Yang, W., 2013. Complexes of HIV-1 RT, NNRTI and RNA/DNA hybrid reveal a structure compatible with RNA degradation. Nat. Struct. Mol. Biol. 20, 230-236.

Lau, K.A., Wong, J.J., 2013. Current trends of HIV recombination worldwide. Infect. Dis. Rep. 5 (Suppl. 1), e4

Le Grice, S.F., 2012. Human immunodeficiency virus reverse transcriptase: 25 years of research, drug discovery, and promise. J. Biol. Chem. 287, 40850-40857.

Leblanc, P., Desset, S., Giorgi, F., Taddei, A.R., Fausto, A.M., Mazzini, M., Dastugue, B., Vaury, C., 2000. Life cycle of an endogenous retrovirus, ZAM, in Drosophila melanogaster. J. Virol. 74, 10658-10669.

Lee, E.G., Stenbak, C.R., Linial, M.L., 2013. Foamy virus assembly with emphasis on pol encapsidation. Viruses 5, 886-900.

Lener, D., Budihas, S.R., Le Grice, S.F., 2002. Mutating conserved residues in the ribonuclease $\mathrm{H}$ domain of Ty3 reverse transcriptase affects specialized cleavage events. J. Biol. Chem. 277, 26486-26495.

Li, A., Li, J., Johnson, K.A., 2016. HIV-1 reverse transcriptase polymerase and RNase $\mathrm{H}$ (ribonuclease $\mathrm{H}$ ) active sites work simultaneously and independently. J. Biol. Chem. 291, 26566-26585.

Lin, J.H., Levin, H.L., 1997. A complex structure in the mRNA of Tf1 is recognized and cleaved to generate the primer of reverse transcription. Genes Dev. 11, 270-285.

Linial, M.L., Eastman, S.W., 2003. Particle assembly and genome packaging. Curr. Top. Microbiol. Immunol. 277, 89-110.

London, R.E., 2016. Structural maturation of HIV-1 reverse transcriptase - a metamorphic solution to genomic instability. Viruses 8, 260.

Lu, G., Lomonosova, E., Cheng, X., Moran, E.A., Meyers, M.J., Le Grice, S.F., Thomas, C.J., Jiang, J.K., Meck, C., Hirsch, D.R., D’Erasmo, M.P., Suyabatmaz, D.M., Murelli, R.P., Tavis, J.E., 2015. Hydroxylated tropolones inhibit hepatitis B virus replication by blocking viral ribonuclease $\mathrm{H}$ activity. Antimicrob. Agents Chemother. 59, 1070-1079.

Lucifora, J., Zoulim, F., 2011. The life cycle of hepatitis B virus and antiviral targets. Future Virol. 6, 599-614.

Magnuson, B., Bedi, K., Ljungman, M., 2016. Genome stability versus transcript diversity. DNA Repair (Amst.) 44, 81-86.

Mak, J., Kleiman, L., 1997. Primer tRNAs for reverse transcription. J. Virol. 71, 8087-8095.

Malik, H.S., Henikoff, S., Eickbush, T.H., 2000. Poised for contagion: evolutionary origins of the infectious abilities of invertebrate retroviruses. Genome Res. 10 1307-1318.

Mansky, L.M., 1996. The mutation rate of human immunodeficiency virus type 1 is influenced by the vpr gene. Virology 222, 391-400.

Mansky, L.M., Le Rouzic, E., Benichou, S., Gajary, L.C., 2003. Influence of reverse transcriptase variants drugs, and Vpr on human immunodeficiency virus type 1 mutant frequencies. J. Virol. 77, 2071-2080.

Marquet, R., Isel, C., Ehresmann, C., Ehresmann, B., 1995. tRNAs as primer of reverse transcriptases. Biochimie 77, 113-124.

Mas, A., Vázquez-Álvarez, B.M., Domingo, E., Menéndez-Arias, L., 2002. Multidrug-resistant HIV-1 reverse transcriptase: involvement of ribonucleotide-dependent phosphorolysis in cross-resistance to nucleoside analogue inhibitors. J. Mol. Biol. 323, 181-197.

Masuda, T., Sato, Y., Huang, Y.L., Koi, S., Takahata, T., Hasegawa, A., Kawai, G. Kannagi, M., 2015. Fate of HIV-1 cDNA intermediates during reverse transcription is dictated by transcription initiation site of virus genomic RNA Sci. Rep. 5, 17680

Matamoros, T., Kim, B., Menéndez-Arias, L., 2008. Mechanistic insights into the role of Val75 of HIV-1 reverse transcriptase in misinsertion and mispair extension fidelity of DNA synthesis. J. Mol. Biol. 375, 1234-1248.

Matsuda, T., Bebenek, K., Masutani, C., Hanaoka, F., Kunkel, T.A., 2000. Low fidelity DNA synthesis by human DNA polymerase- $\eta$. Nature 404, 1011-1013.

McCulloch, S.D., Kunkel, T.A., 2008. The fidelity of DNA synthesis by eukaryotic replicative and translesion synthesis polymerases. Cell Res. 18, 148-161.

Mendieta, J., Cases-González, C.E., Matamoros, T., Ramírez, G., Menéndez-Arias, L. 2008. A $\mathrm{Mg}^{2+}$-induced conformational switch rendering a competent DNA polymerase catalytic complex. Proteins 71, 565-574.

Menéndez-Arias, L., 2002. Molecular basis of fidelity of DNA synthesis and nucleotide specificity of retroviral reverse transcriptases. Progr. Nucleic Acid Res. Mol. Biol. 71, 91-147

Menéndez-Arias, L., 2008. Mechanisms of resistance to nucleoside analogue inhibitors of HIV-1 reverse transcriptase. Virus Res. 134, 124-146.

Menéndez-Arias, L., 2009. Mutation rates and intrinsic fidelity of retroviral reverse transcriptases. Viruses 1, 1137-1165.

Menéndez-Arias, L., 2013a. Molecular basis of human immunodeficiency virus type 1 drug resistance: overview and recent developments. Antiviral Res. 98, 93-120.

Menéndez-Arias, L., 2013b. HIV reverse transcriptase fidelity, clade diversity, and acquisition of drug resistance. In: Le Grice, S.F.J., Götte, M. (Eds.), Human 
Immunodeficiency Virus Reverse Transcriptase: A Bench-to-Bedside Success. Springer Science + Business Media, New York, pp. 225-252.

Menéndez-Arias, L., Betancor, G., Matamoros, T., 2011. HIV-1 reverse transcriptase connection subdomain mutations involved in resistance to approved non-nucleoside inhibitors. Antiviral Res. 92, 139-149.

Menéndez-Arias, L., Álvarez, M., Pacheco, B., 2014. Nucleoside/nucleotide analog inhibitors of hepatitis B virus polymerase: mechanism of action and resistance. Curr. Opin. Virol. 8, 1-9.

Meyer, P.R., Matsuura, S.E., Mian, A.M., So, A.G., Scott, W.A., 1999. A mechanism of AZT resistance: an increase in nucleotide-dependent primer unblocking by mutant HIV-1 reverse transcriptase. Mol. Cell. 4, 35-43.

Michailidis, E., Kirby, K.A., Hachiya, A., Yoo, W., Hong, S.P., Kim, S.O., Folk, W.R., Sarafianos, S.G., 2012. Antiviral therapies: focus on hepatitis B reverse transcriptase. Int. J. Biochem. Cell Biol. 44, 1060-1071.

Michailidis, E., Huber, A.D., Ryan, E.M., Ong, Y.T., Leslie, M.D., Matzek, K.B., Singh, K., Marchand, B., Hagedorn, A.N., Kirby, K.A., Rohan, L.C., Kodama, E.N., Mitsuya, H., Parniak, M.A., Sarafianos, S.G., 2014. 4'-Ethynyl-2-fluoro-

2 '-deoxyadenosine (EFdA) inhibits HIV-1 reverse transcriptase with multiple mechanisms. J. Biol. Chem. 289, 24533-24548.

Misra, H.S., Pandey, P.K., Pandey, V.N., 1998. An enzymatically active chimeric HIV-1 reverse transcriptase (RT) with the RNase-H domain of murine leukemia virus RT exists as a monomer. J. Biol. Chem. 273, 9785-9789.

Mitchell, M.S., Tözsér, J., Princler, G., Lloyd, P.A., Auth, A., Derse, D., 2006. Synthesis, processing, and composition of the virion-associated HTLV-1 reverse transcriptase. J. Biol. Chem. 281, 3964-3971.

Molina, J.M., Cahn, P., Grinsztejn, B., Lazzarin, A., Mills, A., Saag, M., Supparatpinyo, K., Walmsley, S., Crauwels, H., Rimsky, L.T., Vanveggel, S., Boven, K., ECHO study group, 2011. Rilpivirine versus efavirenz with tenofovir and emtricitabine in treatment-naive adults infected with HIV-1 (ECHO): a phase 3 randomised double-blind active-controlled trial. Lancet 378, 238-246.

Moore, M.D., Fu, W., Nikolaitchik, O., Chen, J., Ptak, R.G., Hu, W.S., 2007. Dimer initiation signal of human immunodeficiency virus type 1: its role in partner selection during RNA copackaging and its effects on recombination. J. Virol. 81, 4002-4011

Nair, G.R., Dash, C., Le Grice, S.F., DeStefano, J.J., 2012. Viral reverse transcriptases show selective high affinity binding to DNA-DNA primer-templates that resemble the polypurine tract. PLoS One 7, e41712.

Nassal, M., 2008. Hepatitis B viruses: reverse transcription a different way. Virus Res. 134, 235-249.

Nassal, M., 2015. HBV cccDNA: viral persistence reservoir and key obstacle for a cure of chronic hepatitis B. Gut 64, 1972-1984.

Ndongwe, T.P., Adedeji, A.O., Michailidis, E., Ong, Y.T., Hachiya, A., Marchand, B., Ryan, E.M., Rai, D.K., Kirby, K.A., Whatley, A.S., Burke, D.H., Johnson, M., Ding, S., Zheng, Y.M., Liu, S.L., Kodama, E., Delviks-Frankenberry, K.A., Pathak, V.K., Mitsuya, H., Parniak, M.A., Singh, K., Sarafianos, S.G., 2012. Biochemical, inhibition and inhibitor resistance studies of xenotropic murine leukemia virus-related virus reverse transcriptase. Nucleic Acids Res. 40, 345-359.

Nikolenko, G.N., Palmer, S., Maldarelli, F., Mellors, J.W., Coffin, J.M., Pathak, V.K., 2005. Mechanism for nucleoside analog-mediated abrogation of HIV-1 replication: balance between RNase $\mathrm{H}$ activity and nucleotide excision. Proc. Natl. Acad. Sci. U. S. A. 102, 2093-2098.

Ninio, J., 1991. Transient mutators: a semiquantitative analysis of the influence of translation and transcription errors on mutation rates. Genetics 129, 957-962.

Nowak, E., Potrzebowski, W., Konarev, P.V., Rausch, J.W., Bona, M.K., Svergun, D.I., Bujnicki, J.M., Le Grice, S.F., Nowotny, M., 2013. Structural analysis of monomeric retroviral reverse transcriptase in complex with an RNA/DNA hybrid. Nucleic Acids Res. 41, 3874-3887.

Nowak, E., Miller, J.T., Bona, M.K., Studnicka, J., Szczepanowski, R.H., Jurkowski, J., Le Grice, S.F., Nowotny, M., 2014. Ty3 reverse transcriptase complexed with an RNA-DNA hybrid shows structural and functional asymmetry. Nat. Struct. Mol. Biol. 21, 389-396.

O’Neil, P.K., Sun, G., Yu, H., Ron, Y., Dougherty, J.P., Preston, B.D., 2002. Mutational analysis of HIV-1 long terminal repeats to explore the relative contribution of reverse transcriptase and RNA polymerase II to viral mutagenesis. J. Biol. Chem. 277, 38053-38061

Ohrui, H., 2006. 2'-Deoxy-4'-C-ethynyl-2-fluoroadenosine, a nucleoside reverse transcriptase inhibitor, is highly potent against all human immunodeficiency viruses type 1 and has low toxicity. Chem. Rec. 6, 133-143.

Olivares, I., Mulky, A., Boross, P.I., Tözsér, J., Kappes, J.C., López-Galíndez, C., Menéndez-Arias, L, 2007. HIV-1 protease dimer interface mutations that compensate for viral reverse transcriptase instability in infectious virions. J. Mol. Biol. 372, 369-381

Onafuwa, A., An, W., Robson, N.D., Telesnitsky, A., 2003. Human immunodeficiency virus type 1 genetic recombination is more frequent than that of Moloney murine leukemia virus despite similar template switching rates. J. Virol. 77, 4577-4587.

Onafuwa-Nuga, A., Telesnitsky, A., 2009. The remarkable frequency of human immunodeficiency virus type 1 genetic recombination. Microbiol. Mol. Biol. Rev. 73, 451-480.

Operario, D.J., Reynolds, H.M., Kim, B., 2005. Comparison of DNA polymerase activities between recombinant feline immunodeficiency and leukemia virus reverse transcriptases. Virology 335, 106-121.

Oz-Gleenberg, I., Herschhorn, A., Hizi, A., 2011. Reverse transcriptases can clamp together nucleic acids strands with two complementary bases at their 3'-termini for initiating DNA synthesis. Nucleic Acids Res. 39, 1042-1053.
Oz-Gleenberg, I., Herzig, E., Hizi, A., 2012. Template-independent DNA synthesis activity associated with the reverse transcriptase of the long terminal repeat retrotransposon Tf1. FEBS J. 279, 142-153.

Panganiban, A.T., Fiore, D., 1988. Ordered interstrand and intrastrand DNA transfer during reverse transcription. Science 241, 1064-1069.

Paulson, B.A., Zhang, M., Schultz, S.J., Champoux, J.J., 2007. Substitution of alanine for tyrosine-64 in the fingers subdomain of M-MuLV reverse transcriptase impairs strand displacement synthesis and blocks viral replication in vivo. Virology 366, 361-376.

Perach, M., Hizi, A., 1999. Catalytic features of the recombinant reverse transcriptase of bovine leukemia virus expressed in bacteria. Virology 259, 176-189.

Perrino, F.W., Preston, B.D., Sandell, L.L., Loeb, L.A., 1989. Extension of mismatched 3' termini of DNA is a major determinant of the infidelity of human immunodeficiency virus type 1 reverse transcriptase. Proc. Natl. Acad. Sci. U. S. A. $86,8343-8347$

Piekna-Przybylska, D., Sharma, G., Bambara, R.A., 2013. Mechanism of HIV-1 RNA dimerization in the central region of the genome and significance for viral evolution. J. Biol. Chem. 288, 24140-24150.

Poch, O., Sauvaget, I., Delarue, M., Tordo, N., 1989. Identification of four conserved motifs among the RNA-dependent polymerase encoding elements. EMBO J. 8, 3867-3874.

Pullen, K.A., Ishimoto, L.K., Champoux, J.J., 1992. Incomplete removal of the RNA primer for minus-strand DNA synthesis by human immunodeficiency virus type 1 reverse transcriptase. J. Virol. 66, 367-373.

Pullen, K.A., Rattray, A.J., Champoux, J.J., 1993. The sequence features important for plus strand priming by human immunodeficiency virus type 1 reverse transcriptase. J. Biol. Chem. 268, 6221-6227.

Pult, I., Abbott, N., Zhang, Y.Y., Summers, J., 2001. Frequency of spontaneous mutations in an avian hepadnavirus infection. J. Virol. 75, 9623-9632.

Rausch, J.W., Bona-Le Grice, M.K., Henrietta, M., Nymark-McMahon, H., Miller, J.T., Le Grice, S.F., 2000. Interaction of p55 reverse transcriptase from the Saccharomyces cerevisiae retrotransposon Ty3 with conformationally distinct nucleic acid duplexes. J. Biol. Chem. 275, 13879-13887.

Ray, A.S., Fordyce, M.W., Hitchcock, M.J., 2016. Tenofovir alafenamide: a novel prodrug of tenofovir for the treatment of human immunodeficiency virus. Antiviral Res. 125, 63-70.

Rein, A., 2010. Nucleic acid chaperone activity of retroviral Gag proteins. RNA Biol. 7, 700-705.

Ren, J., Stammers, D.K., 2008. Structural basis for drug resistance mechanisms for non-nucleoside inhibitors of HIV reverse transcriptase. Virus Res. 134, $157-170$.

Ren, J., Bird, L.E., Chamberlain, P.P., Stewart-Jones, G.B., Stuart, D.I., Stammers, D.K., 2002. Structure of HIV-2 reverse transcriptase at 2.35-Å resolution and the mechanism of resistance to non-nucleoside inhibitors. Proc. Natl. Acad. Sci. U. S. A. 99, 14410-14415.

Rethwilm, A., 2003. The replication strategy of foamy viruses. Curr. Top. Microbiol. Immunol. 277, 1-26.

Rethwilm, A., 2010. Molecular biology of foamy viruses. Med. Microbiol. Immunol. 199, 197-207.

Rezende, L.F., Drosopoulos, W.C., Prasad, V.R., 1998. The influence of 3TC resistance mutation M184I on the fidelity and error specificity of human immunodeficiency virus type 1 reverse transcriptase. Nucleic Acids Res. 26, 3066-3072.

Rhee, S.Y., Blanco, J.L., Jordan, M.R., Taylor, J., Lemey, P., Varghese, V., Hamers, R.L., Bertagnolio, S., Rinke de Wit, T.F., Aghokeng, A.F., Albert, J., Avi, R., Avila-Rios, S., Bessong, P.O., Brooks, J.I., Boucher, C.A., Brumme, Z.L., Busch, M.P., Bussmann, H., Chaix, M.L., Chin, B.S., D'Aquin, T.T., De Gascun, C.F., Derache, A., Descamps, D., Deshpande, A.K., Djoko, C.F., Eshleman, S.H., Fleury, H., Frange, P., Fujisaki, S., Harrigan, P.R., Hattori, J., Holguin, A., Hunt, G.M., Ichimura, H., Kaleebu, P., Katzenstein, D., Kiertiburanakul, S., Kim, J.H., Kim, S.S., Li, Y., Lutsar I., Morris, L., Ndembi, N., Ng, K.P., Paranjape, R.S., Peeters, M., Poljak, M., Price, M.A., Ragonnet-Cronin, M.L., Reyes-Terán, G., Rolland, M., Sirivichayakul, S., Smith, D.M., Soares, M.A., Soriano, V.V., Ssemwanga, D., Stanojevic, M., Stefani, M.A., Sugiura, W., Sungkanuparph, S., Tanuri, A., Tee, K.K., Truong, H.M., van de Vijver, D.A., Vidal, N., Yang, C., Yang, R., Yebra, G., Ioannidis, J.P., Vandamme, A.M., Shafer, R.W., 2015. Geographic and temporal trends in the molecular epidemiology and genetic mechanisms of transmitted HIV-1 drug resistance: an individual-patient- and sequence-level meta-analysis. PLoS Med. 12, e1001810, Erratum in: PLoS Med. 12, 2015, e1001845.

Rhodes, T., Wargo, H., Hu, W.S., 2003. High rates of human immunodeficiency virus type 1 recombination: near-random segregation of markers one kilobase apart in one round of viral replication. J. Virol. 77, 11193-11200.

Rhodes, T.D., Nikolaitchik, O., Chen, J., Powell, D., Hu, W.S., 2005. Genetic recombination of human immunodeficiency virus type 1 in one round of viral replication: effects of genetic distance, target cells, accessory genes, and lack of high negative interference in crossover events. J. Virol. 79, 1666-1677.

Roberts, J.D., Bebenek, K., Kunkel, T.A., 1988. The accuracy of reverse transcriptase from HIV-1. Science 242, 1171-1173.

Roberts, J.D., Preston, B.D., Johnston, L.A., Soni, A., Loeb, L.A., Kunkel, T.A., 1989 Fidelity of two retroviral reverse transcriptases during DNA-dependent DNA synthesis in vitro. Mol. Cell. Biol. 9, 469-476.

Roth, M.J., Tanese, N., Goff, S.P., 1985. Purification and characterization of murine retroviral reverse transcriptase expressed in Escherichia coli. J. Biol. Chem. 260 9326-9335. 
Rothnie, H.M., Chapdelaine, Y., Hohn, T., 1994. Pararetroviruses and retroviruses: a comparative review of viral structure and gene expression strategies. Adv. Virus Res. 44, 1-67.

Salie, Z.L., Kirby, K.A., Michailidis, E., Marchand, B., Singh, K., Rohan, L.C., Kodama, E.N., Mitsuya, H., Parniak, M.A., Sarafianos, S.G., 2016. Structural basis of HIV inhibition by translocation-defective RT inhibitor 4'-ethynyl-2-fluoro-2'deoxyadenosine (EFdA). Proc. Natl. Acad. Sci. U. S. A. 113, 9274-9279.

Sarafianos, S.G., Das, K., Clark, A.D., Jr., Ding, J., Boyer, P.L., Hughes, S.H., Arnold, E., 1999. Lamivudine (3TC) resistance in HIV-1 reverse transcriptase involves steric hindrance with $\beta$-branched amino acids. Proc. Natl. Acad. Sci. U. S. A. 96, 10027-10032.

Sarafianos, S.G., Das, K., Tantillo, C., Clark Jr., A.D., Ding, Whitcomb, J.M., Boyer, P.L., Hughes, S.H., Arnold, E., 2001. Crystal structure of HIV-1 reverse transcriptase in complex with a polypurine tract RNA:DNA. EMBO J. 20, 1449-1461.

Sarafianos, S.G., Clark Jr., A.D., Das, K., Tuske, S., Birktoft, J.J., Ilankumaran, P., Ramesha, A.R., Sayer, J.M., Jerina, D.M., Boyer, P.L., Hughes, S.H., Arnold, E., 2002. Structures of HIV-1 reverse transcriptase with pre- and post-translocation AZTMP-terminated DNA. EMBO J. 21, 6614-6624.

Sarafianos, S.G., Marchand, B., Das, K., Himmel, D.M., Parniak, M.A., Hughes, S.H., Arnold, E., 2009. Structure and function of HIV-1 reverse transcriptase: molecular mechanisms of polymerization and inhibition. J. Mol. Biol. 385, 693-713.

Schlub, T.E., Smyth, R.P., Grimm, A.J., Mak, J., Davenport, M.P., 2010. Accurately measuring recombination between closely related HIV-1 genomes. PLoS Comput. Biol. 6, e1000766.

Schlub, T.E., Grimm, A.J., Smyth, R.P., Cromer, D., Chopra, A., Mallal, S., Venturi, V., Waugh, C., Mak, J., Davenport, M.P., 2014. Fifteen to twenty percent of HIV substitution mutations are associated with recombination. J. Virol. 88, 3837-3849.

Schneider, A., Peter, D., Schmitt, J., Leo, B., Richter, F., Rösch, P., Wöhrl, B.M., Hartl, M.J., 2014. Structural requirements for enzymatic activities of foamy virus protease-reverse transcriptase. Proteins 82, 375-385.

Shah, F.S., Curr, K.A., Hamburgh, M.E., Parniak, M., Mitsuya, H., Arnez, J.G., Prasad, V.R., 2000. Differential influence of nucleoside analog-resistance mutations K65R and L74V on the overall mutation rate and error specificity of human immunodeficiency virus type 1 reverse transcriptase. J. Biol. Chem. 275 , 27037-27044

Sharaf, N.G., Poliner, E., Slack, R.L., Christen, M.T., Byeon, I.J., Parniak, M.A., Gronenborn, A.M., Ishima, R., 2014. The p66 immature precursor of HIV-1 reverse transcriptase. Proteins 82, 2343-2352.

Simon-Loriere, E., Galetto, R., Hamoudi, M., Archer, J., Lefeuvre, P., Martin, D.P. Robertson, D.L., Negroni, M., 2009. Molecular mechanisms of recombination restriction in the envelope gene of the human immunodeficiency virus. PLoS Pathog. 5, e1000418

Simon-Loriere, E., Rossolillo, P., Negroni, M., 2011. RNA structures, genomic organization and selection of recombinant HIV. RNA Biol. 8, 280-286.

Smith, J.S., Roth, M.J., 1992. Specificity of human immunodeficiency virus-1 reverse transcriptase-associated ribonuclease $\mathrm{H}$ in removal of the minus-strand primer, tRNA(Lys3). J. Biol. Chem. 267, 15071-15079.

Smith, S.J., Pauly, G.T., Akram, A., Melody, K., Ambrose, Z., Schneider, J.P., Hughes, S.H., 2016. Rilpivirine and doravirine have complementary efficacies against NNRTI-resistant HIV-1 mutants. J. Acquir. Immune Defic. Syndr. 72, 485-491.

Smyth, R.P., Davenport, M.P., Mak, J., 2012. The origin of genetic diversity in HIV-1. Virus Res. 169, 415-429.

Smyth, R.P., Schlub, T.E., Grimm, A.J., Waugh, C., Ellenberg, P., Chopra, A., Mallal, S. Cromer, D., Mak, J., Davenport, M.P., 2014. Identifying recombination hot spots in the HIV-1 genome. J. Virol. 88, 2891-2902.

Spannaus, R., Schneider, A., Hartl, M.J., Wöhrl, B.M., Bodem, J., 2013. Foamy virus Gag p71-p68 cleavage is required for template switch of the reverse transcriptase. J. Virol. 87, 7774-7776.

Stuke, A.W., Ahmad-Omar, O., Hoefer, K., Hunsmann, G., Jentsch, K.D., 1997. Mutations in the SIV env and the M13 lacZ $\alpha$ gene generated in vitro by reverse transcriptases and DNA polymerases. Arch. Virol. 142, 1139-1154.

Stuyver, L.J., Locarnini, S.A., Lok, A., Richman, D.D., Carman, W.F., Dienstag, J.L., Schinazi, R.F., 2001. Nomenclature for antiviral-resistant human hepatitis B virus mutations in the polymerase region. Hepatology 33, 751-757.

Swanstrom, R., Varmus, H.E., Bishop, J.M., 1981. The terminal redundancy of the retrovirus genome facilitates chain elongation by reverse transcriptase. J. Biol. Chem. 256, 1115-1121

Takamatsu, Y., Tanaka, Y., Kohgo, S., Murakami, S., Singh, K., Das, D., Venzon, D.J. Amano, M., Higashi-Kuwata, N., Aoki, M., Delino, N.S., Hayashi, S., Takahashi, S., Sukenaga, Y., Haraguchi, K., Sarafianos, S.G., Maeda, K., Mitsuya, H., 2015. 4'-modified nucleoside analogs: potent inhibitors active against entecavir-resistant hepatitis B virus. Hepatology 62, 1024-1036.

Taube, R., Loya, S., Avidan, O., Perach, M., Hizi, A., 1998. Reverse transcriptase of mouse mammary tumour virus: expression in bacteria, purification and biochemical characterization. Biochem. J. 329, 579-587.

Tavis, J.E., Lomonosova, E., 2015. The hepatitis B virus ribonuclease $\mathrm{H}$ as a drug target. Antiviral Res. 118, 132-138.

Tavis, J.E., Cheng, X., Hu, Y., Totten, M., Cao, F., Michailidis, E., Aurora, R., Meyers, M.J., Jacobsen, E.J., Parniak, M.A., Sarafianos, S.G., 2013. The hepatitis B virus ribonuclease $\mathrm{H}$ is sensitive to inhibitors of the human immunodeficiency virus ribonuclease $\mathrm{H}$ and integrase enzymes. PLoS Pathog. 9, e1003125.

Tekeste, S.S., Wilkinson, T.A., Weiner, E.M., Xu, X., Miller, J.T., Le Grice, S.F., Clubb, R.T., Chow, S.A., 2015. Interaction between reverse transcriptase and integrase is required for reverse transcription during HIV-1 replication. J. Virol. 89 , 12058-12069.

Temin, H.M., Mizutani, S., 1970. RNA-dependent DNA polymerase in virions of Rous sarcoma virus. Nature 226, 1211-1213.

Thomas, J.A., Gorelick, R.J., 2008. Nucleocapsid protein function in early infection processes. Virus Res. 134, 39-63.

Thomas, D.C., Voronin, Y.A., Nikolenko, G.N., Chen, J., Hu, W.S., Pathak, V.K., 2007 Determination of the ex vivo rates of human immunodeficiency virus type 1 reverse transcription by using novel strand-specific amplification analysis. J. Virol. 81, 4798-4807.

Torruella, M., Gordon, K., Hohn, T., 1989. Cauliflower mosaic virus produces an aspartic proteinase to cleave its polyproteins. EMBO J. 8, 2819-2825.

Traverse, C.C., Ochman, H., 2016. Conserved rates and patterns of transcription errors across bacterial growth states and lifestyles. Proc. Natl. Acad. Sci. U. S. A. 113, 3311-3316, Erratum in: Proc. Natl. Acad. Sci. U. S. A. 113, 2016, E4257-E4258.

Tu, X., Das, K., Han, Q., Bauman, J.D., Clark Jr., A.D., Hou, X., Frenkel, Y.V., Gaffney, B.L., Jones, R.A., Boyer, P.L., Hughes, S.H., Sarafianos, S.G., Arnold, E., 2010. Structural basis of HIV-1 resistance to AZT by excision. Nat. Struct. Mol. Biol. $17,1202-1209$.

Tuske, S., Sarafianos, S.G., Clark Jr., A.D., Ding, J., Naeger, L.K., White, K.L., Miller M.D., Gibbs, C.S., Boyer, P.L., Clark, P., Wang, G., Gaffney, B.L., Jones, R.A., Jerina, D.M., Hughes, S.H., Arnold, E., 2004. Structures of HIV-1 RT-DNA complexes before and after incorporation of the anti-AIDS drug tenofovir. Nat. Struct. Mol. Biol. 11, 469-474.

Villa, J.A., Pike, D.P., Patel, K.B., Lomonosova, E., Lu, G., Abdulqader, R., Tavis, J.E., 2016. Purification and enzymatic characterization of the hepatitis B virus ribonuclease H: a new target for antiviral inhibitors. Antiviral Res. 132, 186-195.

Vörös, J., Urbanek, A., Rautureau, G.J., O’Connor, M., Fisher, H.C., Ashcroft, A.E., Ferguson, N., 2014. Large-scale production and structural and biophysica characterizations of the human hepatitis B virus polymerase. J. Virol. 88, 2584-2599.

Wainberg, M.A., Drosopoulos, W.C., Salomon, H., Hsu, M., Borkow, G., Parniak, M. Gu, Z., Song, Q., Manne, J., Islam, S., Castriota, G., Prasad, V.R., 1996. Enhanced fidelity of 3TC-selected mutant HIV-1 reverse transcriptase. Science 271, $1282-1285$

Wang, G.H., Seeger, C., 1992. The reverse transcriptase of hepatitis B virus acts as a protein primer for viral DNA synthesis. Cell 71, 663-670.

Wang, J.C., Nickens, D.G., Lentz, T.B., Loeb, D.D., Zlotnick, A., 2014. Encapsidated hepatitis B virus reverse transcriptase is poised on an ordered RNA lattice. Proc. Natl. Acad. Sci. U. S. A. 111, 11329-11334.

Wang, G., Zhao, N., Berkhout, B., Das, A.T., 2016. CRISPR-Cas9 can inhibit HIV-1 replication but NHEJ repair facilitates virus escape. Mol. Ther. 24, 522-526.

Wapling, J., Moore, K.L., Sonza, S., Mak, J., Tachedjian, G., 2005. Mutations that abrogate human immunodeficiency virus type 1 reverse transcriptase dimerization affect maturation of the reverse transcriptase heterodimer. J. Virol. 79, 10247-10257

Warren, K., Warrilow, D., Meredith, L., Harrich, D., 2009. Reverse transcriptase and cellular factors: regulators of HIV-1 reverse transcription. Viruses 1, 873-894.

Weiss, K.K., Chen, R., Skasko, M., Reynolds, H.M., Lee, K., Bambara, R.A., Mansky, L.M., Kim, B., 2004. A role for dNTP binding of human immunodeficiency virus type 1 reverse transcriptase in viral mutagenesis. Biochemistry 43, 4490-4500.

Whitcomb, J.M., Kumar, R., Hughes, S.H., 1990. Sequence of the circle junction of human immunodeficiency virus type 1: Implications for reverse transcription and integration. J. Virol. 64, 4903-4906.

Whiting, S.H., Champoux, J.J., 1994. Strand displacement synthesis capability of Moloney murine leukemia virus reverse transcriptase. J. Virol. 68, 4747-4758.

Whiting, S.H., Champoux, J.J., 1998. Properties of strand displacement synthesis by Moloney murine leukemia virus reverse transcriptase: mechanistic implications. J. Mol. Biol. 278, 559-577.

Wilhelm, M., Wilhelm, F.X., 2005. Role of integrase in reverse transcription of the Saccharomyces cerevisiae retrotransposon Ty1. Eukaryot. Cell 4, 1057-1065.

Wilhelm, M., Boutabout, M., Heyman, T., Wilhelm, F.X., 1999. Reverse transcription of the yeast Ty1 retrotransposon: the mode of first strand transfer is either intermolecular or intramolecular. J. Mol. Biol. 288, 505-510.

Wilhelm, M., Boutabout, M., Wilhelm, F.X., 2000. Expression of an active form of recombinant Ty1 reverse transcriptase in Escherichia coli: a fusion protein containing the C-terminal region of the Ty1 integrase linked to the reverse transcriptase-RNase $\mathrm{H}$ domain exhibits polymerase and RNase $\mathrm{H}$ activities. Biochem. J. 348, 337-342.

Wood, N., Bhattacharya, T., Keele, B.F., Giorgi, E., Liu, M., Gaschen, B., Daniels, M., Ferrari, G., Haynes, B.F., McMichael, A., Shaw, G.M., Hahn, B.H., Korber, B., Seoighe, C., 2009. HIV evolution in early infection: selection pressures, patterns of insertion and deletion, and the impact of APOBEC. PLoS Pathog. 5, e1000414.

Xiong, Y., Eickbush, T.H., 1990. Origin and evolution of retroelements based upon their reverse transcriptase sequences. EMBO J. 9, 3353-3362.

Yang, W., Summers, J., 1998. Infection of ducklings with virus particles containing linear double-stranded duck hepatitis B virus DNA: illegitimate replication and reversion. J. Virol. 72, 8710-8717.

Yang, W., Lee, J.Y., Nowotny, M., 2006. Making and breaking nucleic acids: two- $\mathrm{Mg}^{2+}$-ion catalysis and substrate specificity. Mol. Cell. 22, 5-13.

Yu, H., Goodman, M.F., 1992. Comparison of HIV-1 and avian myeloblastosis virus reverse transcriptase fidelity on RNA and DNA templates. J. Biol. Chem. 267 10888-10896. 
Yu, H., Jetzt, A.E., Ron, Y., Preston, B.D., Dougherty, J.P., 1998. The nature of human immunodeficiency virus type 1 strand transfers. J. Biol. Chem. 273, 28384-28391.

Zábranský, A., Andreánsky, M., Hrusková-Heidingsfeldová, O., Havlícek, V., Hunter, E., Ruml, T., Pichová, I., 1998. Three active forms of aspartic proteinase from Mason-Pfizer monkey virus. Virology 245, 250-256.

Zhang W.-H., Svarovskaia, E.S., Barr, R., Pathak, V.K., 2002. Y586F mutation in murine leukemia virus reverse transcriptase decreases fidelity of DNA synthesis in regions associated with adenine-thymine tracts. Proc. Natl. Acad. Sci. U. S. A. 99, 10090-10095.
Zheng, X., Pedersen, L.C., Gabel, S.A., Mueller, G.A., Cuneo, M.J., DeRose, E.F., Krahn, J.M., London, R.E., 2014. Selective unfolding of one ribonuclease H domain of HIV reverse transcriptase is linked to homodimer formation. Nucleic Acids Res. 42, 5361-5377.

Zheng, X., Perera, L., Mueller, G.A., DeRose, E.F., London, R.E., 2015. Asymmetric conformational maturation of HIV-1 reverse transcriptase. Elife 4, e06359.

Zinnen, S., Hsieh, J.-C., Modrich, P., 1994. Misincorporation and mispaired primer extension by human immunodeficiency virus reverse transcriptase. J. Biol. Chem. 269, 24195-24202 